US Army Corps of Engineers ${ }_{\circledast}$

Engineer Research and

Development Center

Rapid Airfield Damage Recovery Program

\title{
Evaluation of Expedient Surfaces for Remote Piloted Aircraft
}

Lyan Garcia, Timothy W. Rushing, and Craig A. Rutland

December 2017 
The U.S. Army Engineer Research and Development Center (ERDC) solves the nation's toughest engineering and environmental challenges. ERDC develops innovative solutions in civil and military engineering, geospatial sciences, water resources, and environmental sciences for the Army, the Department of Defense, civilian agencies, and our nation's public good. Find out more at www.erdc.usace.army.mil.

To search for other technical reports published by ERDC, visit the ERDC online library at http://acwc.sdp.sirsi.net/client/default. 


\section{Evaluation of Expedient Surfaces for Remote Piloted Aircraft}

Lyan Garcia and Timothy W. Rushing, PhD

Geotechnical and structures Laboratory

U.S. Army Engineer Research and Development Center

3909 Halls Ferry Road

Vicksburg, MS 39180-6199

Craig A. Rutland, PhD

Engineering Division

Civil Engineering Branch

Air Force Civil Engineer Center

139 Barnes Drive, Suite 1

Tyndall AFB, FL 32403

Final report

Approved for public release; distribution is unlimited.

Prepared for Headquarters, Air Force Civil Engineer Center

Tyndall Air Force Base, FL 32403-5319

Under Project number 463347 


\section{Abstract}

The U.S. military began using remote piloted aircraft (RPAs) for reconnaissance and offensive operations in the mid-1990s. Their effectiveness has led to the development of several new airframes with increasing capability and operational requirements. RPA ground movements are ideally separated from manned aircraft traffic areas with their own parking aprons and hangar facilities. For expedient construction of RPA facilities, a matting system is desired to rapidly create parking aprons and hangar flooring. This report describes the evaluation of four commercially available airfield matting systems that were investigated to determine their capabilities for supporting RPAs and support vehicle operations. Each mat system was tested on a full-scale test section consisting of a subgrade with a California bearing ratio (CBR) of 6 surfaced with the airfield mats. Simulated MQ-9A Reaper and P-19 fire truck traffic was applied to the mat surface. Mat breakage and deformation were monitored and compared to performance requirements for compliance. Recommendations were provided for each mat system based on suitability and risk to aid in future procurement decisions.

DISCLAIMER: The contents of this report are not to be used for advertising, publication, or promotional purposes. Citation of trade names does not constitute an official endorsement or approval of the use of such commercial products. All product names and trademarks cited are the property of their respective owners. The findings of this report are not to be construed as an official Department of the Army position unless so designated by other authorized documents. 


\section{Contents}

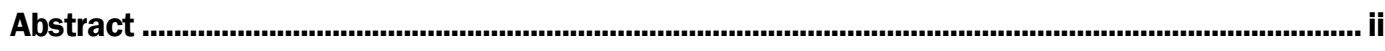

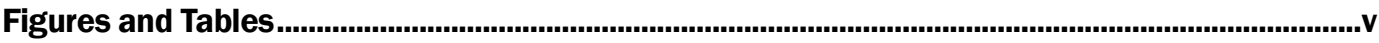

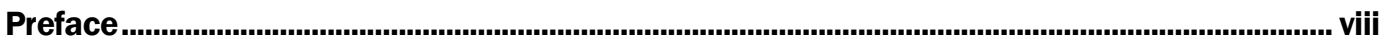

Unit Conversion Factors ............................................................................................................ ix

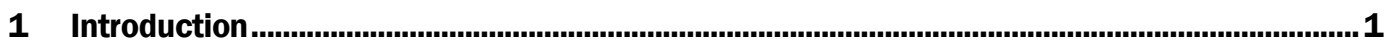

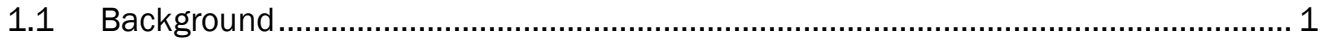

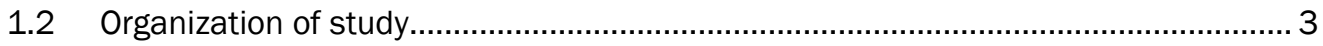

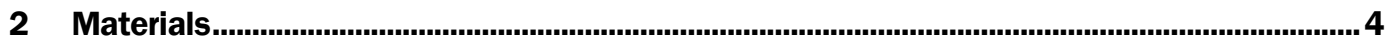

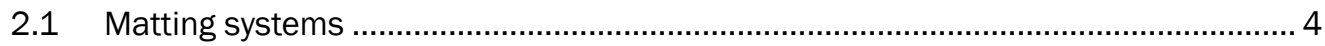

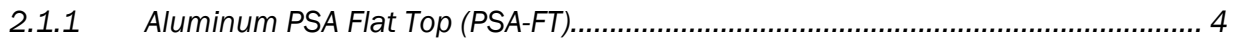

2.1.2 Aluminum PSA Flat Top - Reinforced (PSA-FT-R) ............................................ 6

2.1.3 Aluminum Logistics Military Airfield Take-off and Landing Surface (ALMATS) ................ 7

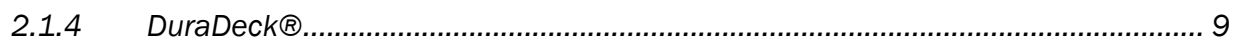

2.2 Subgrade and foundation ....................................................................... 10

2.2.1 High-plasticity clay $(\mathrm{CH})$ subgrade................................................................. 10

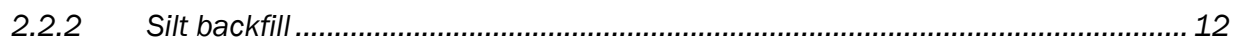

2.2.3 Natural foundation ......................................................................................... 12

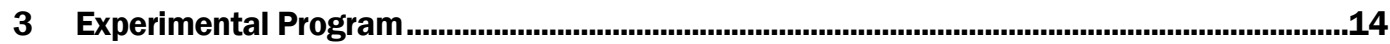

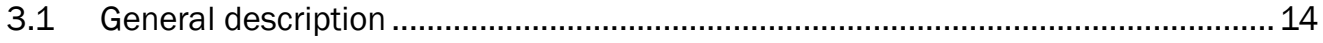

3.2 Subgrade construction and posttest forensics ................................................... 16

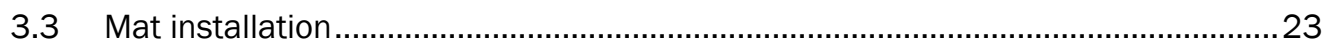

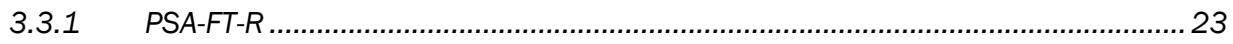

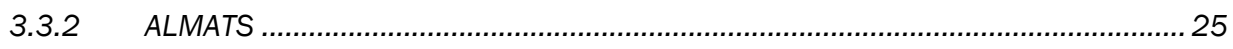

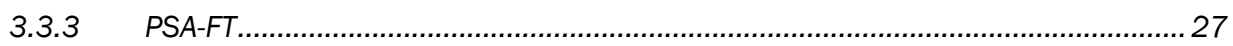

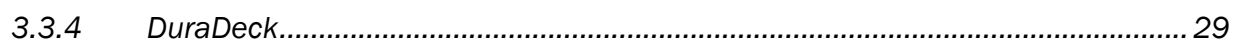

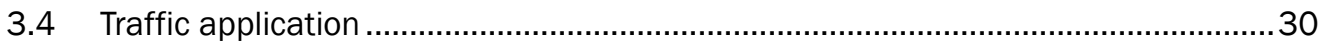

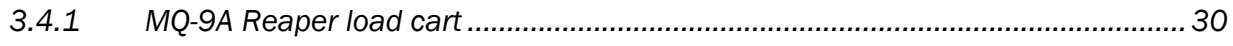

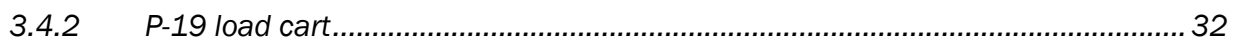

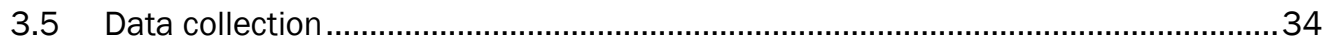

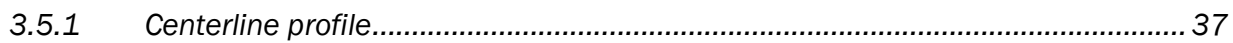

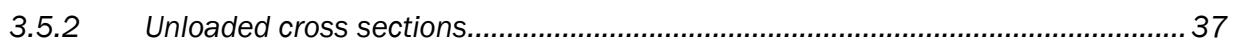

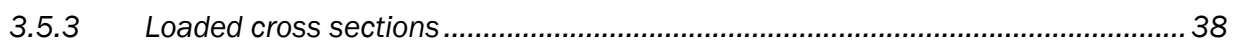

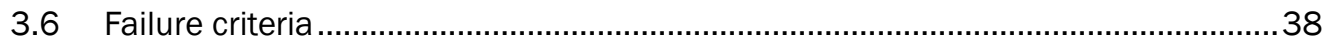

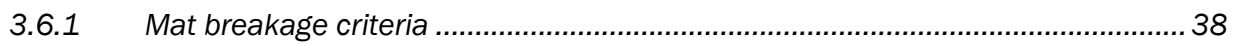

3.6.2 Permanent deformation criteria.................................................................... 38

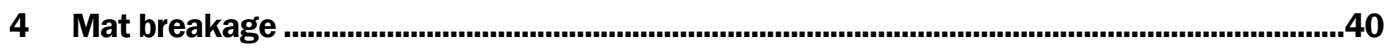

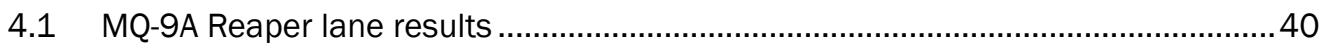

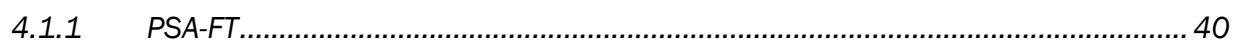




\begin{tabular}{|c|c|}
\hline 4.1.2 & PSA-FT-R \\
\hline 4.1 .3 & ALMATS \\
\hline 4.1 .4 & DuraDeck... \\
\hline P-19 lane results ............ & 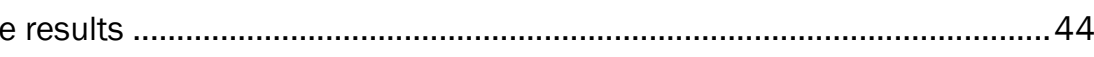 \\
\hline \multicolumn{2}{|r|}{ 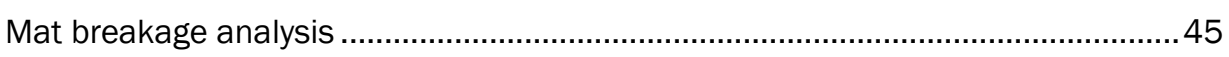 } \\
\hline 4.3.1 & 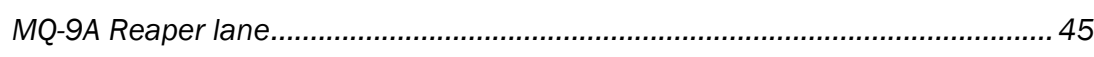 \\
\hline 4.3.2 & P-19 lane. \\
\hline
\end{tabular}

5 Permanent deformation ........................................................................................................47

5.1 Permanent deformation results.................................................................... 47

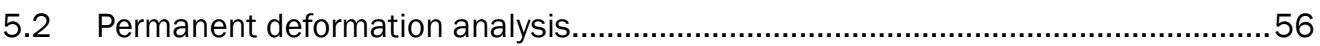

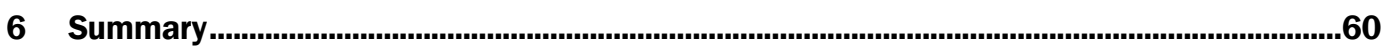

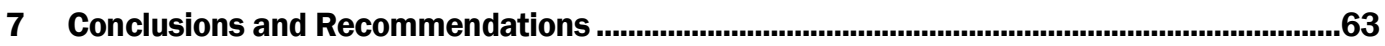

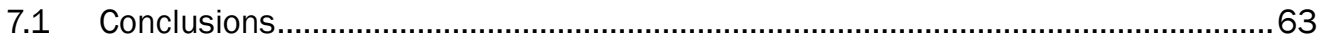

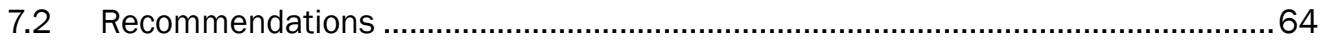

References .......................................................................................................................................65

Appendix A: Request for Information for an RPA Mat System ........................................................67

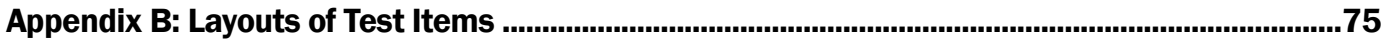

Appendix C: Hangar 2 Foundation DCP Data ...............................................................................80

Appendix D: ML Backfill DCP Data .....................................................................................................84

Appendix E: MQ-9A Reaper Lane Trafficking Data .........................................................................8

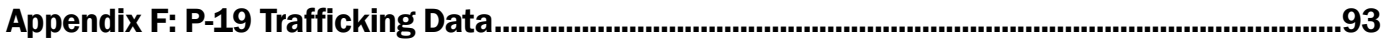

Report Documentation Page 


\section{Figures and Tables}

\section{Figures}

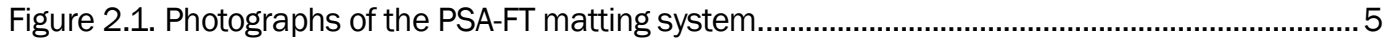

Figure 2.2. Photographs of the PSA-FT-R matting system. .................................................................

Figure 2.3. Photographs of ALMATS matting system. .................................................................... 8

Figure 2.4. Photographs of DuraDeck mat system. ……….................................................................

Figure 2.5. Classification data for Vicksburg Buckshot $\mathrm{CH}$.............................................................10

Figure 2.6. Laboratory $\mathrm{CBR}$ vs. moisture content for $\mathrm{CH}$ subgrade material....................................11

Figure 2.7. Modified Proctor curve for $\mathrm{CH}$ subgrade material............................................................11

Figure 2.8. Classification data for low plasticity silt (ML) ..............................................................12

Figure 2.9. Classification data for low plasticity clay (CL) ...............................................................13

Figure 3.1. Test-section profile. ................................................................................................

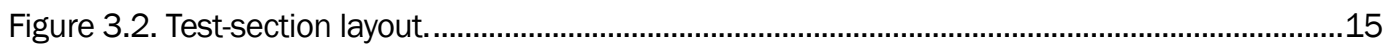

Figure 3.3. Test-section excavation (left) lined with impervious sheeting (right)...............................16

Figure 3.4. Pulverizing $\mathrm{CH}$ (left) and adding moisture (right). .......................................................17

Figure 3.5. Leveling (left) and compacting (right) CH.................................................................17

Figure 3.6. Sand cone (left) and CBR test (right).....................................................................18

Figure 3.7. Steel plate and rubber mat at interface between test items..........................................23

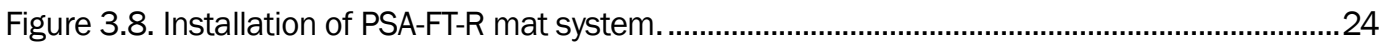

Figure 3.9. Assembled PSA-FT-R test item...................................................................................2

Figure 3.10. Installation of ALMATS. ........................................................................................2

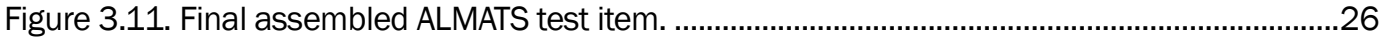

Figure 3.12. Installation of PSA-FT mat system.

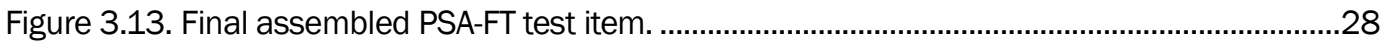

Figure 3.14. Installation of DuraDeck mat system.........................................................................29

Figure 3.15. Final assembled DuraDeck test item......................................................................30

Figure 3.16. MQ-9A Reaper load cart........................................................................................31

Figure 3.17. Normally distributed traffic pattern for MQ-9A Reaper................................................32

Figure 3.18. P-19 load cart. ......................................................................................................3

Figure 3.19. Traffic pattern for the P-19 truck...............................................................................34

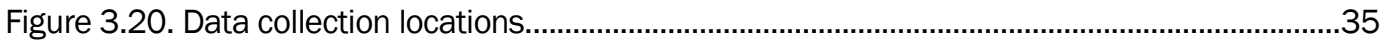

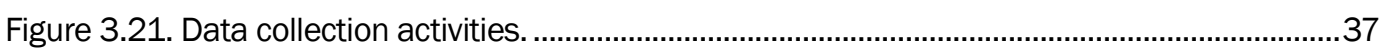

Figure 4.1. Cracking on surface of PSA-FT after 1,936 passes........................................................ 41

Figure 4.2. Damage on PSA-FT after 7,398 passes......................................................................42

Figure 4.3. Crack on a PSA-FT-R panel.........................................................................................42

Figure 4.4. Crack along male hinge of PSA-FT-R panel................................................................43

Figure 4.5. Cracking at weld beads of PSA-FT-R panels. ...................................................................43

Figure 4.6. Posttest subgrade of DuraDeck mat system..................................................................4 
Figure 5.1. Average deformation on the subgrade of PSA-FT - MQ-9A Reaper lane. ........................48

Figure 5.2. Average deformation on the subgrade of ALMATS - MQ-9A Reaper lane. ......................48

Figure 5.3. Average deformation on the subgrade of DuraDeck - MQ-9A Reaper lane....................49

Figure 5.4. Average deformation on the loaded mat surface of PSA-FT- MQ-9A Reaper lane.

Figure 5.5. Average deformation on the loaded mat surface of PSA-FT-R - MQ-9A Reaper lane

Figure 5.6. Average deformation on the loaded mat surface of ALMATS - MQ-9A Reaper lane.

Figure 5.7. Average deformation on the loaded mat surface of DuraDeck - MQ-9A Reaper lane. 51

Figure 5.8. Average deformation on the subgrade of PSA-FT - P-19 lane........................................51

Figure 5.9. Average deformation on the subgrade of ALMATS - P-19 lane.......................................52

Figure 5.10. Average deformation on the subgrade of DuraDeck - P-19 lane. ................................52

Figure 5.11. Average deformation on the loaded mat surface of PSA-FT - P-19 lane.......................53

Figure 5.12. Average deformation on the loaded mat surface of PSA-FT-R - P-19 lane. ...................53

Figure 5.13. Average deformation on the loaded mat surface of ALMATS - P-19 lane.....................54

Figure 5.14. Average deformation on the loaded mat surface of DuraDeck - P-19 lane. .................54

Figure 5.15. Average maximum rut depth on the subgrade. ...........................................................55

Figure 5.16. Average maximum rut depth on the loaded mat surface - MQ-9A Reaper lane.

Figure 5.17. Average maximum rut depth on the loaded mat surface - P-19 lane...........................56

Figure B.1. Data collection locations on PSA-FT test item....................................................................76

Figure B.2. Data collection locations on PSA-FT-R test item. ............................................................77

Figure B.3. Data collection locations on ALMATS test item...............................................................78

Figure B.4. Data collection locations on DuraDeck test item. .......................................................79

Figure E.1. Average deformation along centerline of PSA-FT mat surface - MQ-9A

Reaper lane.

Figure E.2. Average deformation along centerline of PSA-FT-R mat surface - MQ-9A

Reaper lane.

Figure E.3. Average deformation along centerline profile of ALMATS mat surface - MQ-9A

Reaper lane.

Figure E.4. Average deformation along centerline of DuraDeck mat surface- MQ-9A

Reaper lane.

Figure E.5. Average deformation on the unloaded mat surface of PSA-FT - MQ-9A

Reaper lane.

Figure E.6. Average deformation on the unloaded mat surface of PSA-FT-R - MQ-9A

Reaper lane.

Figure E.7. Average deformation on the unloaded mat surface of ALMATS - MQ-9A

Reaper lane.

Figure E.8. Average deformation on the unloaded mat surface of DuraDeck - MQ-9A

Reaper lane.

Figure E.9. Average maximum rut depth on the unloaded mat surface - MQ-9A Reaper lane. 
Figure F.1. Average deformation along centerline of PSA-FT mat surface - P-19 lane.....................93

Figure F.2. Average deformation along centerline of PSA-FT-R mat surface - P-19 lane. ................94

Figure F.3. Average deformation along centerline of ALMATS mat surface - P-19 lane....................94

Figure F.4. Average deformation along centerline of DuraDeck mat surface - P-19 lane. ..............95

Figure F.5. Average deformation on the unloaded mat surface of PSA-FT - P-19 lane....................95

Figure F.6. Average deformation on the unloaded mat surface of PSA-FT-R - P-19 lane..................96

Figure F.7. Average deformation on the unloaded mat surface of ALMATS - P-19 lane...................96

Figure F.8. Average deformation on the unloaded mat surface of DuraDeck - P-19 lane................97

Figure F.9. Average maximum rut depth on the unloaded mat surface - P-19 lane. .......................97

\section{Tables}

Table 2.1. Physical properties of matting systems tested compared to AM2 ..................................... 4

Table 2.2. Items delivered for installing the PSA-FT matting system. ................................................ 6

Table 2.3. Items delivered for installing the PSA-FT-R matting system............................................... 7

Table 2.4. Items delivered for installing the ALMATS matting system. ................................................8

Table 2.5. Laboratory tests for Vicksburg Buckshot $\mathrm{CH}$....................................................................10

Table 3.1. Field tests on each constructed $\mathrm{CH}$ lift. ...........................................................................18

Table 3.2. Hangar 2 natural foundation (CL) in-situ properties. ......................................................18

Table 3.3. In-situ subgrade properties for PSA-FT test item. ................................................................19

Table 3.4. In-situ subgrade properties for PSA-FT-R test item.............................................................20

Table 3.5. In-situ subgrade properties for ALMATS test item..........................................................21

Table 3.6. In-situ subgrade properties for DuraDeck test item.............................................................22

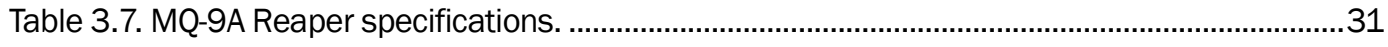

Table 3.8. MQ-9A Reaper load cart characteristics..............................................................................32

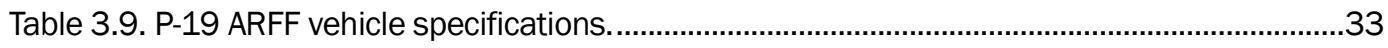

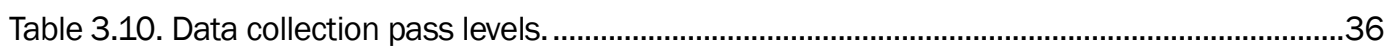

Table 5.1. Pass level at which permanent deformation criterion was exceeded. ..............................57

Table 6.1. Summary of experimental program......................................................................................62 


\section{Preface}

This study was conducted for the U.S. Air Force Civil Engineer Center (AFCEC). Technical oversight was provided by Mr. Jeb S. Tingle.

The work was performed by the Airfields and Pavements Branch (GMA) of the Engineering Systems and Materials Division (GM), U.S. Army Engineer Research and Development Center, Geotechnical and Structures Laboratory (ERDC-GSL). At the time of publication, Dr. Timothy W. Rushing was Chief, CEERD-GMA; Dr. Gordon W. McMahon was Chief, CEERD-GM; and Mr. Nicholas Boone, CEERD-GVT was the Technical Director for Force Projection and Maneuver Support. The Acting Deputy Director of ERDC-GSL was Mr. Charles W. Ertle and the Director was Mr. Bartley P. Durst.

COL Bryan S. Green was the Commander of ERDC, and Dr. David W. Pittman was the Director. 


\section{Unit Conversion Factors}

\begin{tabular}{|c|c|c|}
\hline Multiply & By & To Obtain \\
\hline cubic feet & 0.02831685 & cubic meters \\
\hline feet & 0.3048 & meters \\
\hline inches & 0.0254 & meters \\
\hline kip-inches & 112.948 & newton-meters \\
\hline pounds (force) & 4.448222 & newtons \\
\hline pounds (force) per square foot & 47.88026 & pascals \\
\hline pounds (force) per square inch & 6.894757 & kilopascals \\
\hline pounds (mass) & 0.45359237 & kilograms \\
\hline square feet & 0.09290304 & square meters \\
\hline square inches & 6.4516 E-04 & square meters \\
\hline
\end{tabular}




\section{Introduction}

\subsection{Background}

The U.S. military began using remote piloted aircraft (RPAs) for reconnaissance and offensive operations in the mid-1990s. Their effectiveness has led to the development of several new models with increasing capability and operational requirements, and they are now a major part of air operations. The majority of models are relatively small in comparison to manned fighter and cargo aircraft. Larger RPAs such as the MQ-1 Predator and MQ-9A Reaper generally operate on fixed airfields in conjunction with manned aircraft. RPA ground movements are ideally separated from manned aircraft traffic operations with their own parking aprons and hangar facilities. For expedient construction of RPA facilities, an expedient matting system is desired to rapidly create parking aprons and hangar flooring at contingency locations.

Because of their smaller size and weight, expedient surfaces needed to support expeditionary operations do not have to be as robust as systems designed to support manned aircraft, such as the AM2 matting system. However, only AM2 is available through standard procurement methods as an approved aircraft operating surface. To improve operational effectiveness, a light-duty expeditionary mat system is desired that can effectively support RPA operations while reducing the logistical footprint required to transport the surfacing system to the field.

In an effort to meet this requirement, a request for information was submitted through the U.S. Army Engineer Research and Development Center's (ERDC's) contracting office to solicit products from commercial vendors. Among many requirements, the matting system was required to be approximately half the weight of the standard AM2 matting system while still maintaining operational effectiveness (Appendix A).

Researchers analyzed commercially available RPA systems to determine the expected operating requirements of the matting systems and concluded that the MQ-9A Reaper was the controlling aircraft loading condition. The RQ-4 Global Hawk was considered, since it was the heaviest RPA at the time of the study, but its large size and high tire pressure put it in a class similar to manned aircraft. The research team 
determined that the Global Hawk would require AM2 matting, thus removing it from the consideration of this study.

In addition to controlling aircraft, the research team also evaluated ground support vehicles that may be required to operate on the matting system. After reviewing vehicles, such as fuel trucks, material handling equipment, and crash-support vehicle support, researchers determined that the P-19 crash fire and rescue vehicle was the most critical support vehicle in terms of total load and tire pressure. The P-19 was also included in this study to ensure all support vehicles could operate on the new matting system.

After reviewing vendor solicitations from the RFI posted through the ERDC contracting office, four matting systems were selected for full-scale evaluation. A full-scale experiment was designed, constructed, and executed by the ERDC's Airfields and Pavements Branch (APB) over a subgrade with a California bearing ratio (CBR) of 6 to gather the data required for comparison. Funding for the experiment was provided by the U.S. Air Force. This experiment was performed in the Hangar 2 covered airfield pavement test facility at the ERDC Vicksburg, MS, campus. The highly controlled subgrade was constructed using "Vicksburg Buckshot" high-plasticity clay. The prepared subgrade surface was covered with the four selected matting systems and trafficked with actual MQ-9A Reaper and P-19 crash vehicle main gears mounted on specially designed trafficking vehicles.

The research presented in this report utilizes data collected from the fullscale traffic experiments on four commercial matting systems to determine the performance under traffic. The objectives of this report are to:

1. Provide data collected during full-scale evaluations of four commercial matting systems under simulated MQ-9A and P-19 traffic.

2. Determine the number of passes to failure of commercial matting systems to support MQ-9A Reaper and P-19 operations.

3. Provide recommendations of system(s) to support future acquisition decisions.

The recommendations from this research are envisioned to support future acquisition programs for matting systems to support RPA operations by presenting comparative data collected during full-scale experiments. The 
data collected and recommendations presented will aid decision-makers in risk-reduction tools.

\subsection{Organization of study}

The body of this report is organized into seven chapters. The first chapter is the introduction and the last chapter, Chapter 7 , is the conclusion and recommendations. Chapter 2 describes the matting systems, and Chapter 3 details the experimental program. The failures are described in detail in Chapter 4 and Chapter 5 in terms of mat breakage and permanent subgrade deformation, respectively. Chapter 6 summarizes the results of the experiment. 


\section{Materials}

The following sections describe the four matting systems evaluated under this project, as well as subgrade and foundation materials used for construction of the full-scale test section. Table 2.1 lists measured, physical properties of the matting systems.

Table 2.1. Physical properties of matting systems tested compared to AM2.

\begin{tabular}{|c|c|c|c|c|c|c|c|c|c|c|}
\hline & \multicolumn{3}{|c|}{ PSA-FT } & \multicolumn{2}{|c|}{ PSA-FT-R } & \multicolumn{2}{|c|}{ ALMATS } & \multirow{2}{*}{\begin{tabular}{|c|} 
DuraDeck $₫$ \\
Standard \\
Panel
\end{tabular}} & \multicolumn{2}{|c|}{ AM2 } \\
\hline & $\begin{array}{l}\text { Full } \\
\text { Panel }\end{array}$ & $\begin{array}{l}\text { Left } \\
\text { Half } \\
\text { Panel }\end{array}$ & $\begin{array}{l}\text { Right } \\
\text { Half } \\
\text { Panel }\end{array}$ & $\begin{array}{l}\text { Half } \\
\text { Panel }\end{array}$ & $\begin{array}{l}\text { Full } \\
\text { Panel }\end{array}$ & $\begin{array}{l}\text { Half } \\
\text { Panel }\end{array}$ & $\begin{array}{l}\text { Full } \\
\text { Panel }\end{array}$ & & $\begin{array}{c}\text { Full } \\
\text { Panels }\end{array}$ & $\begin{array}{l}\text { Half } \\
\text { Panel }\end{array}$ \\
\hline Length (in.) & 103.81 & 51.81 & 51.83 & 51.81 & 103.69 & 51.94 & 103.44 & 96 & 144 & 72 \\
\hline Width (in.) & 10.38 & 10.38 & 10.38 & 10.38 & 10.38 & 20.00 & 20.00 & 48 & 24 & 24 \\
\hline $\begin{array}{l}\text { Thickness } \\
\text { (in.) }\end{array}$ & 0.88 & 0.88 & 0.88 & 0.92 & 0.92 & 1.00 & 1.00 & 0.63 & 1.5 & 1.5 \\
\hline Weight (lb) & 26.10 & 12.93 & 13.00 & 13.30 & 26.13 & 30.07 & 57.07 & 86 & 144 & 75 \\
\hline $\begin{array}{l}\text { Unit Surface } \\
\text { Weight (psf) }\end{array}$ & 3.49 & 3.46 & 3.48 & 3.56 & 3.50 & 4.17 & 3.97 & 2.68 & 6.1 & 6.2 \\
\hline Manufacturer & \multicolumn{5}{|c|}{ FAUN Trackway } & \multicolumn{2}{|c|}{ Alfab, Inc. } & $\begin{array}{l}\text { Signature } \\
\text { Systems, } \\
\text { LLC }\end{array}$ & \multicolumn{2}{|l|}{ Alfab, Inc. } \\
\hline
\end{tabular}

\subsection{Matting systems}

\subsubsection{Aluminum PSA Flat Top (PSA-FT)}

The PSA-FT matting system was developed by FAUN Trackway to create temporary RPA runways, taxiways, and parking areas. PSA-FT is a modified version of the PSA airfield mat system (Rushing et al. 2012) that was developed in the 1960s for the United Kingdom Ministry of Defense for use as a temporary surface for $\mathrm{C}-130$ aircraft. FAUN modified the original PSA to provide a flat surface that is more appropriate for RPAs and their more sensitive landing gears. Panels are made from a single aluminum extrusion with welded aluminum blocks at intervals to promote proper fit and to reduce panel movements. The connection along the longer edge is a hinge-type male/female system. The aluminum blocks are located at intervals on the male connection while the female connection is designed with receptor slots to interlock with the male blocks. No connection system is included along the short edge. Panels are produced in full size and half sizes, with a specific assembly for right half-panels and left half-panels. These are identical in dimensions and weight, but the 
locations of the welded aluminum blocks are different to allow a staggered pattern (i.e. not standard brickwork pattern). Photographs of the PSA-FT matting system are provided in Figure 2.1.

The company offers a deployable, palletized kit that includes sufficient quantities of panels, anchors, repair panels, and other accessories for building a $50-\mathrm{ft}$ by $1,000-\mathrm{ft}$ runway. Anchors were provided for the test to secure the matting surface, but the anchors were not evaluated for performance in this study. Table 2.2 lists items provided by FAUN Trackway for installing the PSA-FT mat surface. All panels were inspected and appeared to be in new condition.

Figure 2.1. Photographs of the PSA-FT matting system.

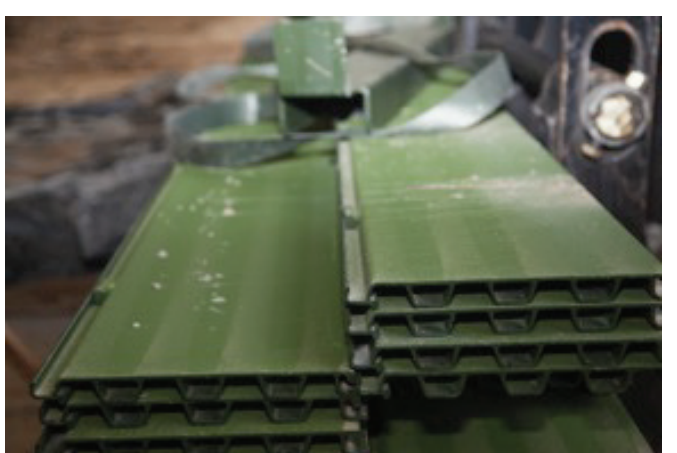

(a) Surface of panels

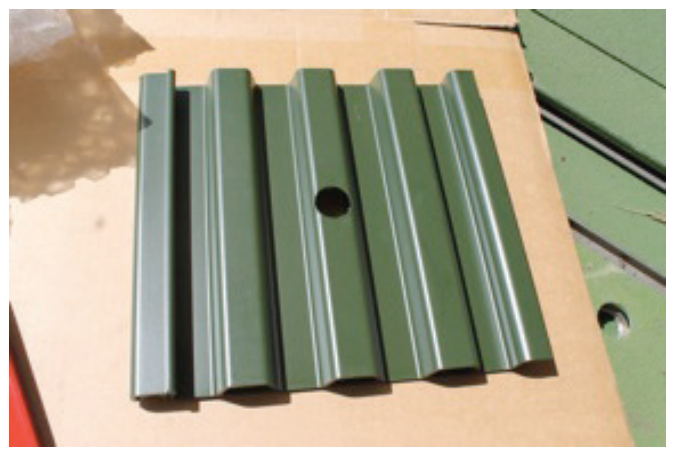

(c) Anchor fitting panel

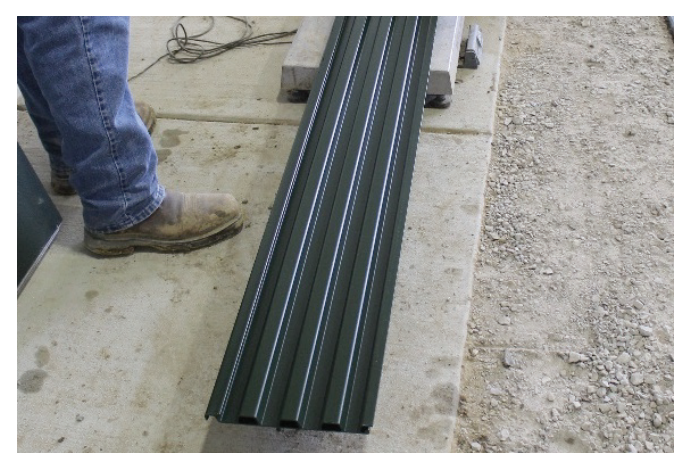

(b) Bottom surface of panels

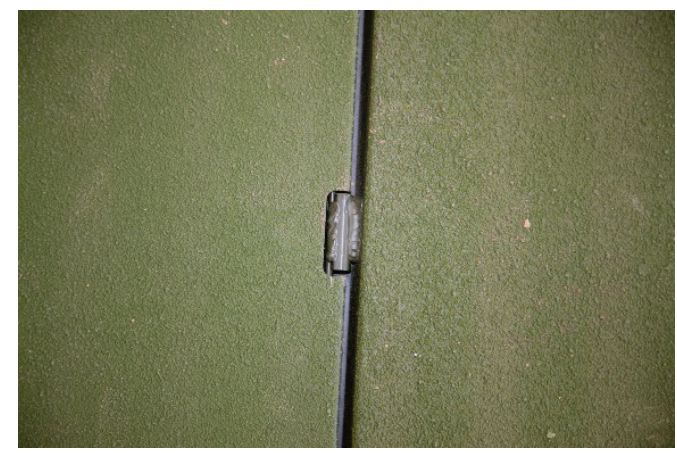

(d) Welded aluminum block 
Table 2.2. Items delivered for installing the PSA-FT matting system.

\begin{tabular}{|l|l|}
\hline Item & Quantity \\
\hline PSA-FT Full Panel & 185 \\
\hline PSA-FT Right Half Panel & 18 \\
\hline PSA-FT Left Half Panel & 19 \\
\hline PSA-FT Male Repair Panel & 2 \\
\hline PSA-FT Female Repair Panel & 2 \\
\hline PSA-FT Anchor Fitting & 18 \\
\hline Ground Anchor Stake & 25 \\
\hline
\end{tabular}

\subsubsection{Aluminum PSA Flat Top - Reinforced (PSA-FT-R)}

The PSA-FT-R matting system, a modified version of the PSA-FT mat system, was also developed by FAUN Trackway to create temporary RPA runways, taxiways, and parking areas. The authors of this report recommend that an end connection be added to the PSA-FT system to improve support at the longitudinal joints where most mat-system failures occur. Each PSA-FT-R panel consisted of a single aluminum extrusion that had a connector welded on each short end to create a single panel. The connectors were made to fit a double-arrow locking key that could be inserted once panels were placed next to each other on the ground. The connection along the long edge was a hinge-type male/female system. The system included a single type of full-size and half-size panels to allow a standard brickwork pattern assembly. Photographs of the matting system are provided in Figure 2.2. Anchors were provided for the test to secure the matting surface, but the anchors were not evaluated for performance in this study. Table 2.3 lists items provided by FAUN Trackway for installing the PSA-FT-R mat surface. All panels were inspected and appeared to be in new condition. 
Figure 2.2. Photographs of the PSA-FT-R matting system.

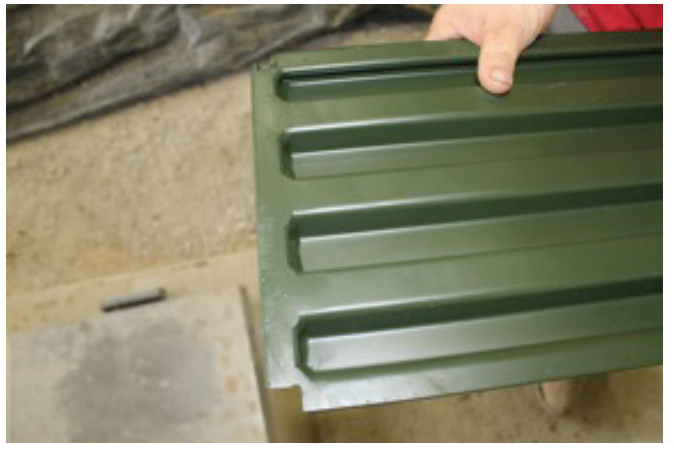

(a) Bottom surface of panels

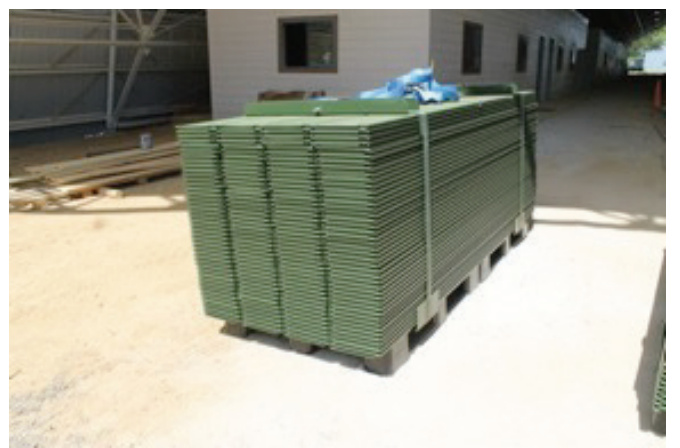

(c) Stack of panels as delivered

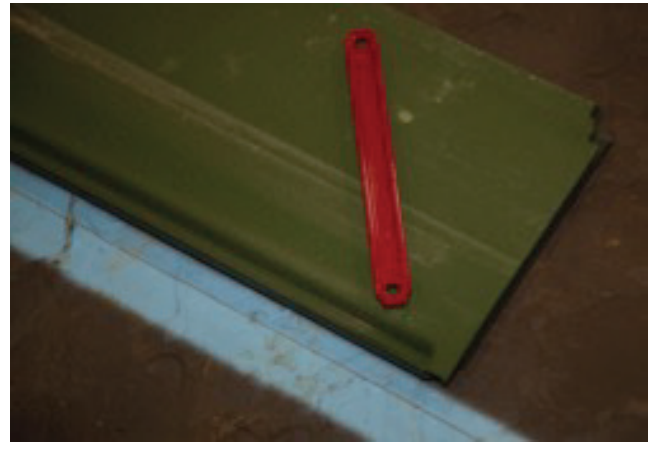

(b) Locking key

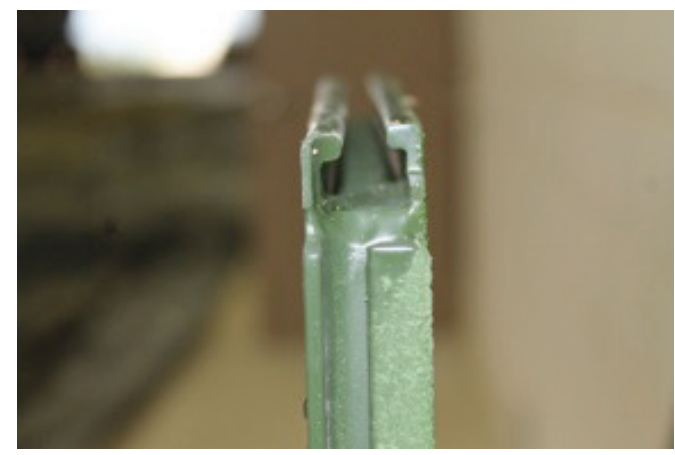

(d) End connector

Table 2.3. Items delivered for installing the PSA-FT-R matting system.

\begin{tabular}{|l|l|}
\hline Item & Quantity \\
\hline PSA-FT-R Full Panel & 185 \\
\hline PSA-FT-R Half Panel & 18 \\
\hline PSA-FT-R Locking Bar & 19 \\
\hline PSA-FT-R Anchor Panel & 20 \\
\hline Ground Anchor Stake & 13 \\
\hline
\end{tabular}

\subsubsection{Aluminum Logistics Military Airfield Take-off and Landing Surface (ALMATS)}

The ALMATS matting system was developed by Alfab Inc., the manufacturer of AM2. ALMATS was designed to resemble AM2 at the mechanical joints and core, but with a reduced panel thickness and length (Table 2-1). Each panel consisted of single extruded aluminum alloy 6082-T6 core with vertical supports that spanned the length of the panels and were spaced approximately 3 in. apart. Overlap and underlap end connectors were welded on the short ends of the mat using a MIG welding process to create a 
single panel. A locking bar was specifically designed to fit the thinner joint cross section of the ALMATS system and secure the overlap/underlap connection. Panels were designed to be compatible with the 463L pallet and 20-ft ISO flatracks and were coated with non-skid paint. Photographs of the ALMATS matting system are shown in Figure 2.3. A list of the materials delivered for installing the matting system is shown in Table 2.4.

Figure 2.3. Photographs of ALMATS matting system.

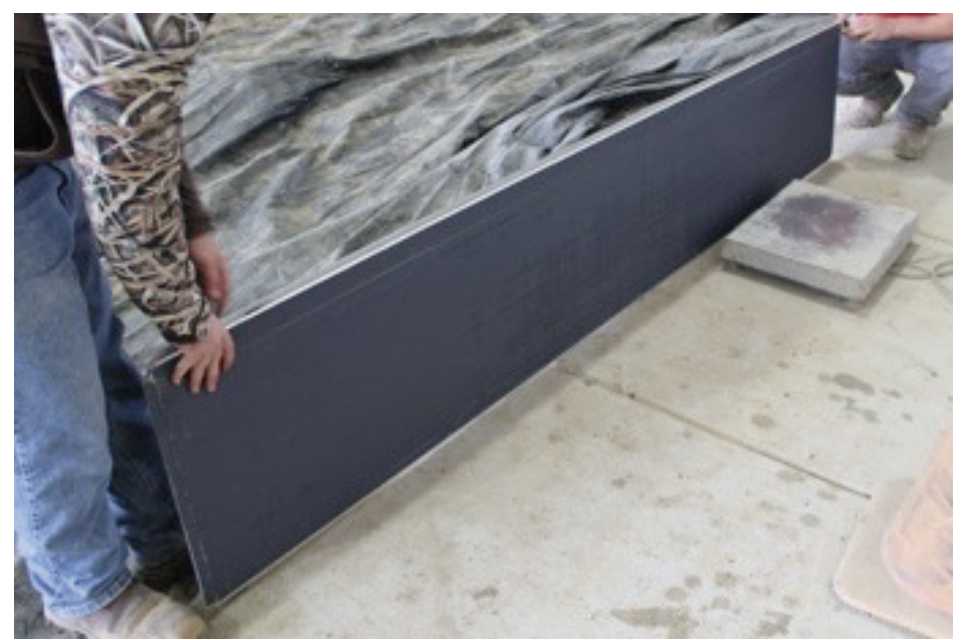

(a) Full panel

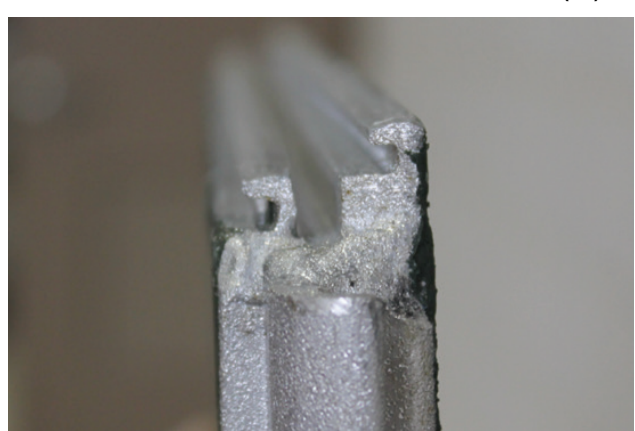

(b) End connector

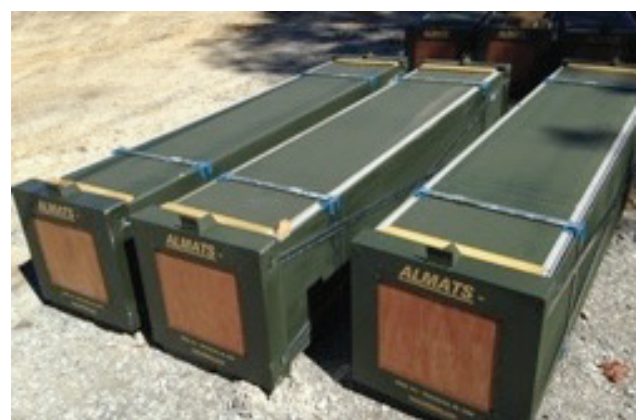

(c) Pallets of panels as delivered

Table 2.4. Items delivered for installing the ALMATS matting system.

\begin{tabular}{|l|l|}
\hline Item & Quantity \\
\hline ALMATS Full Panel & 101 \\
\hline ALMATS Half Panel & 20 \\
\hline ALMATS Locking Bar & 115 \\
\hline
\end{tabular}




\subsubsection{DuraDeck ${ }_{\circledast}$}

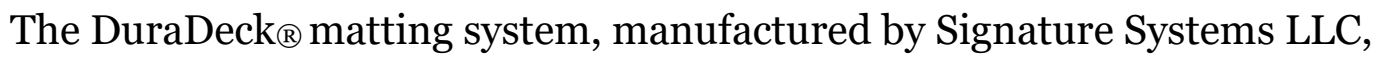
was designed to create temporary roadways for vehicles, trucks and equipment, and large work platforms for drilling and other industrial applications. The system consisted of panels that are constructed of a proprietary blend of high-density polypropylene (HDPE) plastic that was compression-molded into a solid panel with a nonskid surface molded onto each face. Panels are connected by placing metal plates studded with threaded bolts underneath the mat corners and then installing special connector nuts from the top surface to secure the mats together. According to the manufacturer, the panels will not degrade with sunlight or aircraft fluid exposure. If anchoring is required by the user, commercial off-theshelf (COTS) duckbill anchors are recommended to keep the surface from moving during operations; however, anchoring was not included in this test. Photographs of the DuraDeck are shown in Figure 2.4.

Figure 2.4. Photographs of DuraDeck mat system.

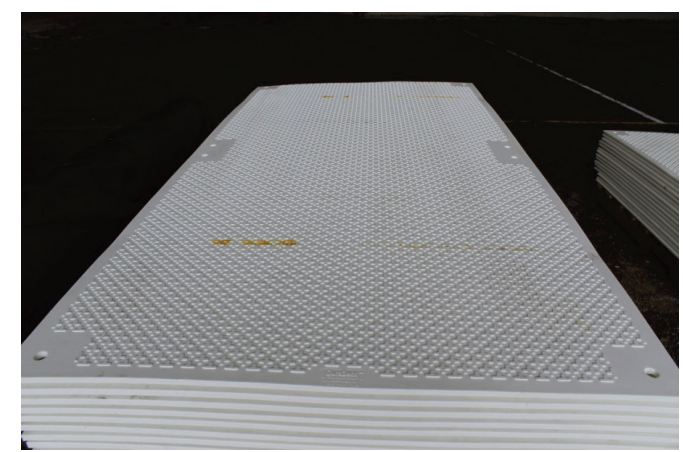

(a) Top surface of panels

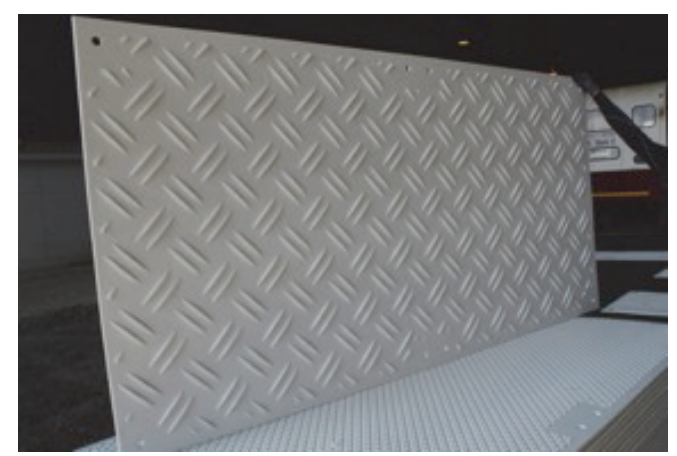

(b) Bottom surface of panels

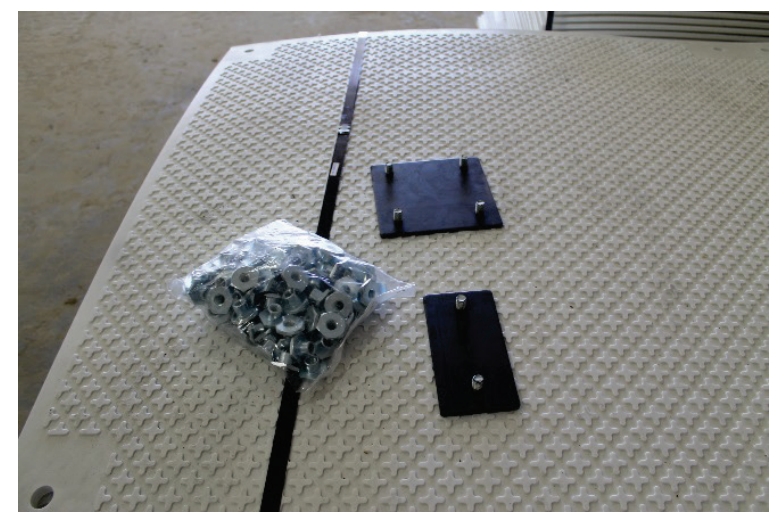

(c) Connection plates and connector nuts 


\subsection{Subgrade and foundation}

\subsubsection{High-plasticity clay (CH) subgrade}

The high-plasticity clay $(\mathrm{CH})$ material used for subgrade construction was procured from a local source in Vicksburg, MS, and was subjected to laboratory tests listed in Table 2.5. Classification data for the subgrade soil are shown in Figure 2.5. Moisture-density and CBR-moisture content relationships are shown in Figures 2.7 and 2.6, respectively. These data were used to determine the target moisture content and dry density required to obtain the target CBR of 6 . As shown in Figure 2.5, the target moisture content was $34 \%$ to achieve a CBR of 6 . The expected dry density for quality control at $34 \%$ moisture content was $87 \mathrm{lb} / \mathrm{ft} 3$.

Table 2.5. Laboratory tests for Vicksburg Buckshot $\mathrm{CH}$.

\begin{tabular}{|l|l|}
\hline Test Name & ASTM \\
\hline Standard Practice for Classification of Soils for Engineering Purposes (USCS) & D 2487 \\
\hline Standard Test Method for Particle Size Analysis of Soils & D 422 \\
\hline Standard Test Method for Laboratory Compaction Characteristics of Soil Using Modified Effort & D 1557 \\
\hline Standard Test Method for CBR of Laboratory Compacted Soils & D 1883 \\
\hline Standard Test Methods for Liquid Limit, Plastic Limit, and Plasticity Index of Soils & D 4318 \\
\hline
\end{tabular}

Figure 2.5. Classification data for Vicksburg Buckshot $\mathrm{CH}$.

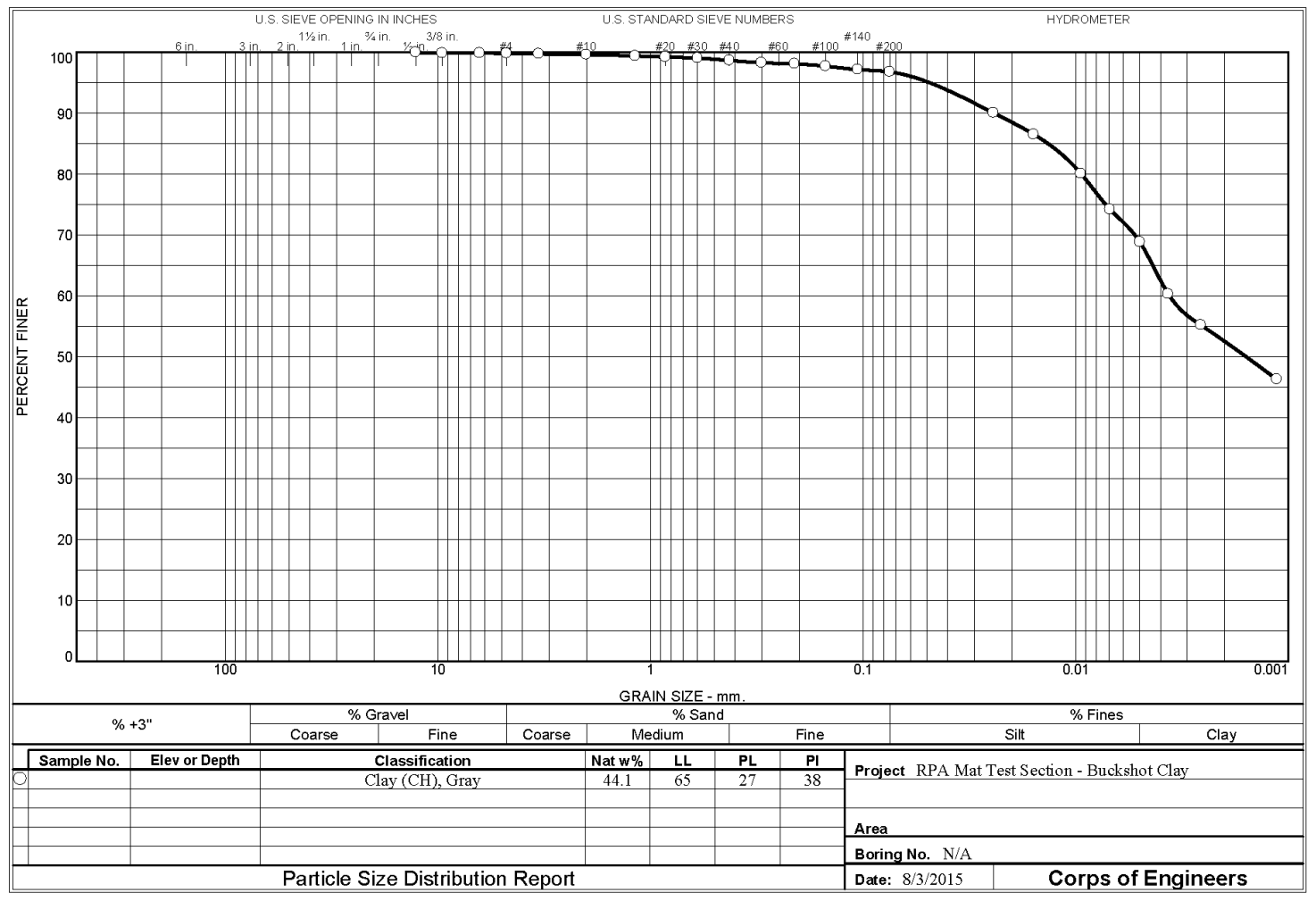


Figure 2.6. Laboratory CBR vs. moisture content for $\mathrm{CH}$ subgrade material.

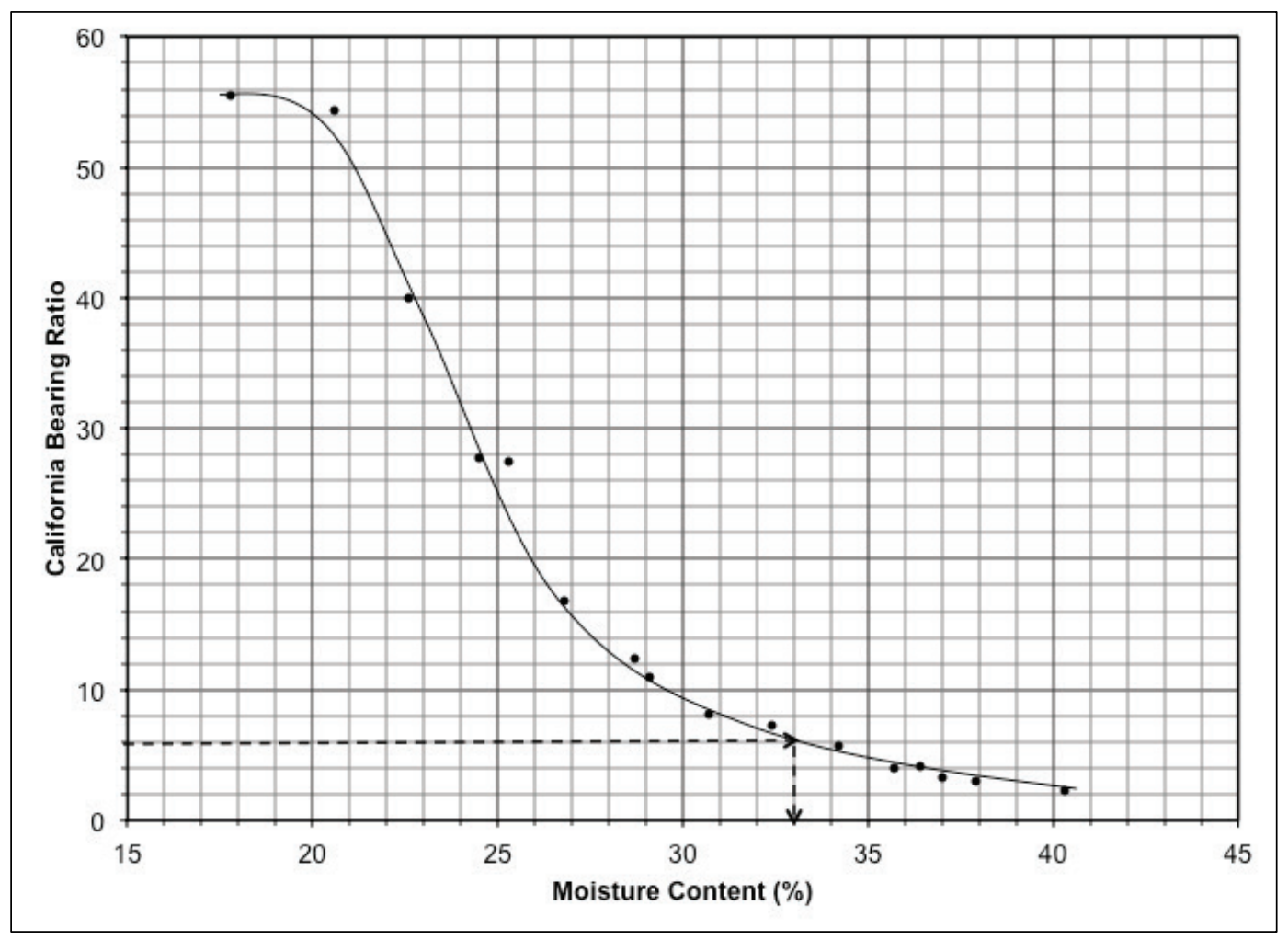

Figure 2.7. Modified Proctor curve for $\mathrm{CH}$ subgrade material.

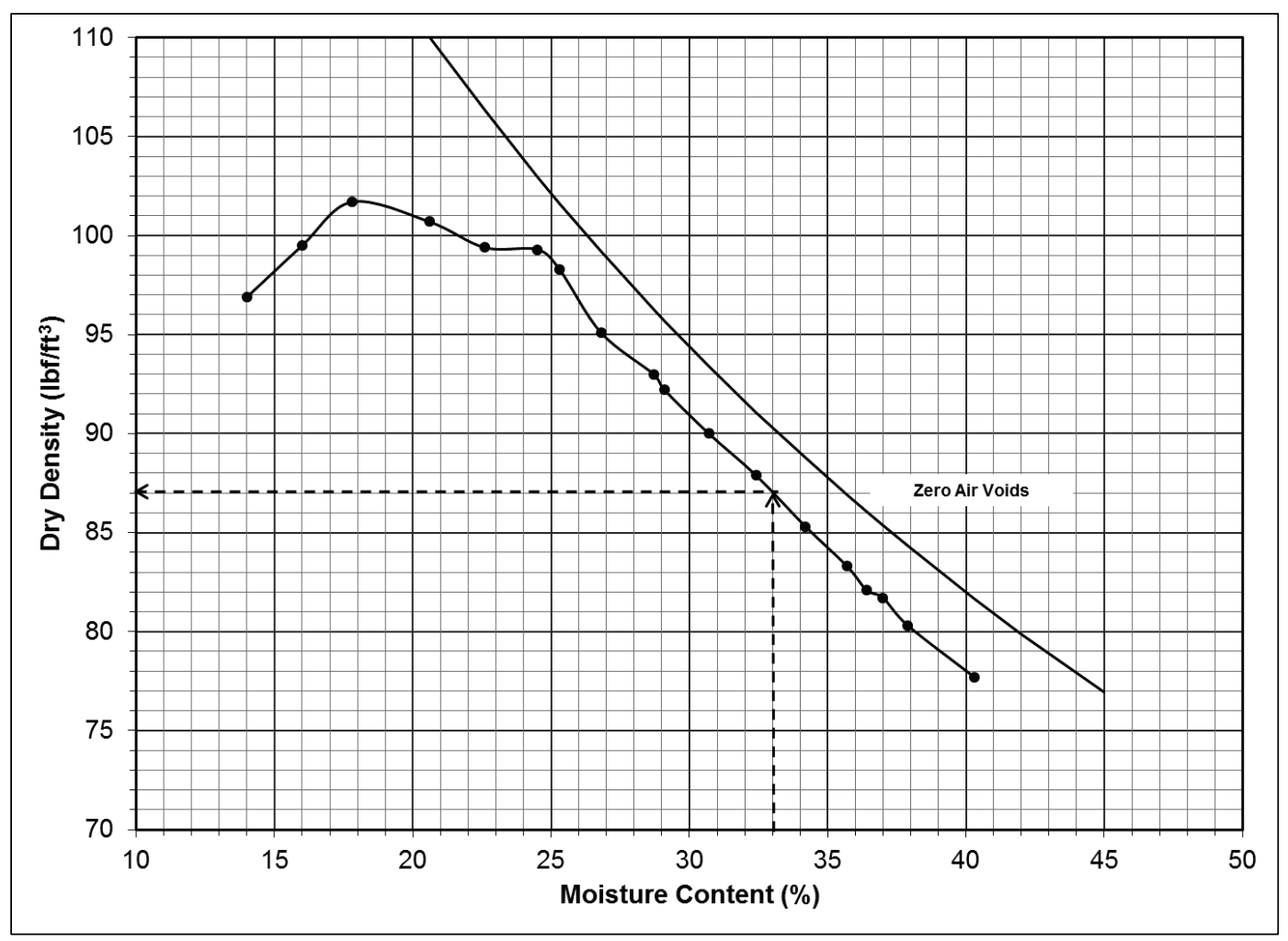




\subsubsection{Silt backfill}

The material used to backfill the excavated test pit to the required subgrade depth was a low plasticity silt (ML), according to ASTM D 2487. This material was used to provide a uniform foundation for the test subgrade. It was procured from a local aggregate supplier, and classification data are shown in Figure 2.8.

Figure 2.8. Classification data for low plasticity silt (ML).

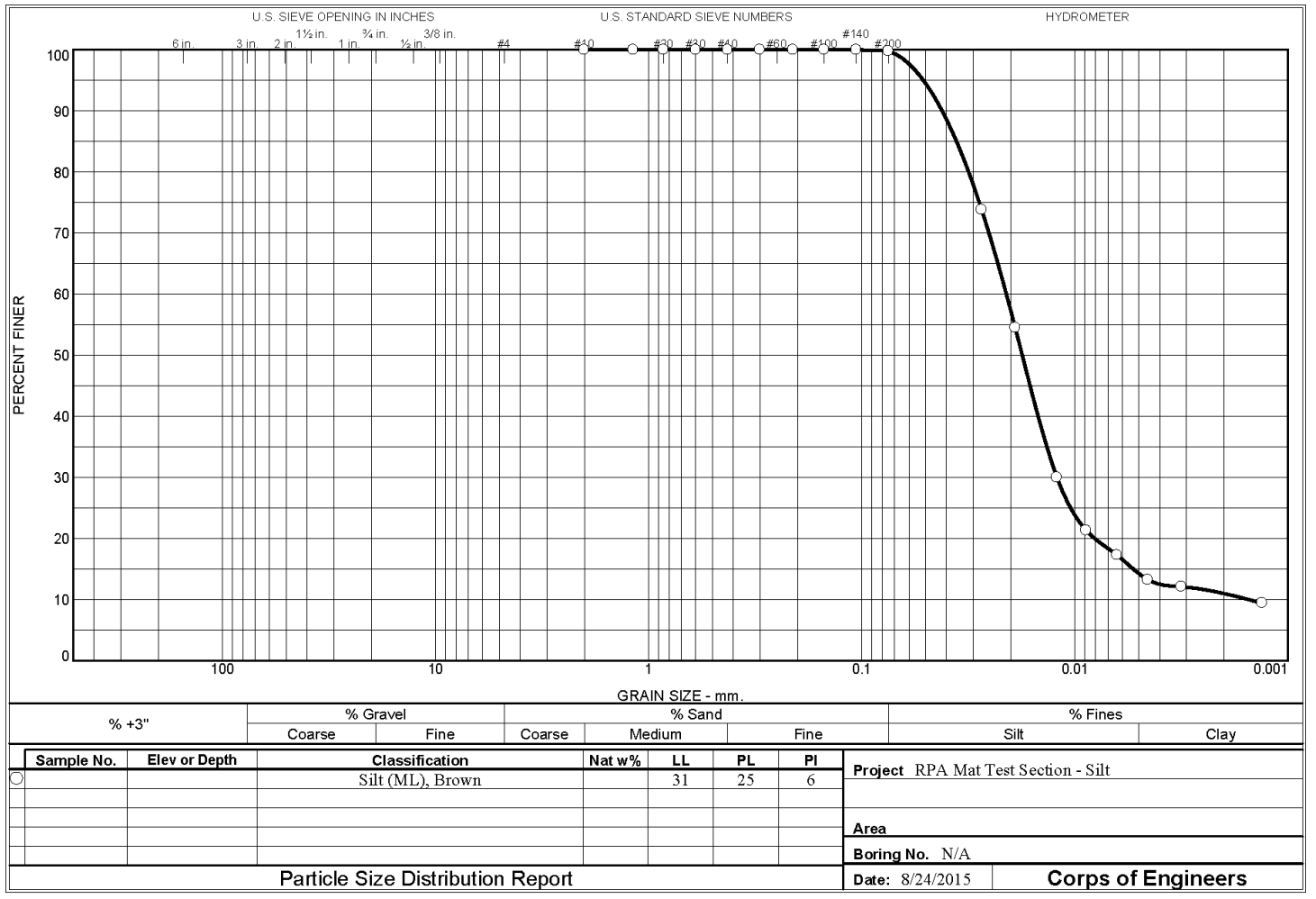

\subsubsection{Natural foundation}

The natural foundation material at the Hangar 2 test facility was classified as a low-plasticity clay (CL), according to ASTM D 2487. Classification data are shown in Figure 2.9. 
Figure 2.9. Classification data for low plasticity clay (CL).

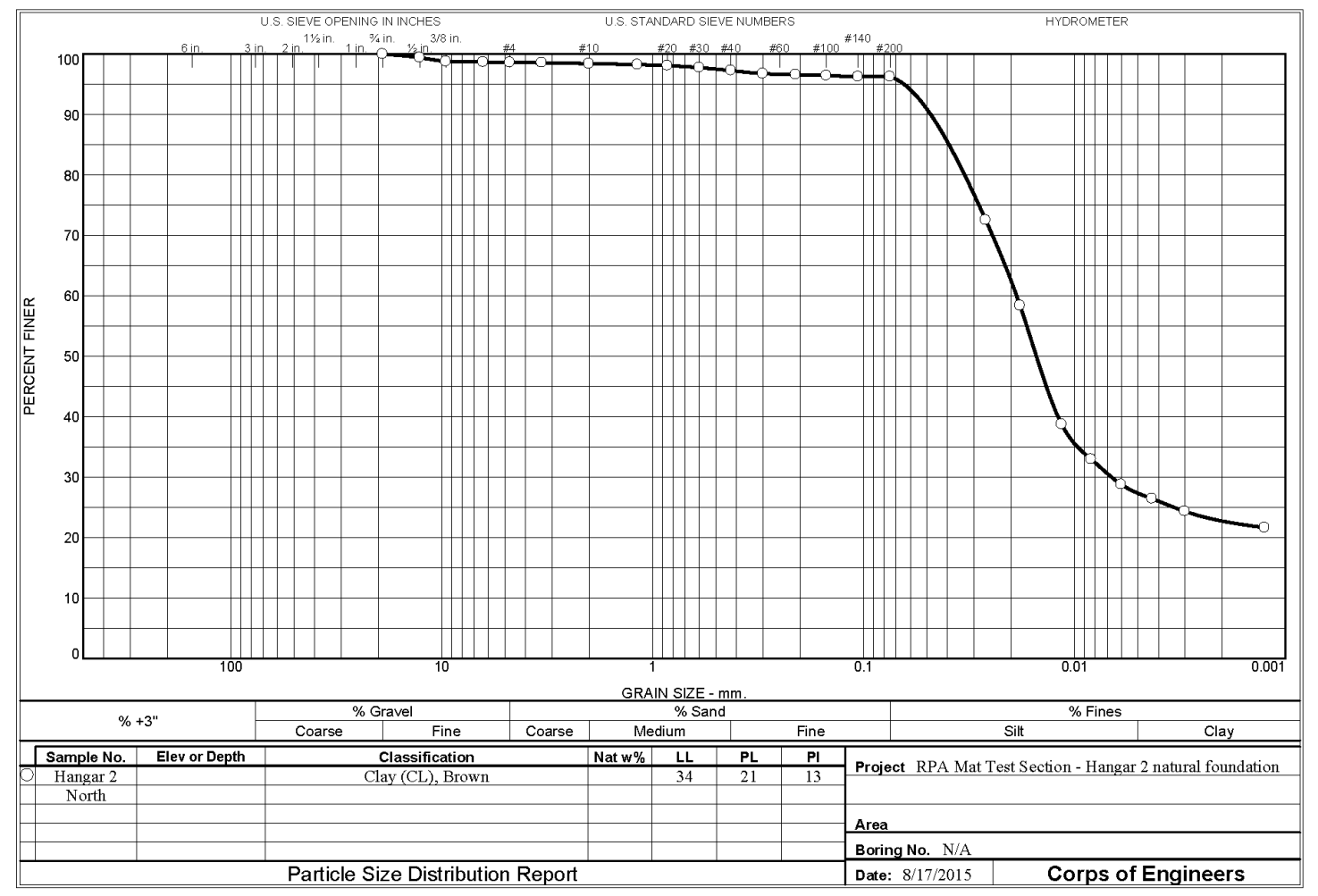




\section{Experimental Program}

\subsection{General description}

The tests were conducted on a full-scale test section constructed and trafficked under shelter in the Hangar 2 Pavement Test Facility at the ERDC. Mat panels were placed directly over a 24-in.-thick $\mathrm{CH}$ subgrade prepared to a CBR of 6 . The subgrade was compacted over a foundation prepared with a ML, which was placed over the natural foundation at the Hangar 2 facility (CL). A general profile of the test section is shown in Figure 3.1, and a general layout of the test section is shown in Figure 3.2.

Detailed drawings of the panel layout of each test item are provided in Appendix B. The test section was approximately $55 \mathrm{ft}$ wide by $122 \mathrm{ft}$ long and was divided into two test lanes: a 25-in.-wide lane designated for simulated MQ-9A Reaper and a 72-in.-wide lane designated for P-19 vehicle traffic. Each mat test item was approximately $30 \mathrm{ft}$ long. The centerline of each lane was marked throughout the length of the section for ease of trafficking and data collection.

Figure 3.1. Test-section profile.

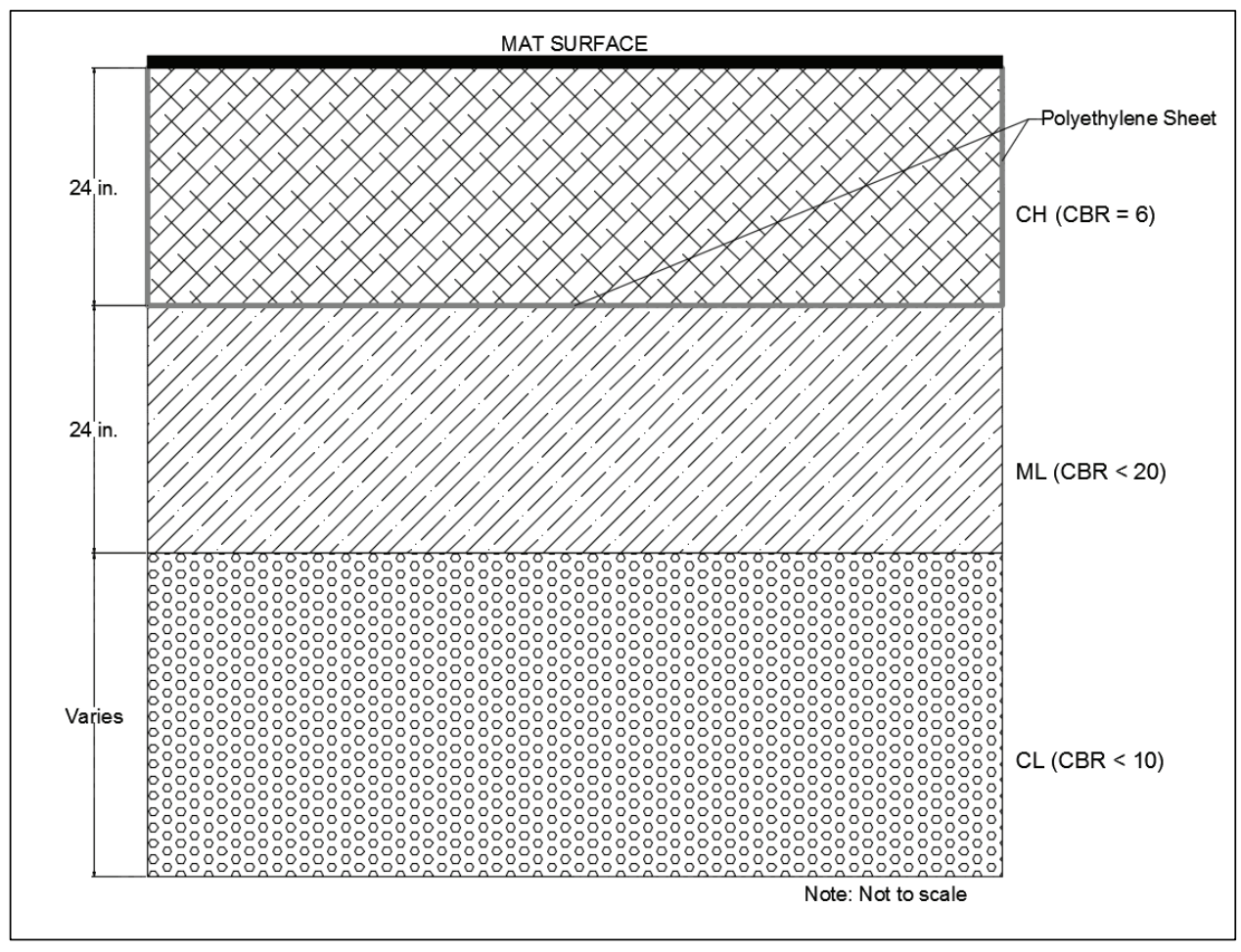


Figure 3.2. Test-section layout.

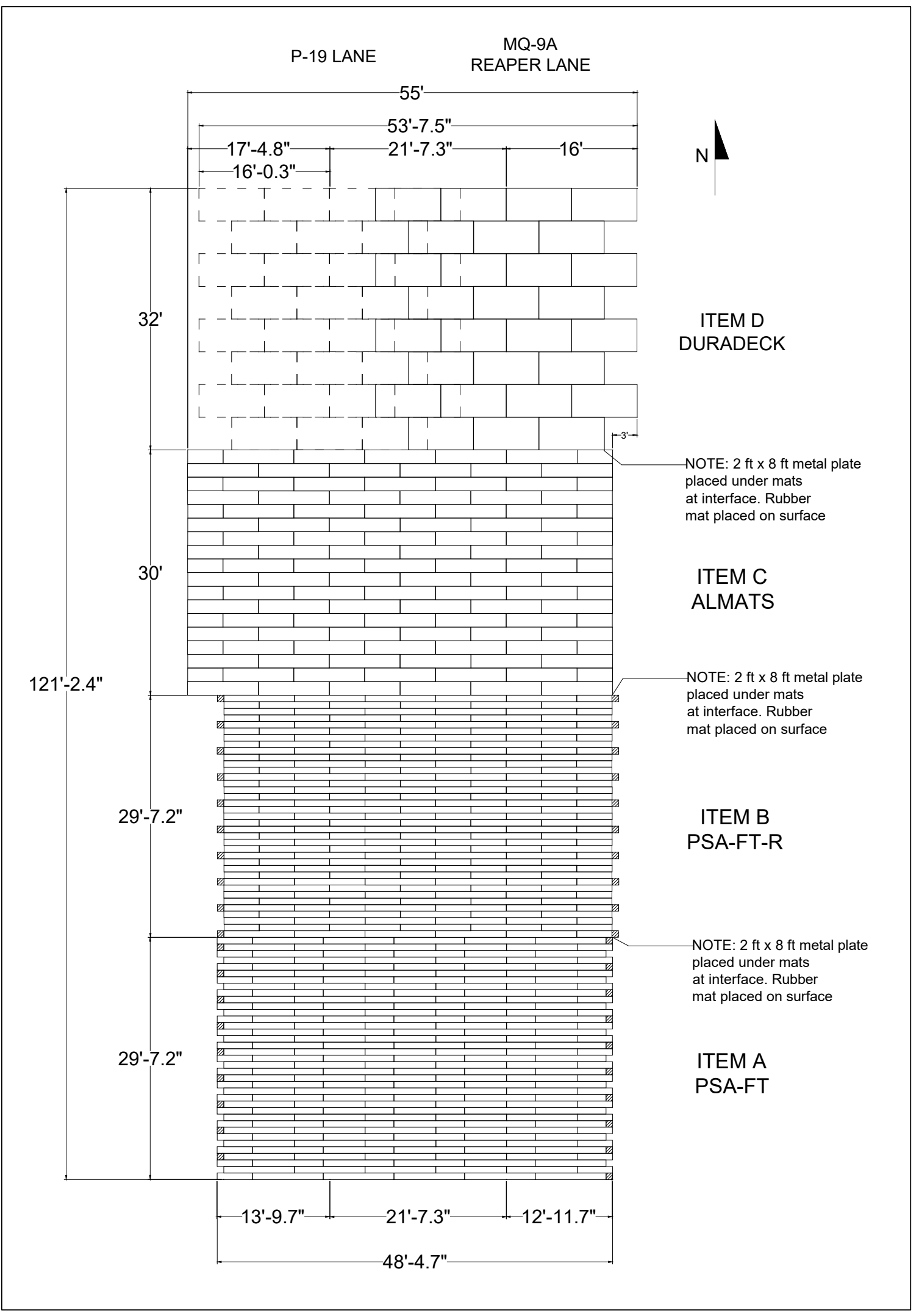




\subsection{Subgrade construction and posttest forensics}

Construction of the test section began by excavating a $130-\mathrm{ft}-$ long by $60-\mathrm{ft}-$ wide test pit to a depth of $4 \mathrm{ft}$ below the existing finished grade of Hangar 2. Dynamic cone penetrometer (DCP) (ASTM D 6951), nuclear gauge (ASTM D 6938), and in-situ CBR (CRD-C654-95) tests were performed on the material at the bottom of the excavation to determine its in-situ properties. The test pit was backfilled with two 12-in. (compacted) lifts of ML. Each lift of the ML material was leveled with a bulldozer and compacted with a pneumatic roller and a vibratory steel-wheel compactor to ensure that the subgrade was constructed over a stable foundation. DCP, nuclear gauge, and in-situ CBR tests were performed on the surface of the 24-in. layer of ML to determine its in-situ properties. The bottom and sides of the test pit were lined with impervious 6-mil polyethylene sheeting to minimize moisture migration from the $24 \mathrm{in}$. of new $\mathrm{CH}$ soil serving as the test-section subgrade, as shown in Figure 3.3.

Figure 3.3. Test-section excavation (left) lined with impervious sheeting (right).
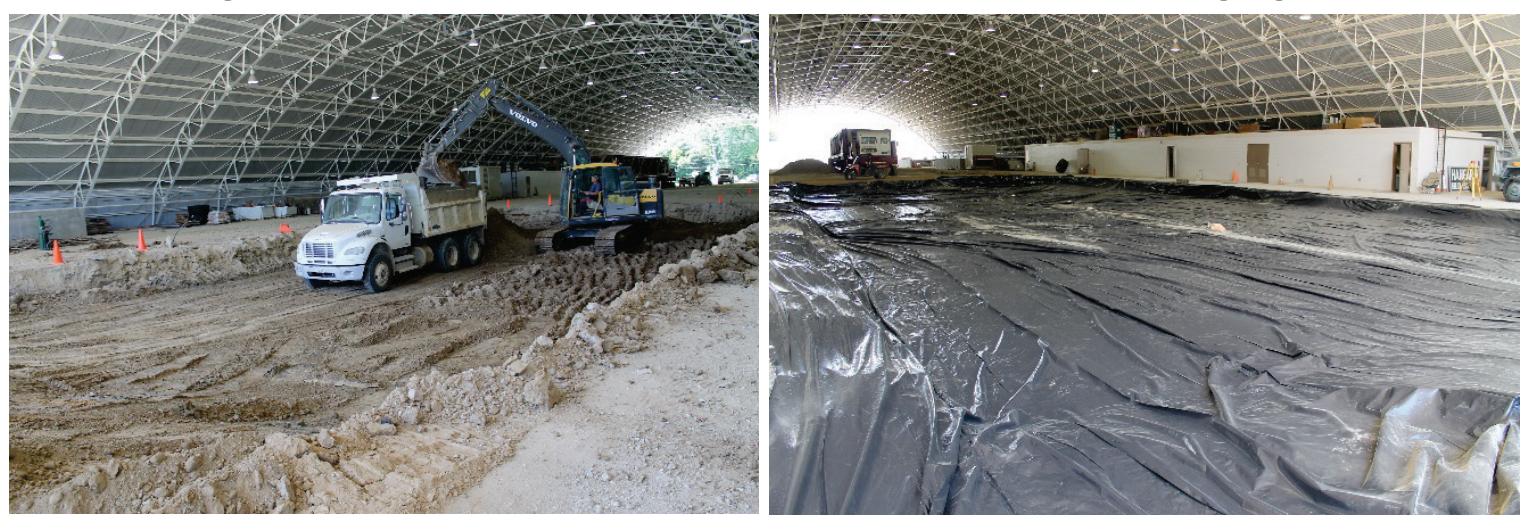

The $\mathrm{CH}$ material was processed at a preparatory site adjacent to Hangar 2 by spreading the material to a uniform 12-in. depth, pulverizing the material with a rotary mixer, adjusting the moisture content, pulverizing the material again, and stockpiling the material to improve consistency (Figure 3.4). This was an iterative process necessary to achieve a uniform distribution of moisture throughout the material. Once the $\mathrm{CH}$ had been processed to the target moisture content, it was placed in the test section, spread by a bulldozer in 8 -in. loose lifts, and compacted with a pneumatic roller to a final lift thickness of 6 in. each (Figure 3.5). 
Figure 3.4. Pulverizing $\mathrm{CH}$ (left) and adding moisture (right).
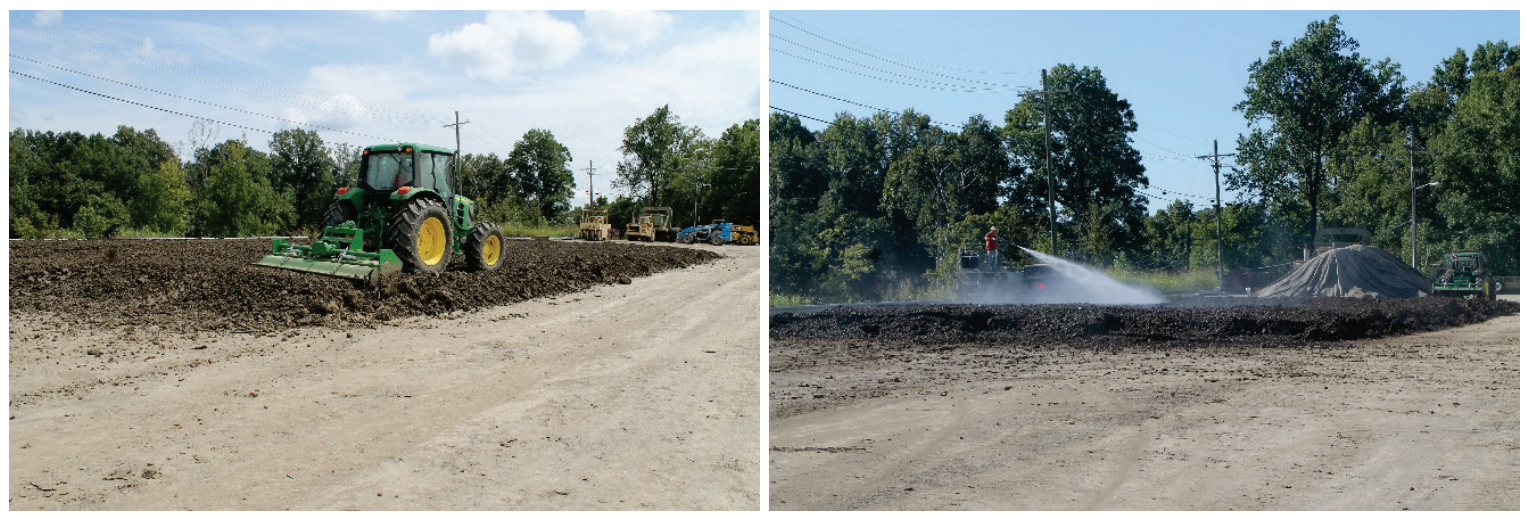

Figure 3.5. Leveling (left) and compacting (right) $\mathrm{CH}$.
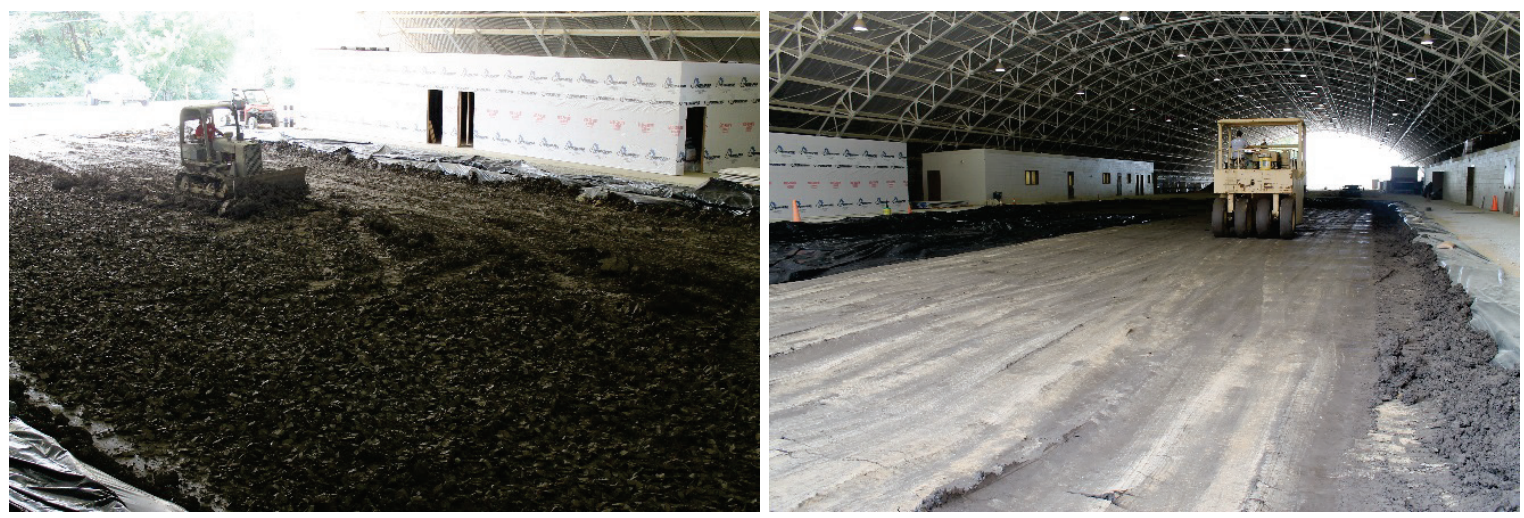

Each compacted lift was subjected to testing in accordance with the test methods listed in Table 3.1 to verify that that target values had been met (Figure 3.6). If the average pretest CBR of a lift differed from the target value by more than +1.0 or $-0.5 \mathrm{CBR}$, the lift was reconstituted. Each lift was surveyed to obtain an average thickness. After data collection, the surface was scarified an average depth of 1 in. with a rotary mixer prior to placement of the following lift to facilitate bonding at the interface. Once fully constructed, the subgrade surface was graded to allow suitability for mat installation.

Data for the natural CL foundation at two stations in the excavated test pit (North and South) in Hangar 2 are shown in Table 3.2. DCP data are provided in Appendix C. Properties for the $\mathrm{CH}$ subgrade and the ML backfill prior to installing mat and after completing traffic on each test item are shown in Table 3.3 through Table 3.6. DCP data for the ML backfill are given in Appendix D. The pretest moisture content and density measurements generally follow the trends found in laboratory measurements presented in Figures 2.6 and 2.7. 
Table 3.1. Field tests on each constructed $\mathrm{CH}$ lift.

\begin{tabular}{|l|c|c|c|c|}
\hline Test Name & Test Number & $\begin{array}{l}\text { Pretest } \\
\text { Subgrade }\end{array}$ & $\begin{array}{l}\text { Posttest } \\
\text { Subgrade }\end{array}$ & $\begin{array}{l}\text { Excavation \& } \\
\text { Silt Backfill }\end{array}$ \\
\hline $\begin{array}{l}\text { Standard Test Method for Density of Soil in Place by } \\
\text { the Drive Cylinder }\end{array}$ & ASTM D 2937 & $\mathrm{X}$ & & \\
\hline $\begin{array}{l}\text { Standard Test Methods for Density of Soil and Soil } \\
\text { Aggregate in Place by Nuclear Methods (Shallow Depth) }\end{array}$ & ASTM D 6938 & $\mathrm{X}$ & $\mathrm{X}$ & $\mathrm{X}$ \\
\hline $\begin{array}{l}\text { Standard Test Method for Density and Unit Weight of } \\
\text { Soil in Place by the Sand Cone Method }\end{array}$ & ASTM D 1556 & $\mathrm{X}$ & $\mathrm{X}$ & $\mathrm{X}$ \\
\hline $\begin{array}{l}\text { Standard Test Method for Laboratory Determination } \\
\text { of Water Content of Soil and Rock Mass }\end{array}$ & ASTM D 2216 & $\mathrm{X}$ & $\mathrm{X}$ & $\mathrm{X}$ \\
\hline $\begin{array}{l}\text { Standard Test Method for Use of the Dynamic Cone } \\
\text { Penetrometer in Shallow Pavement Applications }\end{array}$ & ASTM D 6951 & $\mathrm{X}$ & $\mathrm{X}$ & $\mathrm{X}$ \\
\hline $\begin{array}{l}\text { Standard Test Method for Determining the California } \\
\text { Bearing Ratio of Soils }\end{array}$ & CRD-C654-95 & $\mathrm{X}$ & $\mathrm{X}$ \\
\hline
\end{tabular}

Figure 3.6. Sand cone (left) and CBR test (right).
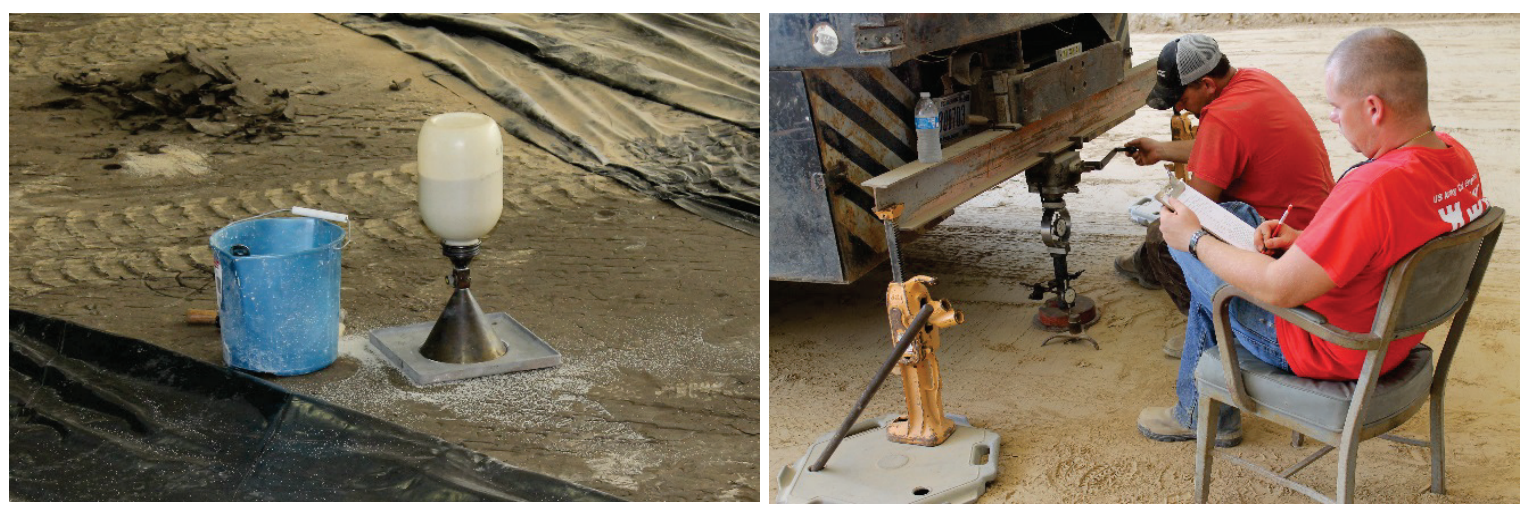

Table 3.2. Hangar 2 natural foundation (CL) in-situ properties.

\begin{tabular}{|l|l|l|}
\hline Property & North & South \\
\hline In situ CBR & 5.5 & 11.7 \\
\hline Moisture (\%) & 16.8 & 16.4 \\
\hline Nuclear Moisture (\%) & 18.6 & 18.6 \\
\hline Nuclear Wet Density $\left(\mathrm{lb} / \mathrm{ft}^{3}\right)$ & 124.7 & 125.7 \\
\hline Nuclear Dry Density $\left(\mathrm{lb} / \mathrm{ft}^{3}\right)$ & 106.0 & 107.2 \\
\hline
\end{tabular}

Once trafficking was completed, posttest forensics were conducted at the same locations as pretest to determine the depth of subgrade that might have undergone gradual drying and possible densification under traffic. Some increase in CBR was expected because of thixotropic properties of clay structures and gradual drying and densification during trafficking. Based on historical testing data, surface increases of less than $5 \mathrm{CBR}$ and increases of less than 3 CBR at a depth of 6 in. are common and therefore acceptable (Rushing and Tingle 2007; Rushing et al. 2012). 
Table 3.3. In-situ subgrade properties for PSA-FT test item.

\begin{tabular}{|c|c|c|c|c|c|c|c|c|c|c|c|c|}
\hline & & \multicolumn{3}{|c|}{ Nuclear Gauge } & \multicolumn{3}{|c|}{ Sand Cone } & \multicolumn{3}{|c|}{ Drive Cylinder } & \multicolumn{2}{|c|}{ CBR } \\
\hline \multicolumn{13}{|c|}{ MQ-9A Reaper } \\
\hline \multicolumn{13}{|c|}{ Pre Test } \\
\hline Layer & Test Depth & $\begin{array}{l}\text { Wet Density } \\
\text { (pcf) }\end{array}$ & $\begin{array}{l}\text { Dry Density } \\
\text { (pcf) }\end{array}$ & $\begin{array}{l}\text { Moisture } \\
(\%)\end{array}$ & $\begin{array}{l}\text { Wet Density } \\
\text { (pcf) }\end{array}$ & $\begin{array}{l}\text { Dry Density } \\
\text { (pcf) }\end{array}$ & $\begin{array}{l}\text { Moisture } \\
(\%)\end{array}$ & $\begin{array}{l}\text { Wet Density } \\
\text { (pcf) }\end{array}$ & $\begin{array}{l}\text { Dry Density } \\
\text { (pcf) }\end{array}$ & $\begin{array}{l}\text { Moisture } \\
\%)\end{array}$ & $\begin{array}{l}\text { Moisture } \\
\text { (\%) }\end{array}$ & CBR \\
\hline \multirow{5}{*}{$\mathrm{CH}$} & Surface & 117.6 & 89.4 & 31.6 & - & - & - & 113.0 & 84.0 & 34.5 & 33.1 & 6.0 \\
\hline & 6 in. & 116.8 & 88.2 & 32.4 & 118.2 & 87.3 & 35.4 & 122.6 & 90.6 & 35.3 & 33.9 & 6.0 \\
\hline & $12 \mathrm{in.}$ & 116.5 & 87.6 & 32.9 & 118.6 & 89.2 & 32.9 & 121.8 & 89.6 & 35.9 & 34.5 & 5.5 \\
\hline & $18 \mathrm{in.}$ & 114.8 & 87.1 & 31.8 & 117.1 & 86.2 & 35.9 & 120.4 & 89.7 & 34.2 & 35.5 & 6.0 \\
\hline & Average & 116.4 & 88.1 & 32.2 & 118.0 & 87.6 & 34.8 & 119.4 & 88.5 & 35.0 & 34.2 & 5.8 \\
\hline ML & $24 \mathrm{in.}$ & 105.4 & 97.7 & 7.8 & - & - & - & - & - & - & 7.0 & 16.0 \\
\hline \multicolumn{13}{|c|}{ Post Test } \\
\hline \multirow[t]{2}{*}{$\mathrm{CH}$} & Surface & 120.3 & 93.2 & 29.1 & - & - & - & - & - & - & 33.5 & 8.8 \\
\hline & 6 in. & 115.8 & 88.2 & 31.4 & - & - & - & - & - & - & 35.2 & 8.1 \\
\hline \multicolumn{13}{|c|}{ P-19 } \\
\hline \multicolumn{13}{|c|}{ Pre Test } \\
\hline \multirow{5}{*}{$\mathrm{CH}$} & Surface & 116.5 & 88.6 & 31.5 & - & - & - & 113.0 & 84.0 & 34.5 & 32.5 & 6.3 \\
\hline & $6 \mathrm{in.}$ & 114.0 & 84.0 & 35.8 & 118.2 & 87.3 & 35.4 & 122.6 & 90.6 & 35.3 & 35.0 & 5.5 \\
\hline & $12 \mathrm{in.}$ & 114.7 & 86.1 & 33.2 & 118.6 & 89.2 & 32.9 & 121.8 & 89.6 & 35.9 & 34.8 & 6.4 \\
\hline & $18 \mathrm{in.}$ & 114.8 & 86.1 & 33.5 & 117.1 & 86.2 & 35.9 & 120.4 & 89.7 & 34.2 & 35.0 & 5.5 \\
\hline & Average & 115.0 & 86.2 & 33.5 & 118.0 & 87.6 & 34.8 & 119.4 & 88.5 & 35.0 & 34.4 & 5.9 \\
\hline$M L$ & $24 \mathrm{in.}$ & 113.1 & 105.3 & 7.5 & - & - & - & - & - & - & 7.0 & 16.0 \\
\hline \multicolumn{13}{|c|}{ Post Test } \\
\hline \multirow[t]{2}{*}{$\mathrm{CH}$} & Surface & 120.1 & 92.6 & 29.7 & - & - & - & - & - & - & 34.9 & 5.9 \\
\hline & 6 in. & 115.4 & 87.5 & 32.1 & - & - & - & - & - & - & 36.3 & 6.7 \\
\hline
\end{tabular}


Table 3.4. In-situ subgrade properties for PSA-FT-R test item.

\begin{tabular}{|c|c|c|c|c|c|c|c|c|c|c|c|c|}
\hline & & \multicolumn{3}{|c|}{ Nuclear Gauge } & \multicolumn{3}{|c|}{ Sand Cone } & \multicolumn{3}{|c|}{ Drive Cylinder } & \multicolumn{2}{|c|}{ CBR } \\
\hline \multicolumn{13}{|c|}{ MQ-9A Reaper } \\
\hline & \multicolumn{12}{|c|}{ Pre Test } \\
\hline Layer & Test Depth & $\begin{array}{l}\text { Wet Density } \\
\text { (pcf) }\end{array}$ & $\begin{array}{l}\text { Dry Density } \\
\text { (pcf) }\end{array}$ & $\begin{array}{l}\text { Moisture } \\
\text { (\%) }\end{array}$ & $\begin{array}{l}\text { Wet Density } \\
\text { (pcf) }\end{array}$ & $\begin{array}{l}\text { Dry Density } \\
\text { (pcf) }\end{array}$ & $\begin{array}{l}\text { Moisture } \\
\text { (\%) }\end{array}$ & $\begin{array}{l}\text { Wet Density } \\
\text { (pcf) }\end{array}$ & $\begin{array}{l}\text { Dry Density } \\
\text { (pcf) }\end{array}$ & $\begin{array}{l}\text { Moisture } \\
\%)\end{array}$ & $\begin{array}{l}\text { Moisture } \\
(\%)\end{array}$ & CBR \\
\hline \multirow{5}{*}{$\mathrm{CH}$} & Surface & 117.0 & 88.8 & 31.8 & 117.2 & 87.9 & 33.4 & 112.4 & 84.1 & 33.7 & 33.8 & 5.9 \\
\hline & $6 \mathrm{in.}$ & 115.2 & 85.2 & 35.3 & 115.9 & 85.1 & 36.2 & 122.6 & 90.0 & 36.1 & 34.6 & 6.1 \\
\hline & $12 \mathrm{in.}$ & 115.7 & 87.3 & 32.6 & 116.6 & 87.9 & 32.6 & 123.4 & 92.4 & 33.5 & 33.9 & 6.8 \\
\hline & $18 \mathrm{in.}$ & 114.9 & 86.4 & 33.0 & 119.2 & 87.9 & 35.7 & 120.2 & 88.3 & 36.2 & 34.8 & 5.5 \\
\hline & Average & 115.7 & 86.9 & 33.2 & 117.2 & 87.2 & 34.5 & 119.6 & 88.7 & 34.9 & 34.3 & 6.1 \\
\hline ML & 24 in. & 105.5 & 98.5 & 7.2 & - & - & - & - & - & - & 7.7 & 16.5 \\
\hline \multicolumn{13}{|c|}{ Post Test } \\
\hline \multirow[t]{2}{*}{$\mathrm{CH}$} & Surface & 117.7 & 88.7 & 32.7 & - & - & - & - & - & - & 36.9 & 7.3 \\
\hline & $6 \mathrm{in.}$ & 110.4 & 81.5 & 35.6 & - & - & - & - & - & - & 35.4 & 8.1 \\
\hline \multicolumn{13}{|c|}{ P-19 } \\
\hline & \multicolumn{12}{|c|}{ Pre Test } \\
\hline \multirow{5}{*}{$\mathrm{CH}$} & Surface & 117.3 & 89.1 & 31.6 & 117.2 & 87.9 & 33.4 & 112.4 & 84.1 & 33.7 & 33.3 & 6.1 \\
\hline & $6 \mathrm{in.}$ & 114.8 & 84.7 & 35.5 & 115.9 & 85.1 & 36.2 & 122.6 & 90.0 & 36.1 & 34.5 & 5.6 \\
\hline & $12 \mathrm{in.}$ & 115.3 & 86.2 & 33.8 & 116.6 & 87.9 & 32.6 & 123.4 & 92.4 & 33.5 & 35.7 & 5.8 \\
\hline & $18 \mathrm{in}$. & 114.5 & 86.5 & 32.3 & 119.2 & 87.9 & 35.7 & 120.2 & 88.3 & 36.2 & 35.0 & 5.8 \\
\hline & Average & 115.5 & 86.6 & 33.3 & 117.2 & 87.2 & 34.5 & 119.6 & 88.7 & 34.9 & 34.6 & 5.8 \\
\hline ML & $24 \mathrm{in.}$ & 105.8 & 99.1 & 6.8 & - & - & - & - & - & - & 7.7 & 16.5 \\
\hline \multicolumn{13}{|c|}{ Post Test } \\
\hline \multirow[t]{2}{*}{$\mathrm{CH}$} & Surface & 117.5 & 88.3 & 33.1 & - & - & - & - & - & - & 39.6 & 4.7 \\
\hline & $6 \mathrm{in.}$ & 114.2 & 84.3 & 35.4 & - & - & - & - & - & - & 32.7 & 5.8 \\
\hline
\end{tabular}


Table 3.5. In-situ subgrade properties for ALMATS test item.

\begin{tabular}{|c|c|c|c|c|c|c|c|c|c|c|c|c|}
\hline & & \multicolumn{3}{|c|}{ Nuclear Gauge } & \multicolumn{3}{|c|}{ Sand Cone } & \multicolumn{3}{|c|}{ Drive Cylinder } & \multicolumn{2}{|c|}{ CBR } \\
\hline \multicolumn{13}{|c|}{ MQ-9A Reaper } \\
\hline \multicolumn{13}{|c|}{ Pre Test } \\
\hline Layer & Test Depth & $\begin{array}{l}\text { Wet Density } \\
\text { (pcf) }\end{array}$ & $\begin{array}{l}\text { Dry Density } \\
\text { (pcf) }\end{array}$ & $\begin{array}{l}\text { Moisture } \\
\text { (\%) }\end{array}$ & $\begin{array}{l}\text { Wet Density } \\
\text { (pcf) }\end{array}$ & $\begin{array}{l}\text { Dry Density } \\
\text { (pcf) }\end{array}$ & $\begin{array}{l}\text { Moisture } \\
(\%)\end{array}$ & $\begin{array}{l}\text { Wet Density } \\
\text { (pcf) }\end{array}$ & $\begin{array}{l}\text { Dry Density } \\
\text { (pcf) }\end{array}$ & $\begin{array}{l}\text { Moisture } \\
\%)\end{array}$ & $\begin{array}{l}\text { Moisture } \\
\text { (\%) }\end{array}$ & CBR \\
\hline \multirow{5}{*}{$\mathrm{CH}$} & Surface & 117.2 & 88.6 & 32.4 & 112.3 & 84.4 & 33.0 & 113.5 & 84.5 & 34.3 & 33.6 & 5.9 \\
\hline & $6 \mathrm{in.}$ & 115.8 & 85.9 & 35.0 & 116.8 & 85.2 & 37.2 & 121.6 & 89.4 & 36.1 & 35.3 & 5.6 \\
\hline & $12 \mathrm{in.}$ & 115.8 & 87.8 & 30.5 & 116.8 & 87.4 & 33.7 & 124.1 & 93.1 & 33.3 & 33.6 & 6.6 \\
\hline & $18 \mathrm{in.}$ & 113.0 & 85.4 & 32.4 & 114.3 & 84.3 & 35.5 & 119.6 & 87.3 & 37.0 & 34.8 & 6.8 \\
\hline & Average & 115.5 & 86.9 & 32.6 & 115.1 & 85.3 & 34.8 & 119.7 & 88.6 & 35.2 & 34.4 & 6.2 \\
\hline$M L$ & $24 \mathrm{in.}$ & 111.3 & 102.2 & 9.0 & - & - & - & - & - & - & 9.1 & 21.3 \\
\hline \multicolumn{13}{|c|}{ Post Test } \\
\hline \multirow[t]{2}{*}{$\mathrm{CH}$} & Surface & 118.9 & 91.4 & 30.1 & - & - & - & - & - & - & 32.9 & 6.7 \\
\hline & 6 in. & 114.6 & 82.2 & 39.6 & - & - & - & - & - & - & 35.5 & 6.9 \\
\hline \multicolumn{13}{|c|}{ P-19 } \\
\hline \multicolumn{13}{|c|}{ Pre Test } \\
\hline \multirow{5}{*}{$\mathrm{CH}$} & Surface & 117.1 & 88.4 & 32.5 & 112.3 & 84.4 & 33.0 & 113.5 & 84.5 & 34.3 & 33.2 & 6.0 \\
\hline & $6 \mathrm{in.}$ & 114.9 & 85.6 & 34.3 & 116.8 & 85.2 & 37.2 & 121.6 & 89.4 & 36.1 & 34.2 & 5.5 \\
\hline & $12 \mathrm{in.}$ & 114.8 & 86.7 & 32.3 & 116.8 & 87.4 & 33.7 & 124.1 & 93.1 & 33.3 & 34.6 & 5.8 \\
\hline & $18 \mathrm{in.}$ & 114.1 & 86.4 & 32.0 & 114.3 & 84.3 & 35.5 & 119.6 & 87.3 & 37.0 & 35.5 & 5.5 \\
\hline & Average & 115.2 & 86.7 & 32.8 & 115.1 & 85.3 & 34.8 & 119.7 & 88.6 & 35.2 & 34.4 & 5.7 \\
\hline ML & 24 in. & 107.3 & 99.9 & 7.5 & - & - & - & - & - & - & 9.1 & 21.3 \\
\hline \multicolumn{13}{|c|}{ Post Test } \\
\hline \multirow[t]{2}{*}{$\mathrm{CH}$} & Surface & 115.8 & 89.3 & 29.9 & - & - & - & - & - & - & 36.0 & 5.5 \\
\hline & $6 \mathrm{in.}$ & 114.3 & 84.7 & 35.2 & - & - & - & - & - & - & 36.4 & 7.7 \\
\hline
\end{tabular}


Table 3.6. In-situ subgrade properties for DuraDeck test item.

\begin{tabular}{|c|c|c|c|c|c|c|c|c|c|c|c|c|}
\hline & & \multicolumn{3}{|c|}{ Nuclear Gauge } & \multicolumn{3}{|c|}{ Sand Cone } & \multicolumn{3}{|c|}{ Drive Cylinder } & \multicolumn{2}{|c|}{ CBR } \\
\hline \multicolumn{13}{|c|}{ MQ-9A Reaper } \\
\hline \multicolumn{13}{|c|}{ Pre Test } \\
\hline Layer & Test Depth & $\begin{array}{l}\text { Wet Density } \\
\text { (pcf) }\end{array}$ & $\begin{array}{l}\text { Dry Density } \\
\text { (pcf) }\end{array}$ & $\begin{array}{l}\text { Moisture } \\
\text { (\%) }\end{array}$ & $\begin{array}{l}\text { Wet Density } \\
\text { (pcf) }\end{array}$ & $\begin{array}{l}\text { Dry Density } \\
\text { (pcf) }\end{array}$ & $\begin{array}{l}\text { Moisture } \\
\text { (\%) }\end{array}$ & $\begin{array}{l}\text { Wet Density } \\
\text { (pcf) }\end{array}$ & $\begin{array}{l}\text { Dry Density } \\
\text { (pcf) }\end{array}$ & $\begin{array}{l}\text { Moisture } \\
\%)\end{array}$ & $\begin{array}{l}\text { Moisture } \\
(\%)\end{array}$ & CBR \\
\hline \multirow{5}{*}{$\mathrm{CH}$} & Surface & 117.2 & 88.7 & 32.2 & 119.1 & 89.4 & 33.2 & 113.5 & 84.8 & 34.0 & 33.7 & 5.9 \\
\hline & $6 \mathrm{in.}$ & 115.9 & 86.0 & 34.8 & 117.8 & 88.5 & 33.2 & 121.4 & 89.3 & 36.0 & 35.7 & 6.0 \\
\hline & $12 \mathrm{in.}$ & 115.8 & 86.8 & 33.5 & 120.5 & 91.0 & 32.5 & 123.7 & 91.8 & 34.8 & 34.6 & 6.1 \\
\hline & $18 \mathrm{in.}$ & 112.3 & 82.9 & 35.5 & 123.5 & 91.9 & 34.3 & 120.2 & 88.5 & 35.9 & 34.7 & 6.0 \\
\hline & Average & 115.3 & 86.1 & 34.0 & 120.2 & 90.2 & 33.3 & 119.7 & 88.6 & 35.1 & 34.7 & 6.0 \\
\hline ML & 24 in. & 109.6 & 99.7 & 9.9 & - & - & - & - & - & - & 10.6 & 13.8 \\
\hline \multicolumn{13}{|c|}{ Post Test } \\
\hline \multirow[t]{2}{*}{$\mathrm{CH}$} & Surface & 114.8 & 88.1 & 30.3 & - & - & - & - & - & - & 37.8 & 4.8 \\
\hline & $6 \mathrm{in.}$ & 114.8 & 84.0 & 36.7 & - & - & - & - & - & - & 35.7 & 7.2 \\
\hline \multicolumn{13}{|c|}{ P-19 } \\
\hline \multicolumn{13}{|c|}{ Pre Test } \\
\hline \multirow{5}{*}{$\mathrm{CH}$} & Surface & 116.1 & 86.9 & 33.6 & 119.1 & 89.4 & 33.2 & 113.5 & 84.8 & 34.0 & 34.0 & 5.9 \\
\hline & $6 \mathrm{in.}$ & 114.4 & 84.3 & 35.8 & 117.8 & 88.5 & 33.2 & 121.4 & 89.3 & 36.0 & 35.1 & 5.8 \\
\hline & $12 \mathrm{in.}$ & 115.4 & 87.2 & 32.4 & 120.5 & 91.0 & 32.5 & 123.7 & 91.8 & 34.8 & 33.8 & 6.0 \\
\hline & $18 \mathrm{in}$. & 115.0 & 86.0 & 33.9 & 123.5 & 91.9 & 34.3 & 120.2 & 88.5 & 35.9 & 35.1 & 6.3 \\
\hline & Average & 115.2 & 86.1 & 33.9 & 120.2 & 90.2 & 33.3 & 119.7 & 88.6 & 35.1 & 34.5 & 6.0 \\
\hline ML & $24 \mathrm{in.}$ & 103.4 & 96.2 & 7.5 & - & - & - & - & - & - & 10.6 & 13.8 \\
\hline \multicolumn{13}{|c|}{ Post Test } \\
\hline \multirow[t]{2}{*}{$\mathrm{CH}$} & Surface & 116.9 & 87.5 & 33.6 & - & - & - & - & - & - & 37.7 & 3.5 \\
\hline & $6 \mathrm{in.}$ & 114.7 & 84.9 & 35.2 & - & - & - & - & - & - & 36.4 & 6.3 \\
\hline
\end{tabular}




\subsection{Mat installation}

Installation of the mat panels on the test-section subgrade began by painting the boundaries of the test area and the individual test items. The test items were assembled in the following order: PSA-FT-R, ALMATS, PSA-FT, and DuraDeck. Other than forklifts used to carry panels near the test area, panels were installed without the use of MHE. Steel panels approximately $2 \mathrm{ft}$ by $8 \mathrm{ft}$ were placed underneath end panels at the interface of test items at each test lane to help with transition of the load carts between test items (Figure 3.7). A rubber section, $2 \mathrm{ft}$ by $8 \mathrm{ft}$ wide, was placed on the mats at the same locations to avoid damage to the load carts and the mats. After assembly of all the test items, full panels of AM2 were installed at the ends of the traffic lanes to facilitate the entrance and exit of the test vehicles. Steel plates were also placed at these interfaces between the test items and the AM2 end ramps for ease of transition. Three 1,00o-lb cast iron blocks were placed on the edges of each of the test items to simulate the resistance to movement provided by a large expanse of matting. Lines were then painted on the mat surface at data collection locations.

Figure 3.7. Steel plate and rubber mat at interface between test items.

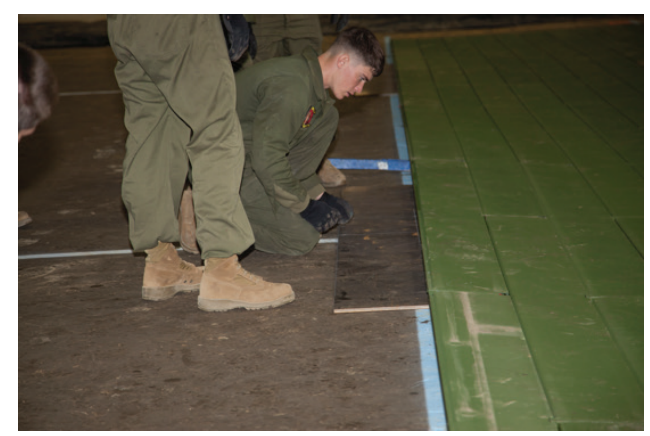

(a) Steel plate

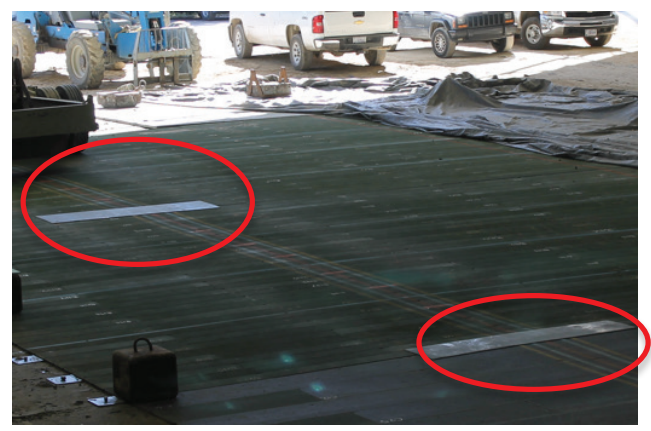

(b) Rubber sections

\subsubsection{PSA-FT-R}

Panel assembly began by placing a half-panel on the northeast corner of the test item with the male hinge connection facing north. The second panel was positioned adjacent to the short end of the first panel, allowing the connectors to form a double-arrow-shaped slot to insert the locking bar. The mat allows for assembly from each end for efficiency. Initially, the full panel on the northwest corner was also installed, and subsequent panels were connected in the same way until they met at the center of the row. However, the last slot formed at the center by the last two panels on the ground was too tight to insert a locking bar. It became evident that the 
connections were too loose and created large gaps that accumulated throughout the row and prevented assembly from each end. It was decided to go on with installation starting from one end (west) and continuing south. The second row was installed by rotating the male connection of a new panel to the female connection of the panels already on the ground. This process was continued until the test item was assembled in a brickwork configuration with a half-panel at alternating ends of each row. Anchor panels and stakes were installed every four rows (a total of 10 anchors on each edge) to secure the test item from movement during trafficking. Photographs of installation are shown in Figure 3.8. The final assembled test item is shown in Figure 3.9.

In general, installation of the PS-FT-R system was simple to perform. Personnel were able to carry two to three full panels at a time, while two people were required to pivot a panel when connecting male/female hinge connectors. Feedback was given to the vendor regarding the tolerances at the end connection and to reduce these to allow installation from both directions. The mat system tended to be forgiving to uneven areas on the subgrade surface, but improvement could be made at the joint to allow easier insertion of the locking key. Although not evaluated for this program, the stakes were also difficult to install because of the small round head. Feedback was provided to the vendor to make the head flat and larger.

Figure 3.8. Installation of PSA-FT-R mat system.

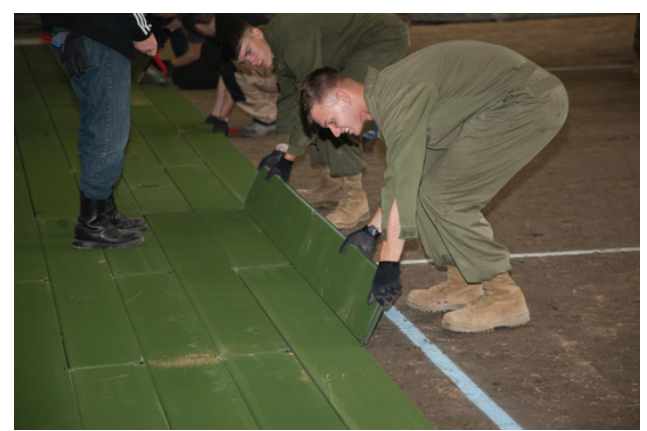

(a) Connecting male/female hinge

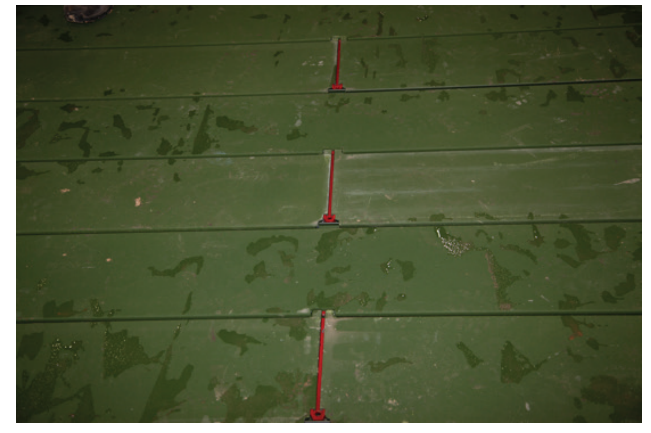

(c) Secured end connectors

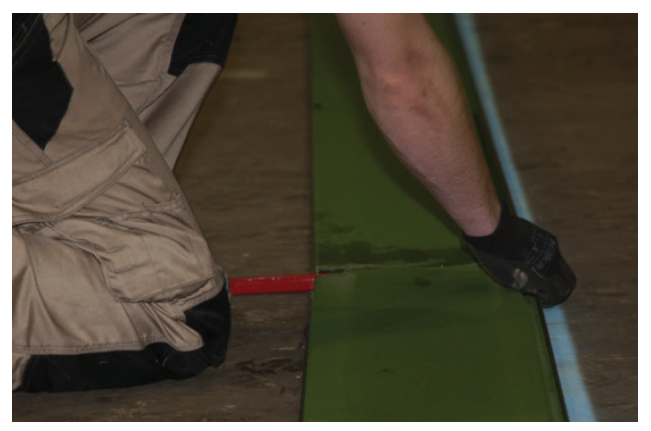

(b) Insertion of locking key

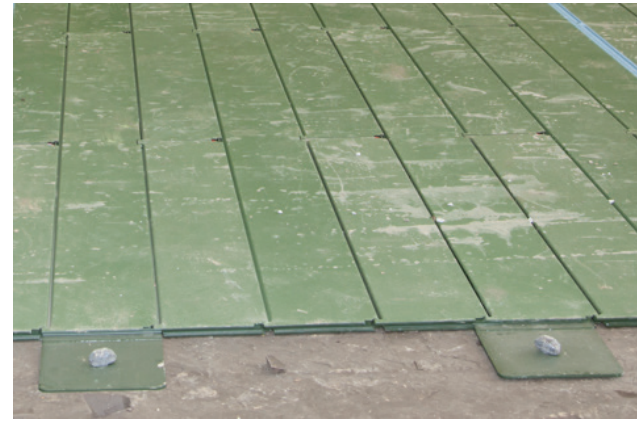

(d) Anchor panels and stakes 
Figure 3.9. Assembled PSA-FT-R test item.

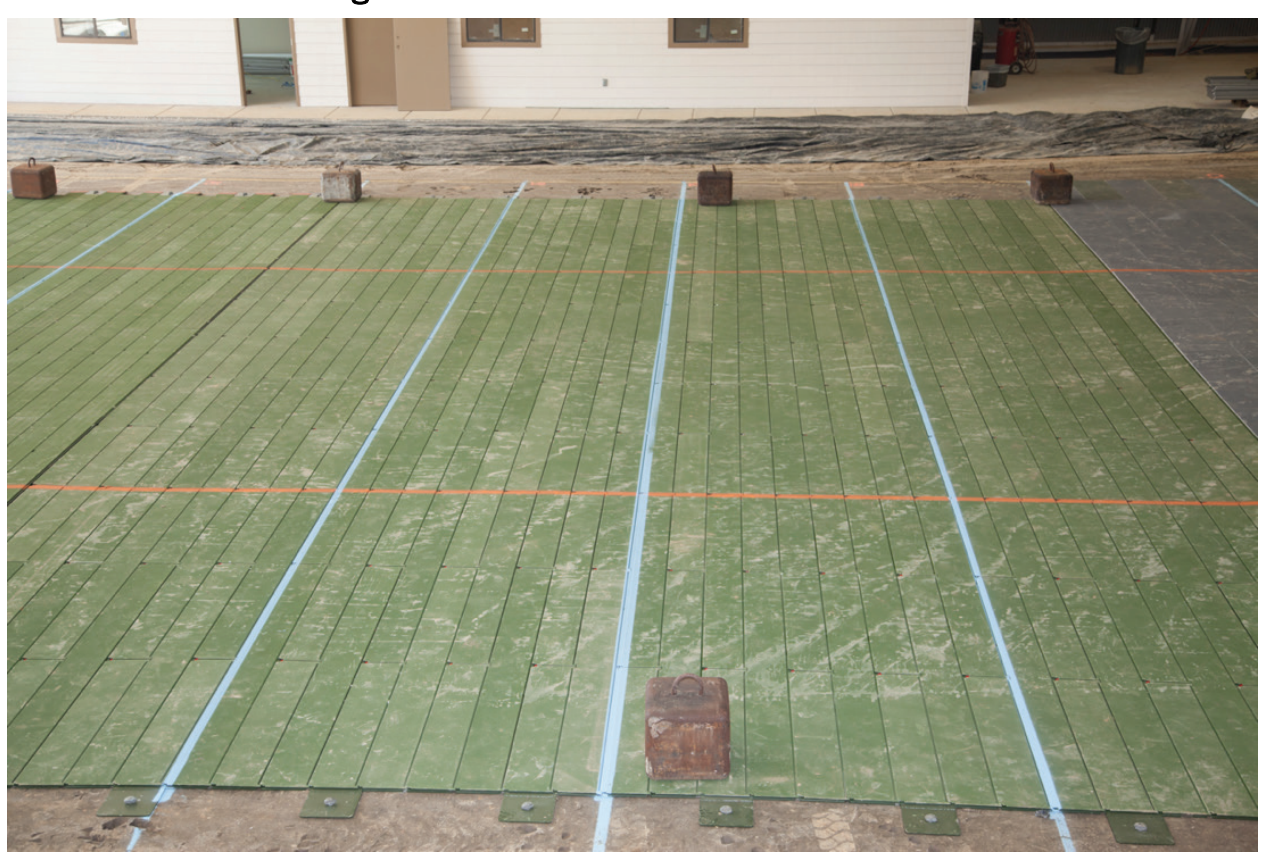

\subsubsection{ALMATS}

The first mat panel was placed on the ground with the long dimension perpendicular to the direction of traffic and with the male hinge connector facing north. Installation began on the southeast corner. The second panel was positioned adjacent to the short end of the first, allowing the overlapping end connector of the second panel to drop into position over the underlapping end connector of the first panel. A rectangular slot was formed between the two end connector rails, and an aluminum locking bar was inserted into the slot. This locking bar prevented the ends of the mat panels from separating. This process was continued until the first row was installed. For the second row, the female hinge connector was attached to the male hinge connector of panels from the first row, and the panel was pivoted into place. The next panel was installed by attaching the female hinge connector to the male hinge connector of panels in the first row and allowing the overlapping end connector rail to pivot over and connect to the underlapping end connector rail of the adjacent panel. An aluminum locking bar was inserted into the space provided to keep the panels from separating. This process was repeated until the entire test item was assembled in a brickwork configuration with half-panels on the ends of every other row. Photographs of installation are shown in Figure 3.10. The final assembled test item is shown in Figure 3.11. 
Figure 3.10. Installation of ALMATS.

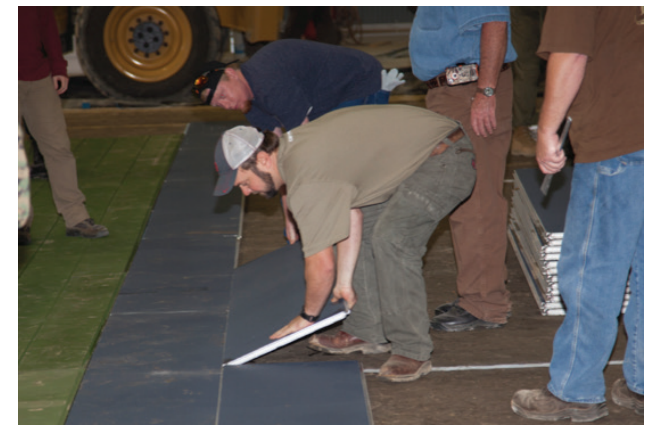

(a) Connecting male/female hinge

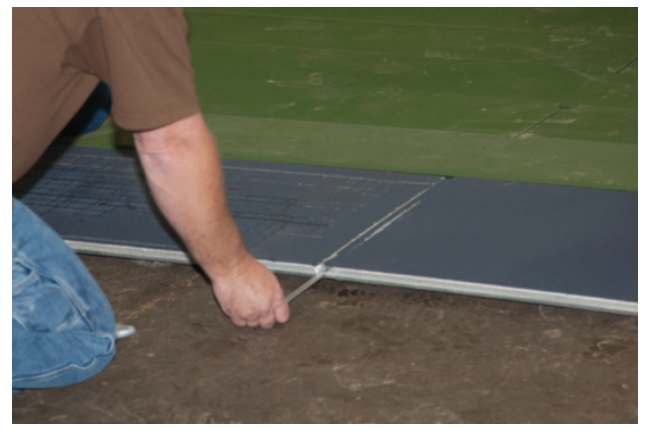

(b) Insertion of locking bar

Figure 3.11. Final assembled ALMATS test item.

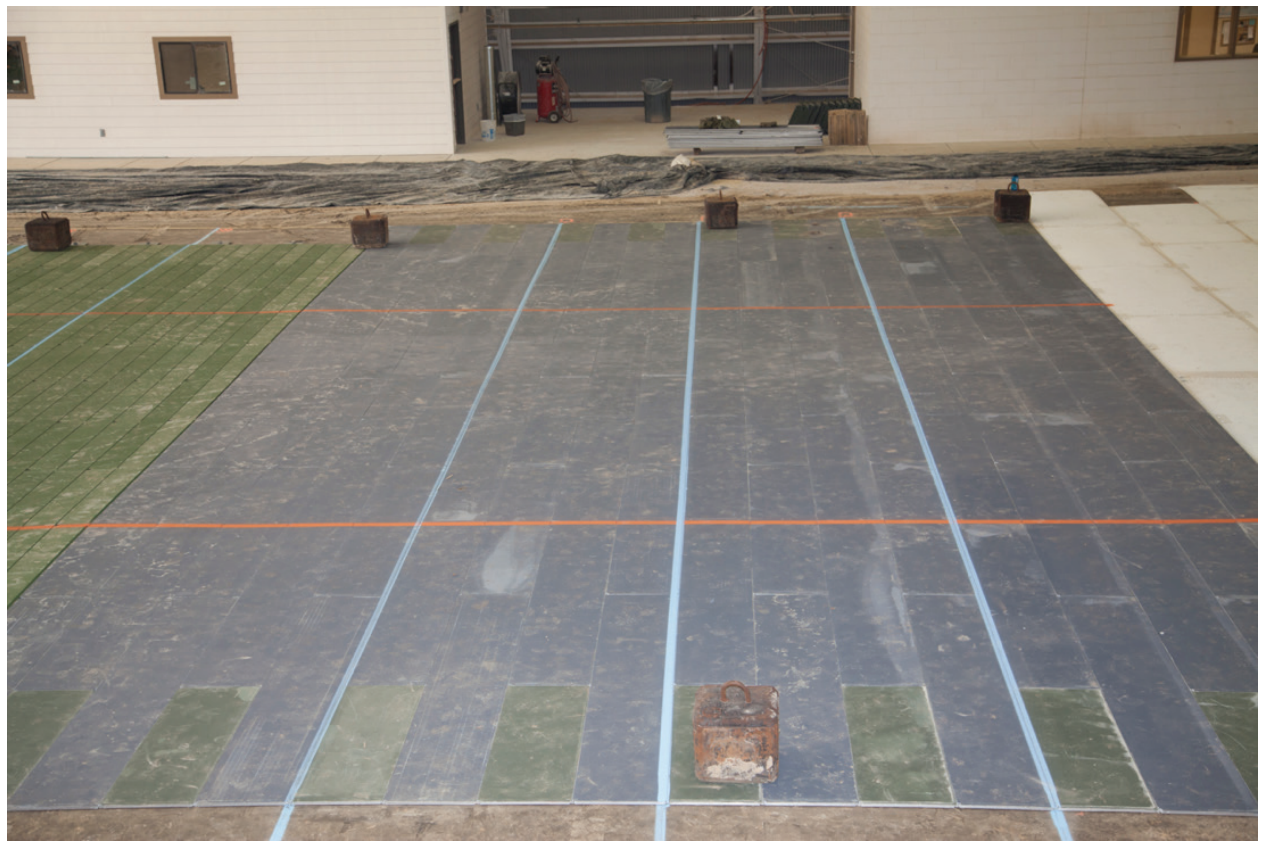

The ALMATS panels were difficult to install for one main reason: the tolerances at the male/female hinge connection and at the overlap/underlap connection were tight. Although panels were lightweight and easy to carry (one member of the crew could carry a single full panel), installation was time consuming. Locking bars did not slide into the slots easily and had to be hammered in, potentially damaging the joint. The female hinge connection did not rotate into place adequately, requiring the crew to lift surrounding panels with a crow bar and hammering the panel into place. Overall feedback was that installation of ALMATS was as demanding as the AM2 mat system. 


\subsubsection{PSA-FT}

Assembly began by placing a panel on the northwest corner and on the northeast corner of the test item and installing subsequent panels in the same row next to those until they met at the center of the test section. This process was allowed since there was no mechanical connection on the short end. The second row was installed by rotating the male connection of a new panel to the female connection of the panels already on the ground. Welded blocks on the male edge of the panels were aligned with receptor slots on the female edges during installation to lock the panels together and to prevent lateral movement along panel rows. This process was continued until the test item was assembled in a staggered brickwork configuration with a half-panel at alternating ends of each row. This pattern yielded staggered edges for the test item that fit the anchor panels.

Anchor panels and stakes were installed every four rows (a total of 9 anchors on each edge) to secure the test item from movement during trafficking. Photographs of installation are shown in Figure 3.12. The final assembled test item is shown in Figure 3.13.

The PSA-FT mat system was easy and simple to install. It was very forgiving to uneven areas on the subgrade, especially because of the absence of a mechanical connection on the short end. Personnel were able to carry two to three panels at a time. Rough calculation on installation rate showed that the mat could be installed in half the time an AM2 VTOL pad could be installed, absent installation of anchors and other accessories. Although not evaluated for this program, the stakes were difficult to install because of the small round head. Feedback was provided to the vendor to make the head flat and larger. 
Figure 3.12. Installation of PSA-FT mat system.

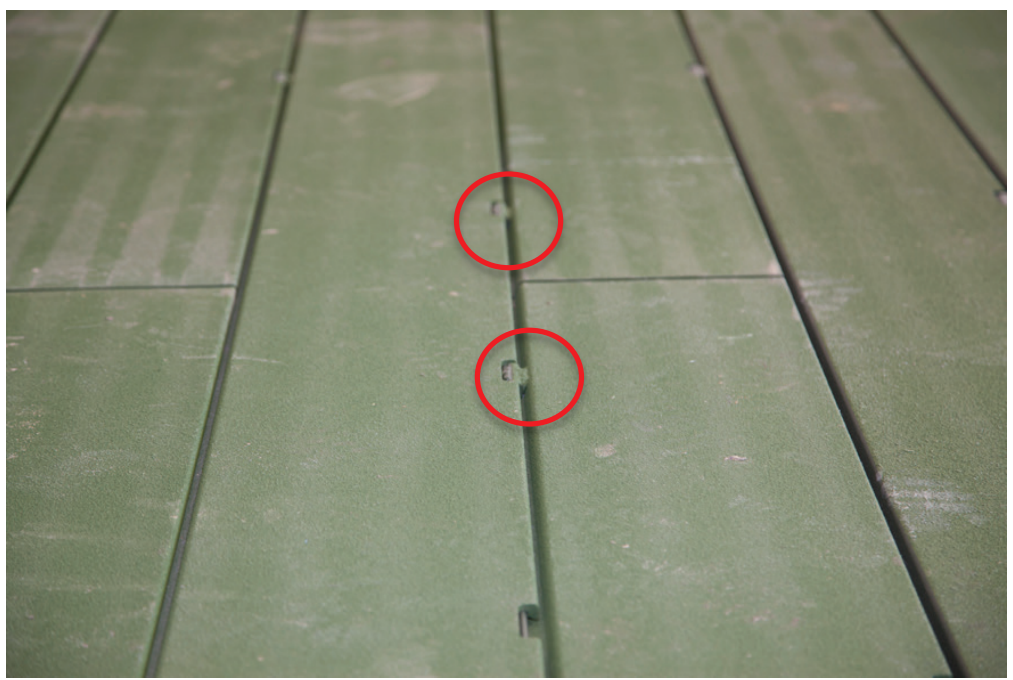

(a) Welded blocks in receptor slots

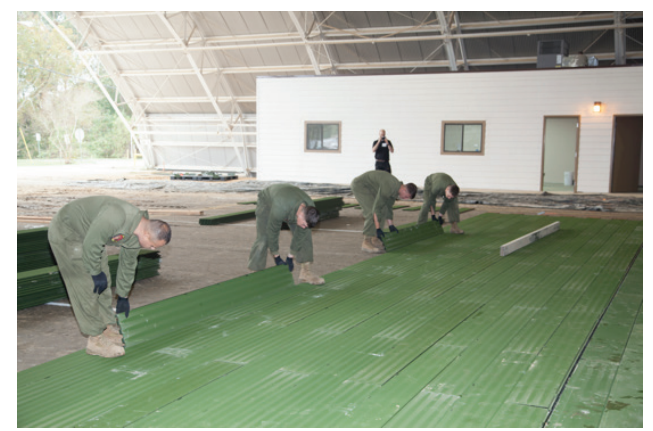

(b) connecting male/female hinge

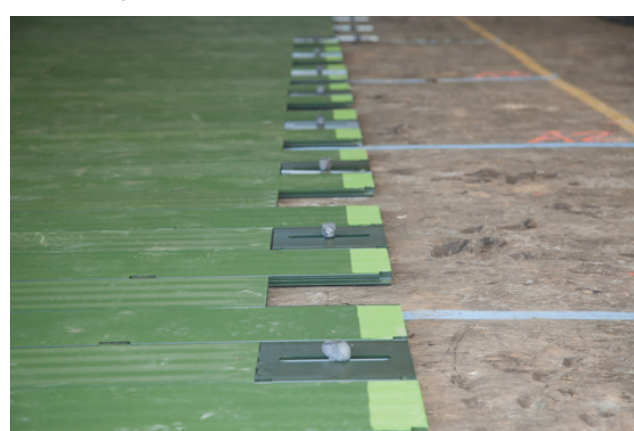

(c) anchor panels and stakes

Figure 3.13. Final assembled PSA-FT test item.

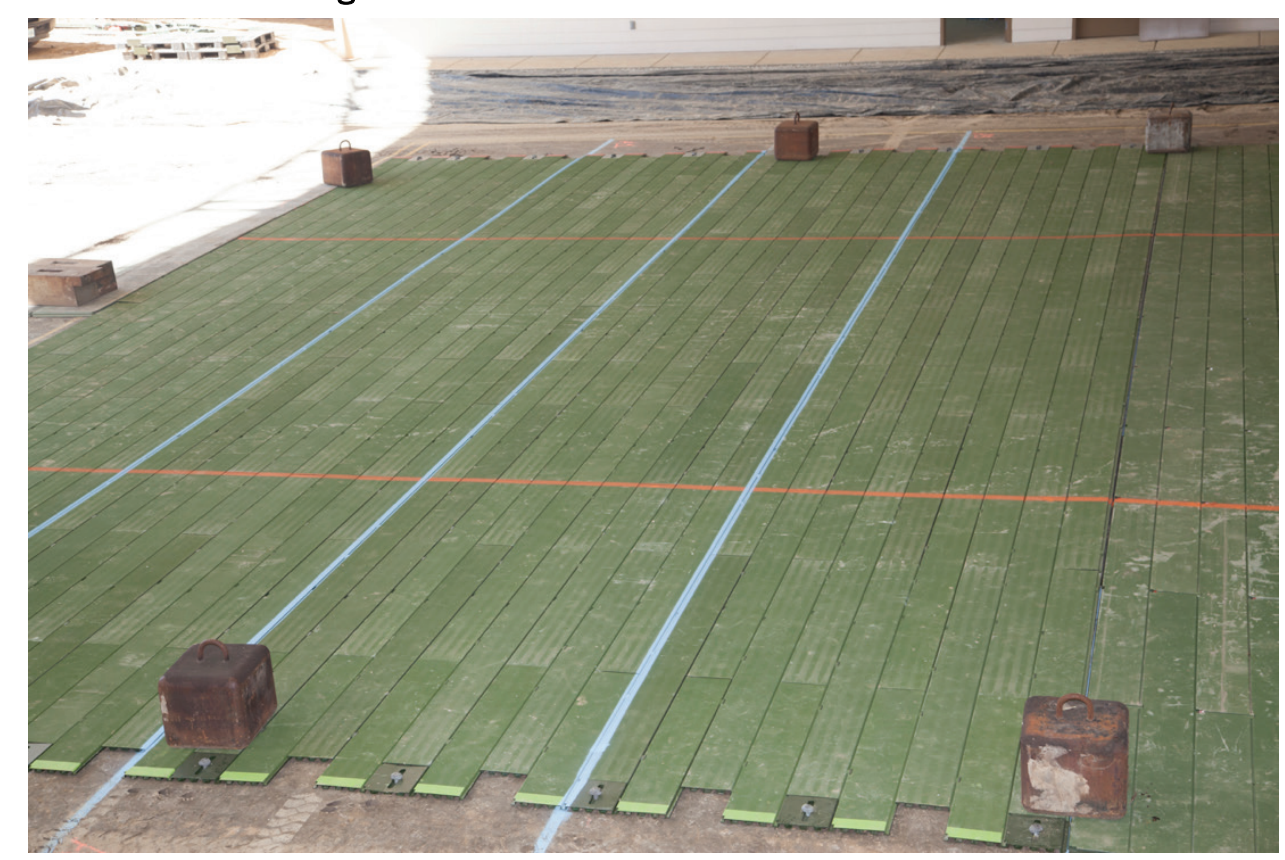




\subsubsection{DuraDeck}

The first panel was placed on the subgrade with the long edge perpendicular to the direction of traffic. A metal connector plate studded with threaded bolts was placed underneath the pre-drilled corner of the panel. The plate was positioned so that the adjacent panels opposite predrilled corner lined up, allowing the panels to be connected. Once the second panel was positioned over the threaded connector, nuts were installed on the threaded studs from the top side of the panels to fasten them securely. This process was continued until the entire panel array was complete. Panels were assembled in a brickwork configuration so that the longitudinal joints were not continuous. Each of the connector nuts was hand-started, then tightened using a cordless drill with a socket designed to fit the nuts. Eight nuts were required for each interior panel, and six were required for edge panels. Half-panels were not used for this test; thus, the test item had staggered edges. Additional details on the DuraDeck mat system and previous testing are provided by Rushing and Garcia (2013). Photographs of installation are shown in Figure 3.14. The final assembled test item is shown in Figure 3.15.

Figure 3.14. Installation of DuraDeck mat system.

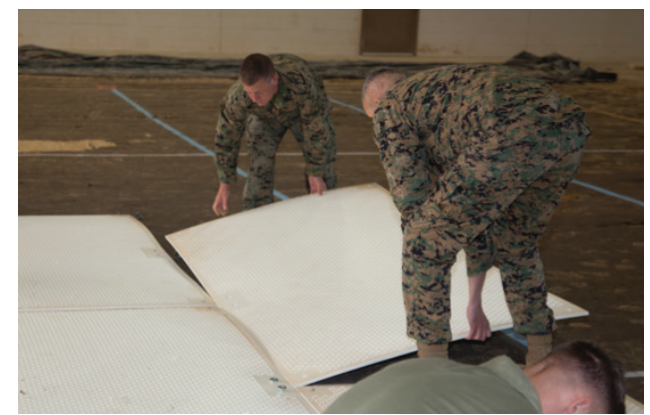

(a) Placing panel on subgrade

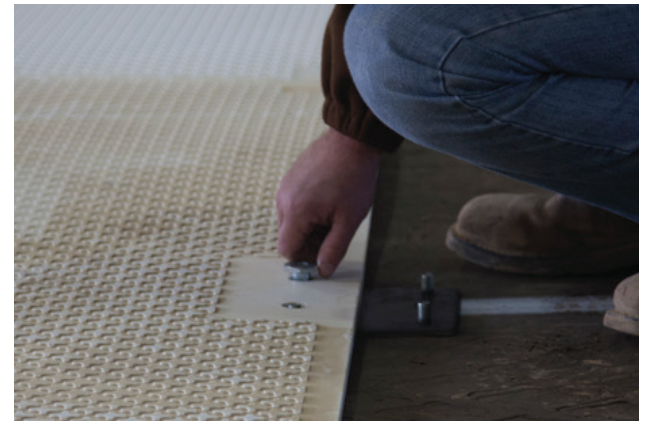

(c) Placing nuts on threaded studs

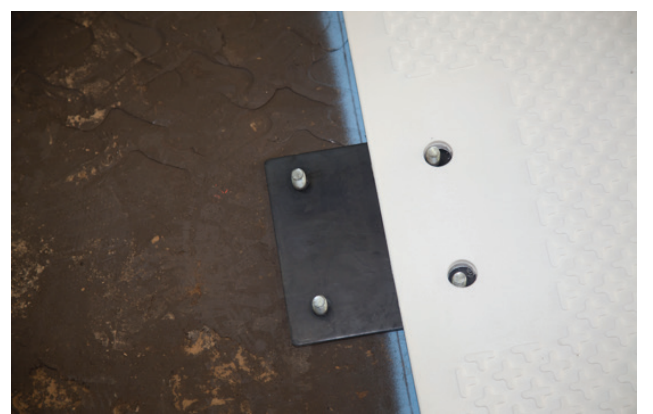

(b) Connector plate

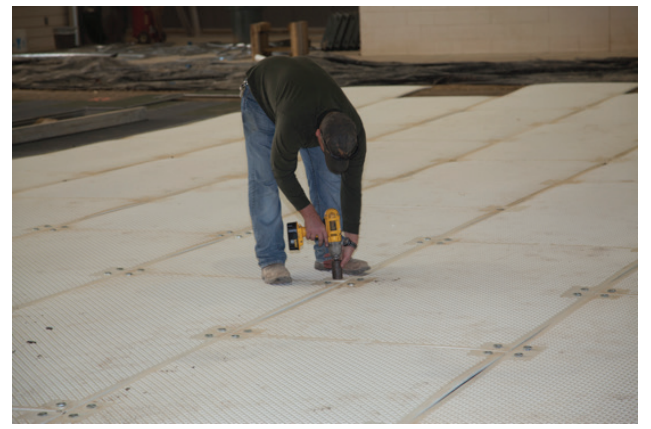

(d) Tightening nuts with drill 
Figure 3.15. Final assembled DuraDeck test item.

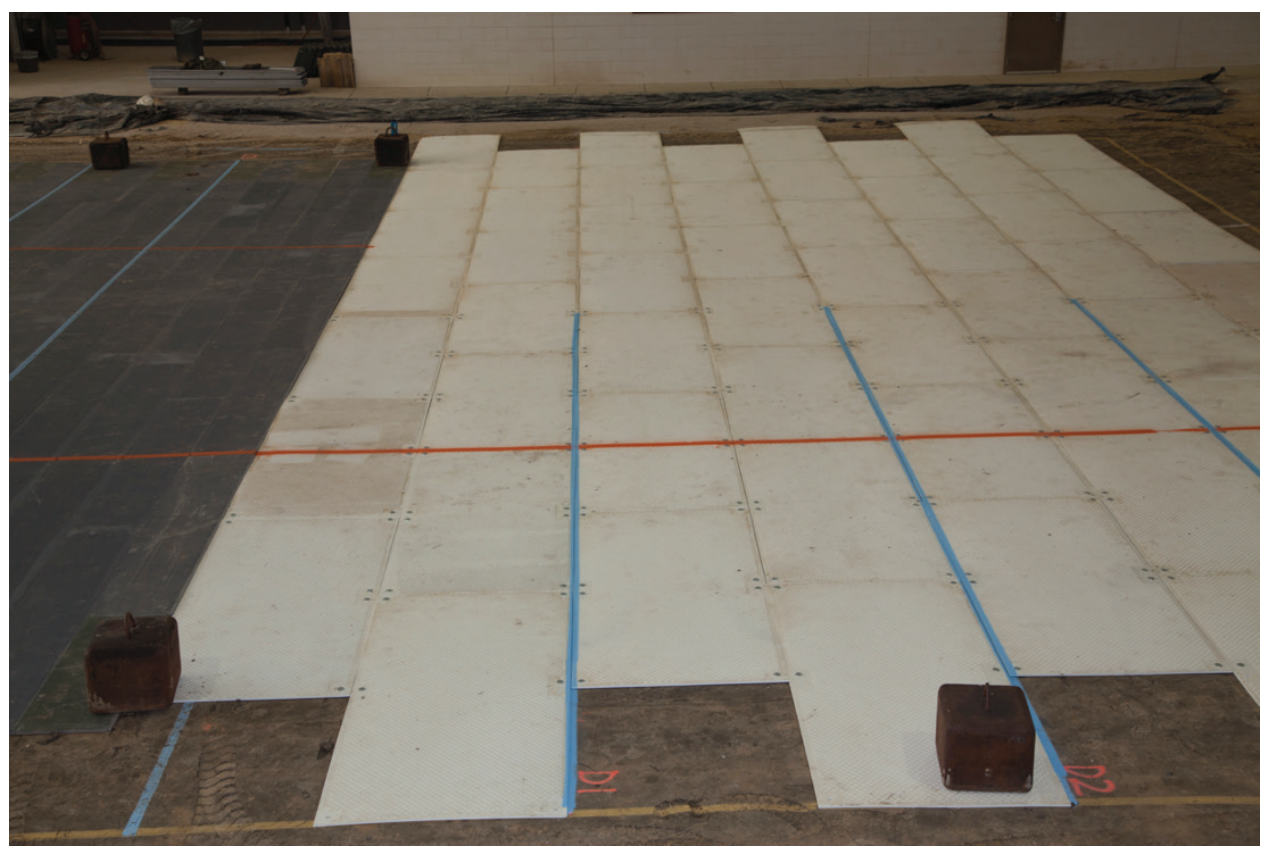

The DuraDeck mat system was simple to install, but had mixed feedback. Although panels are lightweight, the large dimensions still require a twoperson carry. Installation of the metal plate/nut connection was a timeconsuming process that did not provide a tradeoff to the mechanical connections of the other mat systems. Several studs had to be revisited to verify proper torque.

\subsection{Traffic application}

This section describes the application of traffic on the mat surface. Pertinent data concerning the test load carts are provided.

\subsubsection{MQ-9A Reaper load cart}

The MQ-9A load cart was specially designed to simulate single-wheel aircraft traffic of the main landing gear (MLG) of the aircraft. Photographs are provided in Figure 3.16. For this evaluation, the load cart was equipped with a MQ-9A Reaper tire loaded to 5,000 lb at 210 psi. The vehicle was equipped with two outrigger tires for safety and was powered by the prime mover of a Case vibratory steel-wheel roller. Table 3.7 provides size and loading characteristics for the MQ-9A Reaper. The majority of the information in Table 3.7 on the MQ-9A Reaper aircraft specifications was obtained from ETL 1110-3-510. The tire pressure in ETL 110-3-510 is reported as $170 \mathrm{psi}$, but user feedback revealed that the actual tire pressure operationally is 210 psi. Table 3.8 details load cart characteristics. 
Figure 3.16. MQ-9A Reaper load cart.

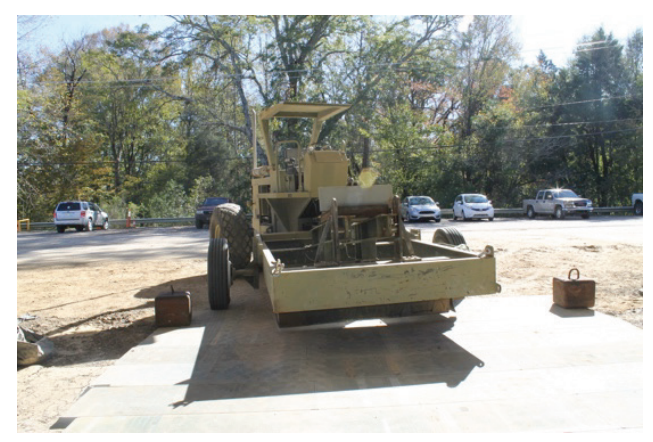

(a) Right outrigger

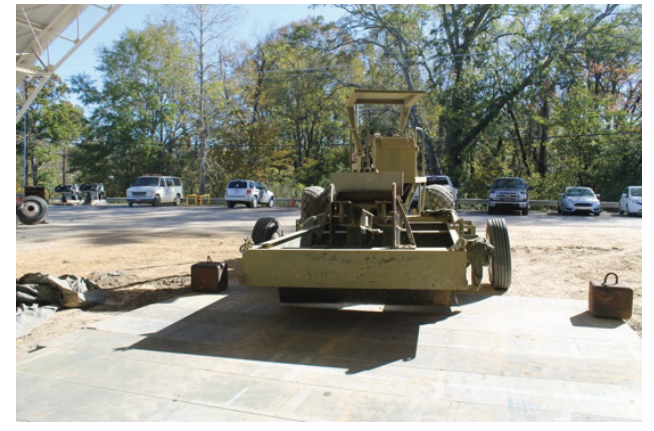

(b) Left outrigger

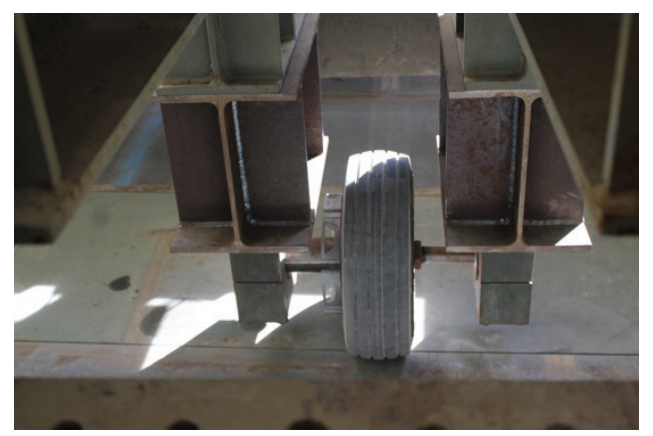

(c) Test tire

Table 3.7. MQ-9A Reaper specifications.

\begin{tabular}{|l|l|}
\hline Max Gross Weight (Ib) & 10,500 \\
\hline Assembly style & Single tricycle \\
\hline \% of gross load on MLG & 94 \\
\hline Load on one wheel of MLG (lb) & 4,935 \\
\hline MLG tire pressure at max weight (psi) & 210 psi \\
\hline Equivalent Tire Model & $\mathrm{P} / \mathrm{N} 178 \mathrm{~K} 43-1$ \\
\hline Equiv. Wheel and Tire Assembly & $\mathrm{P} / \mathrm{N} 5004913-5$ \\
\hline Size (in. $\mathrm{x}$ in.) & $17.5 \times 5.75-8$ \\
\hline Ply Rating & 14 \\
\hline
\end{tabular}

A normally distributed pattern of simulated traffic was applied in a 25-in.wide traffic lane, as shown in Figure 3.17. This pattern was designed to simulate the actual traffic distribution pattern of the main landing gear wheel on a mat surface when taxiing to and from an active runway. The width of each lane corresponded to the measured contact width, 5 in., of the Reaper tire when fully loaded. Traffic was applied by driving the load cart for-ward and then backward over the length of the test section, and then shifting the path of the test wheel laterally approximately one tire 
width on each forward pass. This procedure was continued until one full pattern of traffic was completed. One pattern resulted in 16 passes, or 4 coverages (i.e. pass to coverage ratio of 4). According to the PavementTransportation Computer Assisted Structural Engineering (PCASE) vehicle database, the pass to coverage ratio for the MQ-9A Reaper is 16.14 for Type A traffic on rigid and flexible pavements. To perform this experiment within a reasonable timeframe and on a practical test-section size, a normally distributed traffic pattern was designed with a pass to coverage ratio of 4 .

Figure 3.17. Normally distributed traffic pattern for MQ-9A Reaper.

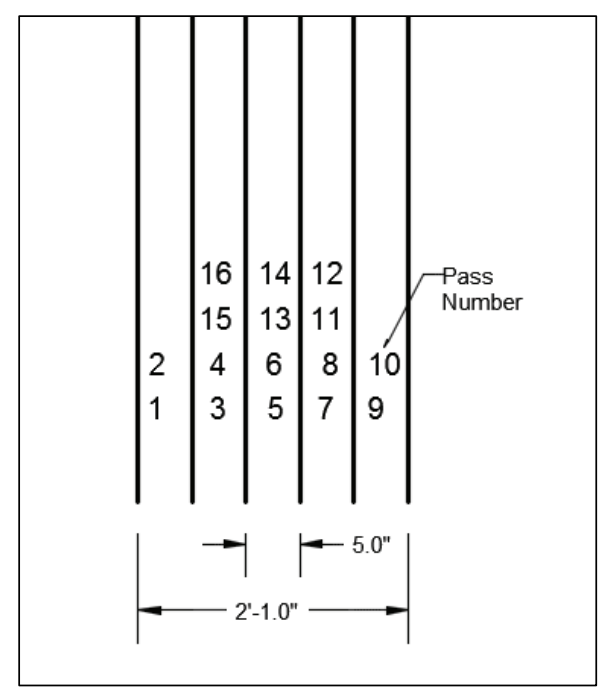

Table 3.8. MQ-9A Reaper load cart characteristics.

\begin{tabular}{|l|l|}
\hline Load on test tire $(\mathrm{lb})$ & 4,900 \\
\hline Total load on all outrigger tires $(\mathrm{lb})$ & 10,000 \\
\hline Total load on both drive tires $(\mathrm{lb})$ & 8,300 \\
\hline Tire pressure on outrigger tires $(\mathrm{psi})$ & 50 \\
\hline Tire pressure on drive tires $(\mathrm{psi})$ & 16 \\
\hline Tire pressure on test tire $(\mathrm{psi})$ & 210 \\
\hline
\end{tabular}

\subsubsection{P-19 load cart}

The P-19 load cart was designed to simulate the load from one tire on a P-19 support vehicle (Figure 3.18). The tire was loaded so that the maximum load and tire pressure on the mat were $13,900 \mathrm{lb}$ and $85 \mathrm{psi}$, respectively. The vehicle was equipped with an outrigger tire for safety. Relevant P-19 vehicle specifications can be seen in Table 3.9. Note that the KME version of the 
P-19 (1,500-gal Class 4 ARFF vehicle), also called the "Legacy," was represented in this test. Trafficking was uniformly distributed in three (3) lanes of equal width, as shown in Figure 3.19. Each lane was approximately $2 \mathrm{ft}$ wide, for a traffic width of $6 \mathrm{ft}$. Traffic was applied by driving the load cart forward and backward over the length of the test section, then shifting the path of the test wheel laterally approximately one tire width on each forward pass. This procedure was continued until one full pattern (6 passes) was completed.

Figure 3.18. P-19 load cart.
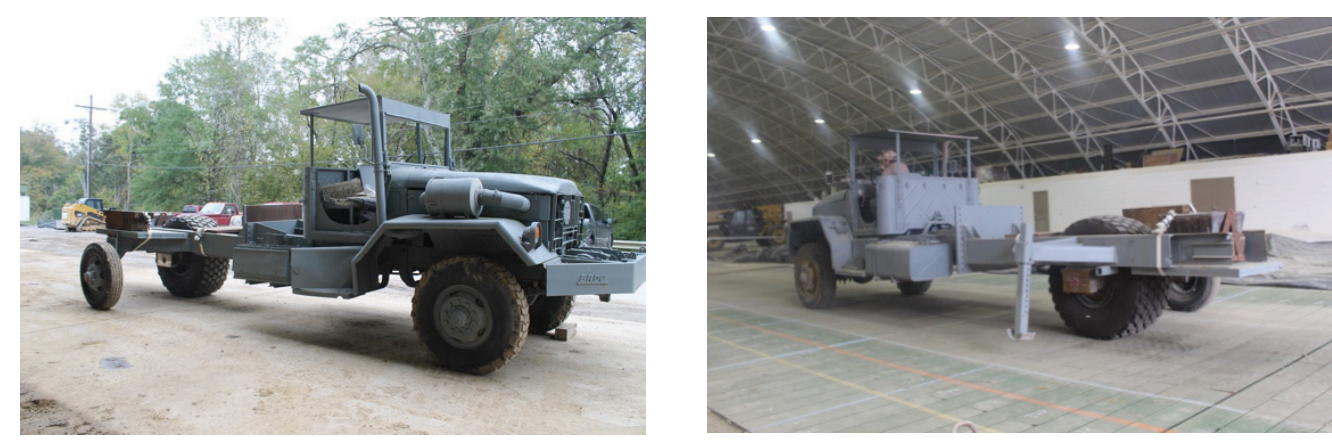

Table 3.9. P-19 ARFF vehicle specifications.

\begin{tabular}{|l|l|}
\hline KME version of the P-19, “Legacy” -- 1,500-gal Class 4 ARFF vehicle \\
\hline Max Gross Weight (lb) & 59,920 \\
\hline Assembly & 4 tires \\
\hline Gross weight on one axle (lb) & Rear: 27,720 / Front: 25,200 [Test Weight: 13,860] \\
\hline Tire pressure (psi) & 85 \\
\hline Tire dimensions (in.) & 54.6 diam.; 23.9 width \\
\hline Tire ply arrangement & 16 ply, radial \\
\hline Tire NSN / Part number & Michelin 24R21 XZL (Part \#: 76025; NSN: 2610-01-443-7040) \\
\hline Wheel dimensions (in. $x$ in.) & 21 by 18 \\
\hline Wheel NSN / Part number & Part \#: 21018028 \\
\hline Wheel Manufacturer & OTR Wheel Engineering \\
\hline
\end{tabular}


Figure 3.19. Traffic pattern for the P-19 truck.

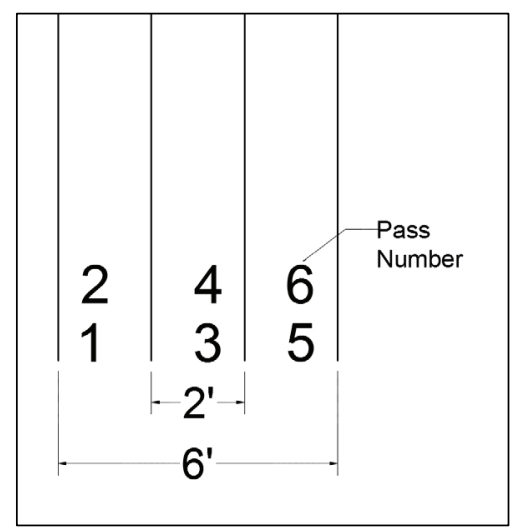

\subsection{Data collection}

Data collection locations on each test item for both traffic lanes are shown in Figure 3.20. Close-ups of these locations on each test item are provided in Appendix B. Pass levels at which data were collected are shown in Table 3.10. Photographs of these activities are shown in Figure 3.21.

Data collection included:

- Robotic total station measurements along the centerlines on both the subgrade and mat surfaces;

- Robotic total station measurements along primary cross sections, on both the loaded and unloaded mat surface and on the subgrade surface;

- Rut depth measurements at the primary and secondary cross sections, on both the loaded and unloaded mat surface and on the subgrade surface; and

- Visual inspection of mats during trafficking and after the tests.

Primary cross sections in Figure 3.20 in each test item were labeled 1 through 3 , while secondary cross sections were labeled 4 through 9. The locations of primary cross sections were selected near the quarter-points of the test items to characterize the average performance while avoiding potential end effects associated with boundary conditions at the ends of the test sections. Secondary cross sections were offset from each primary cross section to record additional rut depth measurements. 
Figure 3.20. Data collection locations.

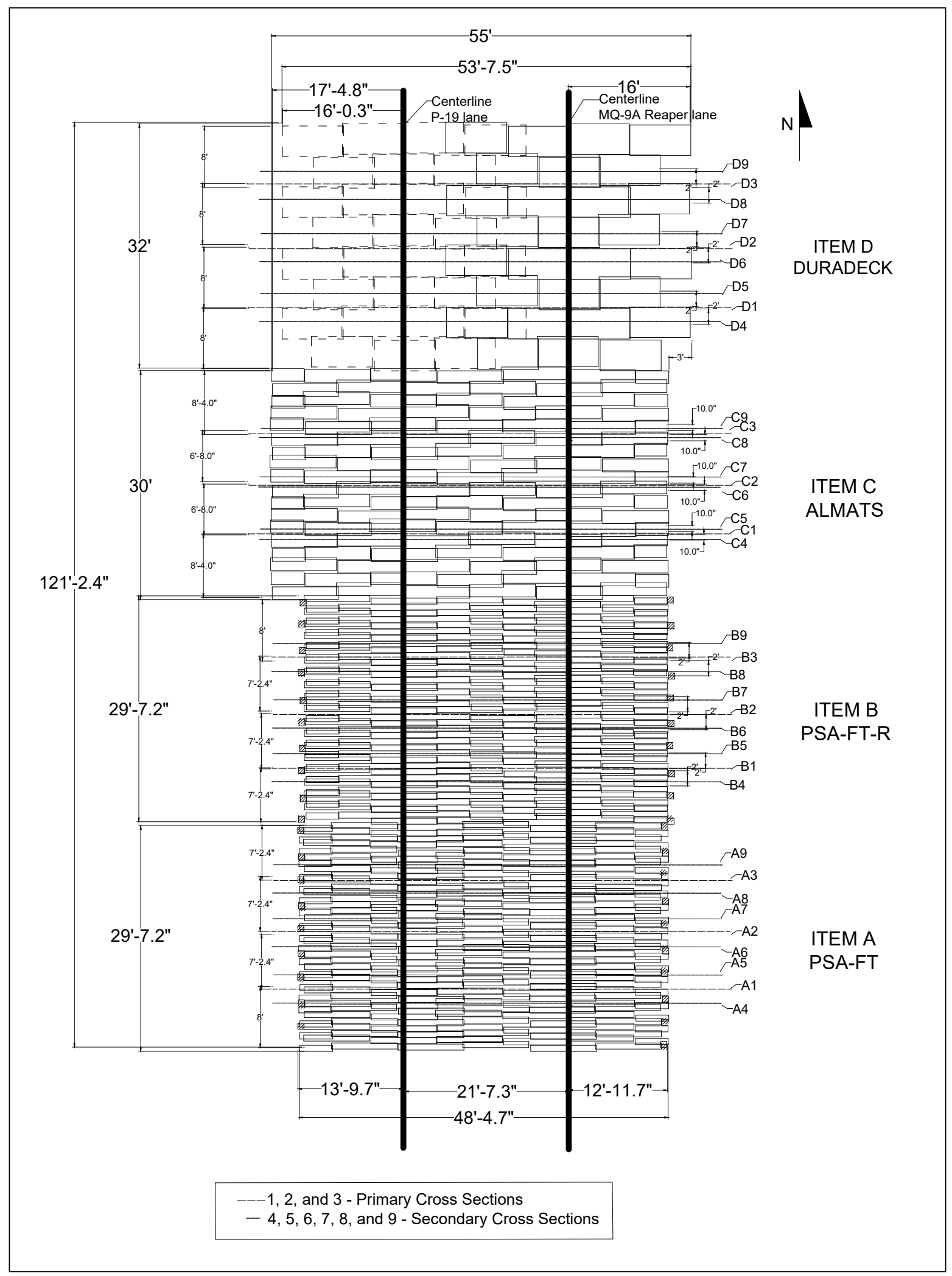


Table 3.10. Data collection pass levels.

\begin{tabular}{|c|c|c|c|c|c|}
\hline \multicolumn{2}{|l|}{ Pass Level } & \multirow[b]{2}{*}{$\begin{array}{l}\text { Centerline } \\
\text { Profile }\end{array}$} & \multirow[b]{2}{*}{$\begin{array}{l}\text { Unloaded Cross } \\
\text { sections }\end{array}$} & \multirow{2}{*}{$\begin{array}{l}\text { Loaded } \\
\text { Cross } \\
\text { sections }\end{array}$} & \multirow[b]{2}{*}{$\begin{array}{l}\text { Inspection of mat } \\
\text { surface }\end{array}$} \\
\hline $\begin{array}{l}\text { MQ-9A Reaper } \\
\text { lane }\end{array}$ & P-19 lane & & & & \\
\hline Pretest Subgrade & $\begin{array}{l}\text { Pretest } \\
\text { Subgrade }\end{array}$ & $\mathrm{x}$ & $x$ & & \\
\hline 0 & 0 & $x$ & $x$ & $x$ & $x$ \\
\hline 16 & 6 & $\mathrm{x}$ & $x$ & $x$ & $x$ \\
\hline 32 & 12 & $x$ & $x$ & $x$ & $x$ \\
\hline 48 & 18 & $x$ & $x$ & $x$ & $\mathrm{x}$ \\
\hline 64 & 30 & $x$ & $x$ & $\mathrm{x}$ & $x$ \\
\hline 96 & 54 & $\mathrm{x}$ & $\mathrm{x}$ & $x$ & $\mathrm{x}$ \\
\hline 128 & 102 & $x$ & $x$ & $x$ & $\mathrm{x}$ \\
\hline 144 & 198 & $\mathrm{x}$ & $x$ & $x$ & $\mathrm{x}$ \\
\hline 176 & 390 & $x$ & $x$ & $x$ & $\mathrm{x}$ \\
\hline 208 & 774 & $\mathrm{x}$ & $x$ & $x$ & $\mathrm{x}$ \\
\hline 240 & 1500 & $x$ & $x$ & $x$ & $\mathrm{x}$ \\
\hline 272 & 3000 & $x$ & $x$ & $x$ & $x$ \\
\hline 336 & 5400 & $x$ & $\mathrm{x}$ & $\mathrm{x}$ & $\mathrm{x}$ \\
\hline 400 & - & $x$ & $x$ & $x$ & $x$ \\
\hline 528 & - & $x$ & $x$ & $x$ & $\mathrm{x}$ \\
\hline 784 & - & $\mathrm{X}$ & $x$ & $\mathrm{x}$ & $\mathrm{x}$ \\
\hline 1296 & - & $\mathrm{x}$ & $x$ & $x$ & $\mathrm{x}$ \\
\hline 1936 & - & $x$ & $x$ & $\mathrm{x}$ & $\mathrm{x}$ \\
\hline 3280 & - & $\mathrm{x}$ & $\mathrm{x}$ & $x$ & $\mathrm{x}$ \\
\hline 3520 & - & $x$ & $x$ & $\mathrm{x}$ & $x$ \\
\hline 5008 & - & $\mathrm{x}$ & $x$ & $x$ & $\mathrm{x}$ \\
\hline 7398 & - & $x$ & $x$ & $x$ & $\mathrm{x}$ \\
\hline Posttest Subgrade & $\begin{array}{l}\text { Posttest } \\
\text { Subgrade }\end{array}$ & $\mathrm{x}$ & $x$ & & \\
\hline
\end{tabular}


Figure 3.21. Data collection activities.

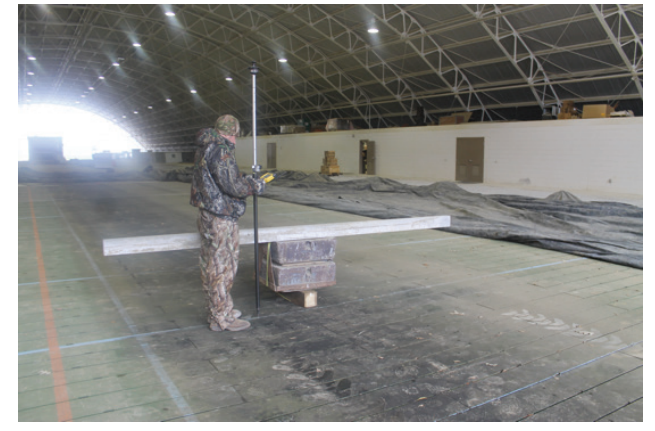

(a) Loaded cross section on P-19 lane

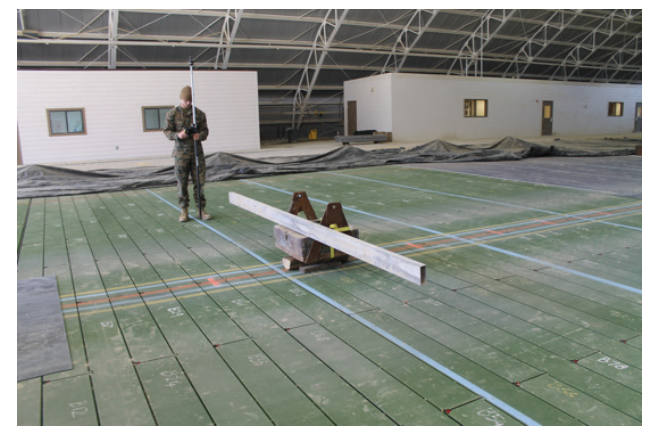

(c) Loaded cross section on MQ-9A Reaper lane

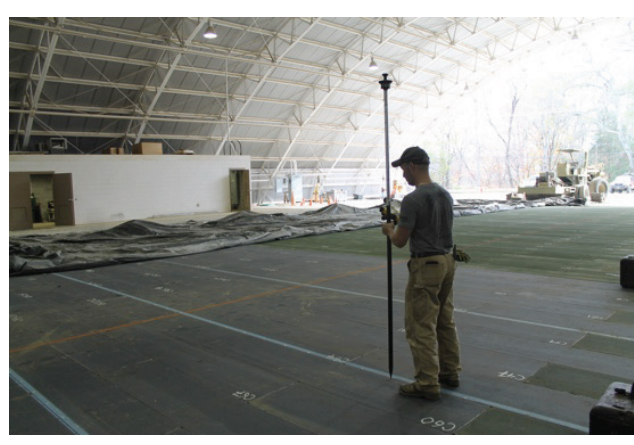

(b) Unloaded cross section

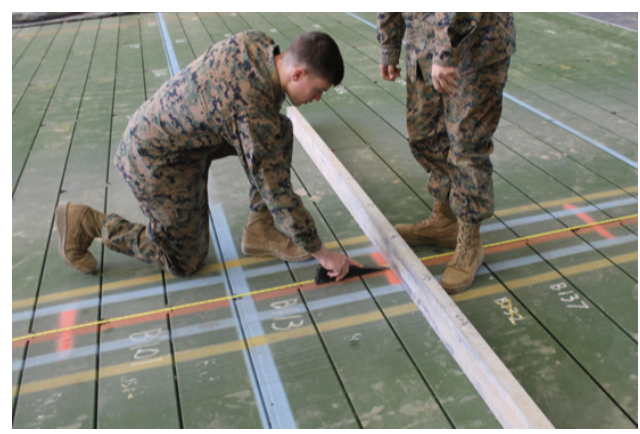

(d) Unloaded rut depth

\subsubsection{Centerline profile}

Data were collected along the traffic centerline on the pretest subgrade, on the mat surface at scheduled pass levels, and the posttest subgrade after removing the mats. Data were collected at 1 - $\mathrm{ft}$ intervals on both the subgrade and mat surface continuously through the length of the test section.

\subsubsection{Unloaded cross sections}

Data were collected on the pretest subgrade, on the mat at scheduled pass levels, and the posttest subgrade after removing the mats. Robotic total station elevation data were collected at $1-\mathrm{ft}$ intervals along primary cross sections. Rut depth data were collected along all cross sections at the centerline and $1 \mathrm{ft}$ east and west of the centerline for the MQ-9A Reaper lane. Rut depths were collected up to $2 \mathrm{ft}$ offset from the centerline in the P-19 lane. Cross sections for the P-19 truck lane and the MQ-9A Reaper lane were $24 \mathrm{ft}$ wide and $20 \mathrm{ft}$ wide, respectively. 


\subsubsection{Loaded cross sections}

In an attempt to measure the permanent deformation of the subgrade underneath the mat surface, lead weights were placed on the mat surface adjacent to cross sections, and data were once again collected. The goal of the load application was to deflect the mat enough to contact the subgrade but not so much as to induce elastic deflections in the subgrade. These data are labeled "loaded cross sections" in this report. For the MQ-9A Reaper, one 2,00o-lb lead block was used. For the P-19 lane, a 4,00o-lb load was applied using two (2) lead blocks. Robotic total station elevation data were collected at $1-\mathrm{ft}$ intervals on the primary cross sections. Rut depth measurements were collected on all primary cross sections and on secondary cross sections 6 and 7. This was done to reduce the amount of time it took to collect loaded cross-section data.

\subsection{Failure criteria}

The failure criteria established were (1) $10 \%$ mat breakage within the test area or (2) the development of 0.75 in. of permanent surface deformation for the MQ-9A or P-19. Each of the mat systems was required to sustain at least 1,500 passes of each vehicle before one of the failure criteria was met. These failure criteria were developed based upon previous testing of airfield matting and USAF requirements. Failure criteria values were recorded and monitored for compliance.

\subsubsection{Mat breakage criteria}

Mat breakage percentages were calculated by dividing the area of the failed panel by the total area influenced by the simulated traffic application in the assembled test item. Individual panels were considered failed if observed damage posed a significant tire hazard or caused instability of the load cart. Tire hazards were defined as damage that could not be reasonably maintained by simple field maintenance procedures.

\subsubsection{Permanent deformation criteria}

The permanent surface deformation limit is based on roughness limitations for the MQ-9A Reaper. It was assumed that the P-19 fire truck would operate on the mat surface if required during an emergency situation; thus, the same deformation limit was placed for $\mathrm{P}-19$. The rut depth limit is required since many connecting taxiways and aprons intersect at $90 \mathrm{deg}$, and crossing perpendicular to a pre-formed rut may cause an abrupt change 
in elevation, exceeding aircraft limits. Permanent surface deformation was determined from robotic total station elevation measurements of cross sections and centerline profiles. Each of the following data collection categories were analyzed for compliance with the failure criteria:

1. centerline profile deformation,

2. unloaded surface deformation, and

3. loaded surface deformation

\subsubsection{Centerline profile deformation}

The difference in elevation between one or two stations apart ( 1 or $2 \mathrm{ft}$ apart) was analyzed from plots of the centerline profile data to determine if an abrupt change in elevation reached failure limits during trafficking.

\subsubsection{Unloaded surface deformation}

Unloaded surface deformation was determined from data collected according to the methods described in section 3.5.2. The maximum deformation at each location was determined as the difference in elevation from the average height of the elevated material on each side of the trough to the deepest point in the bottom of the trough. Measurements were averaged to obtain a single value for comparison to the failure criterion.

\subsubsection{Loaded surface deformation}

Loaded surface deformation was determined from data collected according to the methods described in section 3.5.3. The maximum deformation at each location was determined as the difference in elevation from the average height of the elevated material on each side of the trough to the deepest point in the bottom of the trough. Measurements were averaged to obtain a single value for comparison to the failure criterion. 


\section{Mat breakage}

The following sections describe the behavior of the matting systems under simulated aircraft traffic. Most of the discussion in this chapter will focus on damage observed during trafficking and after removing panels from the subgrade surface. Details on deformation values are shown in Chapter 5 .

\subsection{MQ-9A Reaper lane results}

Trafficking of the MQ-9A Reaper lane was initiated in November 2015. Trafficking was carried out continuously through the length of the test section. The behavior of each of the mat systems is described separately below.

\subsubsection{PSA-FT}

The first damage was noted at 528 passes on the PSA-FT mat system. Several longitudinal joints at the centerline appeared to be faulting and pumping material from the subgrade. The material from the subgrade was pumping through the unsupported longitudinal joint, and the west side of the affected joint was more elevated than the east side. Throughout the remainder of the test, the test tire was increasingly unstable and bounced when it traveled along the centerline. After 1,000 passes, deformation of the surface of 7 panels with joints along the centerline was noted. Center panels, however, appeared to bow upward, or "crown," at the centerline. After 1,936 passes, cracking developed on the surface of 9 panels with their joints at the centerline. Most cracks were 1-2 in. long, propagated perpendicular to the direction of traffic, and were located approximately $1 \mathrm{in.} \mathrm{from} \mathrm{the} \mathrm{north} \mathrm{or} \mathrm{south} \mathrm{edge} \mathrm{of} \mathrm{the} \mathrm{panel} \mathrm{(Figure} \mathrm{4.1).} \mathrm{Cracking}$ continued to propagate and developed in a total of 24 panels after 3,280 passes. However, they were still under $4.5 \mathrm{in}$. in length and did not pose a hazard to the load cart tire.

After 5,020 passes, two panels at the north end of the test item were severely damaged and had to be replaced. Failure of these panels was associated with the interface of the test item and the steel plate located underneath. Two repair panels were used to replace these and continue trafficking. Cracking was noted on the surface of all panels with joints along the traffic lane. However, they did not appear to pose a hazard to the tire and were still under $7 \mathrm{in.} \mathrm{long.}$ 
Figure 4.1. Cracking on surface of PSA-FT after 1,936 passes.

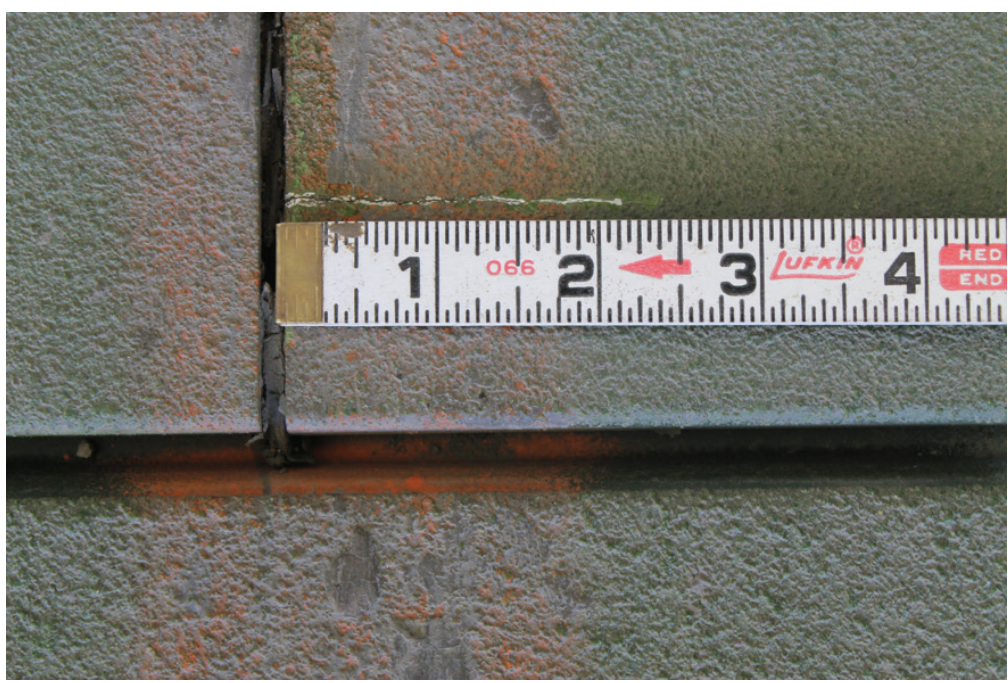

After 7,398 passes, crack lengths varied between 2 in. and 18 in., and the larger ones were posing a hazard to the tire. The test item failed by mat breakage at this point. Trafficking was concluded on the entire test section since minimum test requirements were already accomplished. Photographs of damage after 7,398 passes are shown in Figure 4.2. Panels were inspected after removing them from the subgrade surface. The female and male hinges appeared to be in good condition. Some minor cracking was noted on the surface of the aluminum blocks of the female hinge. Most center panels were bowed.

\subsubsection{PSA-FT-R}

The PSA-FT-R test item sustained 7,398 passes of simulated MQ-9A Reaper traffic with limited damage. After 784 passes, deformation of the surface of most panels with joints along the centerline was noted. Center panels, however, appeared to crown at the centerline. After 1,152 passes, cracking was noted on the surface of one panel near the end connector (Figure 4.3). Similar damage was noted on another panel after 1,630 passes. The end connectors of both panels appeared to have bent upward. However, not much change was observed for the remainder of the test. Neither panel posed a risk to the tire. 
Figure 4.2. Damage on PSA-FT after 7,398 passes.

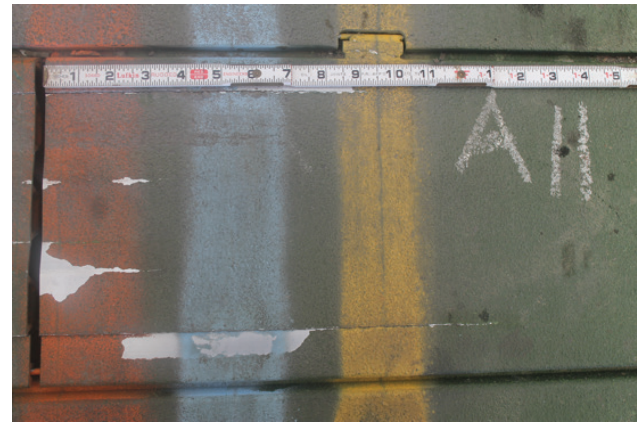

(a) cracking observed from surface

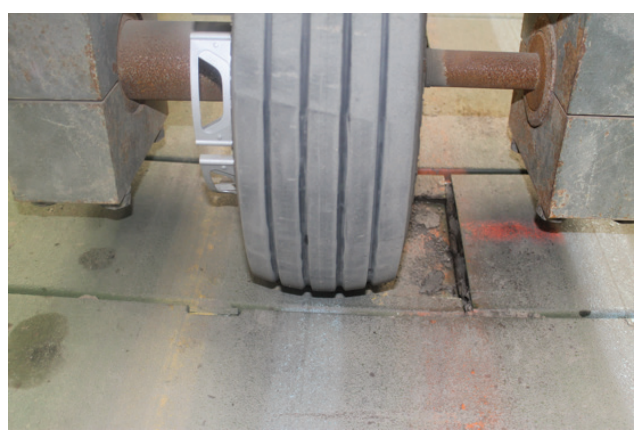

(c) Tire hazard

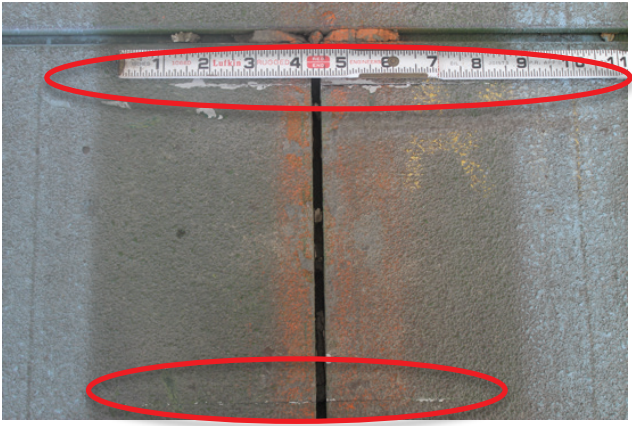

(a) cracking on 2 panels at joint

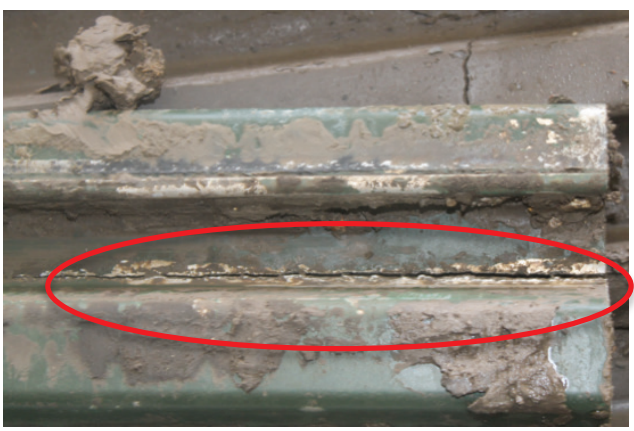

(d) Cracking on bottom surface

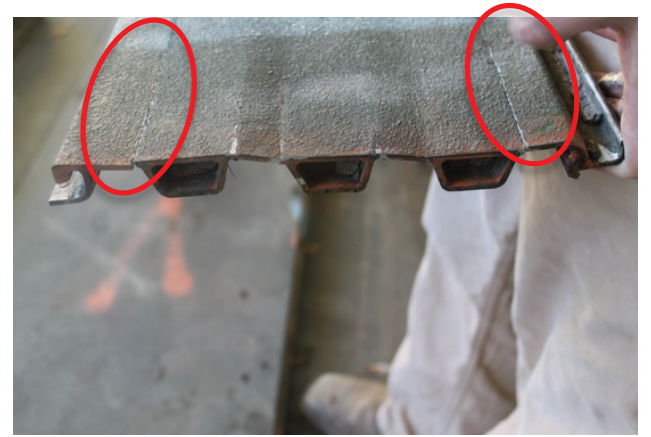

(e) Cross-section view of damaged panel

Figure 4.3. Crack on a PSA-FT-R panel.

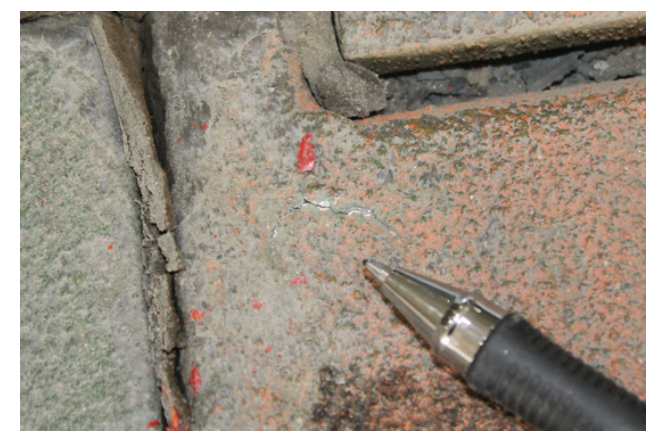

(a) 1,152 passes

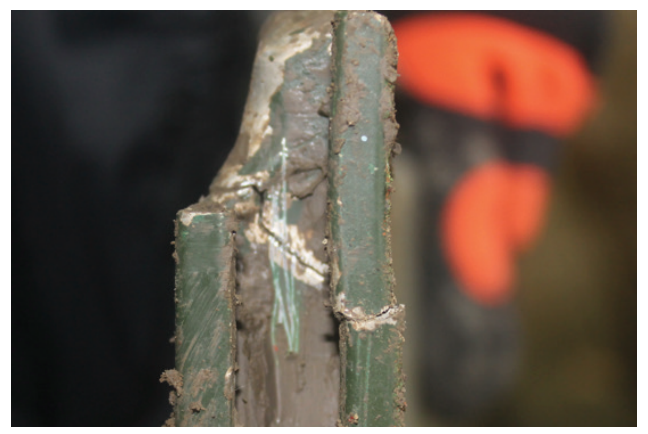

(b) 7,398 passes 
Some cracking was noted on a few panels after they were removed from the test-section subgrade. Most of cracks were observed at the corner of the end connector, where the weld bead was located. Photographs of these are shown in Figure 4.4. One panel had a 19-in.-long tear along the male connector (Figure 4.5). Panels were somewhat difficult to remove from the subgrade for inspection because subgrade material was lodged into the locking bar slot, making it hard to slide out the locking bar to separate panels. However, the general condition of the PSA-FT-R test item was good and it was concluded that the test item did not fail by mat breakage after 7,398 passes.

Figure 4.4. Crack along male hinge of PSA-FT-R panel.

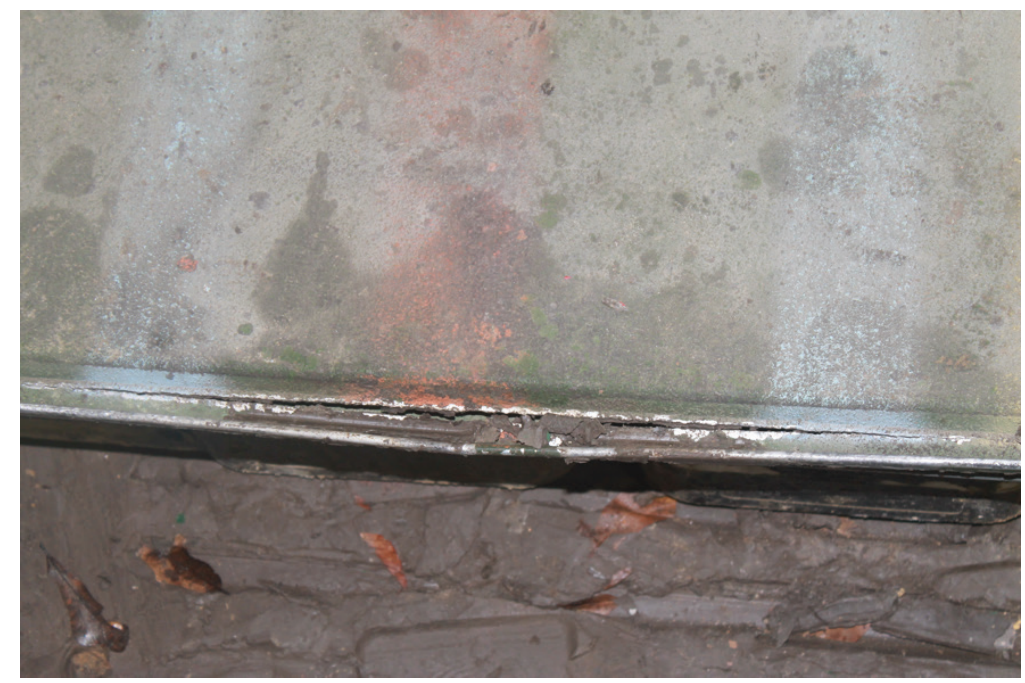

Figure 4.5. Cracking at weld beads of PSA-FT-R panels.
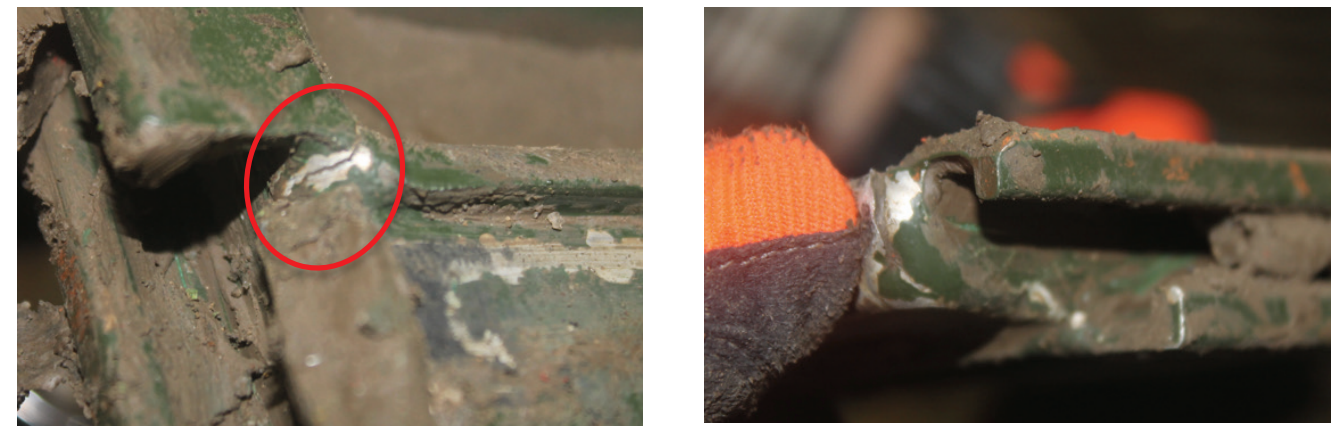

\subsubsection{ALMATS}

The ALMATS test item was able to sustain 7,398 passes of simulated MQ9A Reaper traffic without damage. Little movement of the panels was observed during traffic. Panels were very difficult to remove from the 
subgrade for inspections. Subgrade material had lodged into the locking bar slot and locking bars were difficult to remove. The male/female hinge connectors were also difficult to disconnect.

\subsubsection{DuraDeck}

A total of 128 passes of simulated MQ-9A Reaper traffic were applied on the DuraDeck mat system before trafficking was concluded on the test item. The deformation of the subgrade increased very rapidly to a point where the load cart became unstable as it traveled on the DuraDeck mats. Bolts from the test tire frame were scratching the DuraDeck mat surface. To avoid damage to the test vehicle, the test was concluded. Although there was significant movement of the matting during trafficking and large deformation in the subgrade, no damage to the matting or connection system was noted. A photograph of deformation on the subgrade after the test is shown in Figure 4.6.

Figure 4.6. Posttest subgrade of DuraDeck mat system.

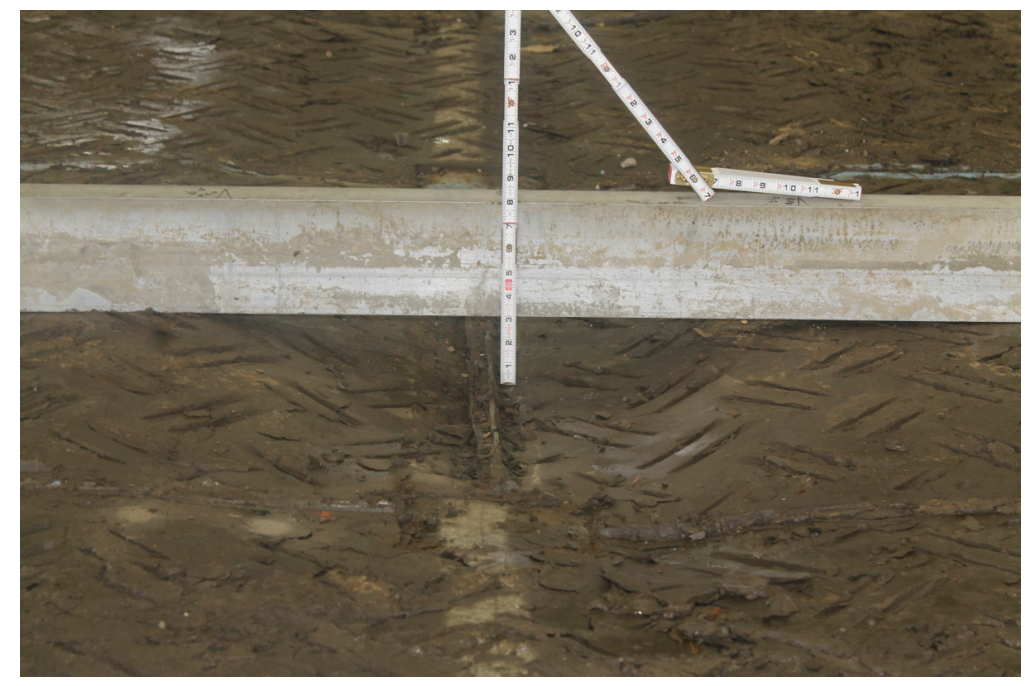

\subsection{P-19 lane results}

Trafficking of the P-19 lane was initiated in December 2015. Trafficking was carried out continuously through the length of the test section. Prior to the start of trafficking, the DuraDeck mats in the MQ-9A Reaper lane were shifted to allow the joints to align with the centerline of the P-19 lane, representing the worst case loading scenario.

The PSA-FT, PSA-FT-R, and ALMATS test items all sustained 5,400 passes of simulated P-19 traffic without any damage being observed on the 
mat surface. Since minimum test requirements had been met, trafficking was stopped before failure was reached by mat breakage because of project timeline constraints. Trafficking of the DuraDeck was concluded after 1,500 passes because the large permanent deformation on the subgrade was causing instability to the load cart. However, no damage to the mats was observed. Applied stresses from protruding threaded studs caused a slight elongation of connector holes in the mat, but the panels could be reused without concern or modification.

Posttest inspection of the PSA-FT and PSA-FT-R panels showed slightly bowed panels where trafficking occurred at the center area of panels. Minor, hairline cracks were observed at the weld beads of some panels in the PSAFT-R panels. However, the general condition of the test items was good.

\subsection{Mat breakage analysis}

\subsubsection{MQ-9A Reaper lane}

A total of 7,398 passes of simulated MQ-9A Reaper traffic were applied to the PSA-FT, PSA-FT-R and ALMATS test items. Traffic was stopped at 128 passes on the DuraDeck test item. With the exception of DuraDeck, the mat systems worked well in supporting at least 1,500 passes of simulated MQ-9A Reaper traffic prior to any damage or breakage of the mat components. The only test item to fail by mat breakage was PSA-FT after 7,398 passes, but breakage was noted well after minimum test requirements were met.

Cracking in the PSA-FT was likely caused by fatigue under repetitive loading at the intersection of the unsupported joint. The working joint caused a crack to initiate near the panel interface and propagate under continued traffic operations. The unsupported joint did not protect the subgrade and caused material to pump onto the mat surface, eventually causing the joint to lose support from the subgrade and deforming the panels severely near the centerline. This also produced increasing instability of the tire when traveling along the centerline. The end connector of the PSA-FT-R improved the longitudinal joint performance, and worked well at resisting the bending forces of the tire. The ALMATS system performed the best in terms of mat breakage. Unlike the PSA systems, ALMATS has a bottom skin that provides resistance to vertical deflection induced by bending stress by increasing the section modulus. The tight tolerance at the end connector, while making installation 
difficult, also limited bending at the underlap/overlap connection considerably and allowed better load transfer across the joint, reducing stress concentrations in critical areas. Although this connection is much weaker than that of the AM2 mat system (because of a reduction in thickness of 0.5 in.), it is suitable for the relatively small load of the MQ9A Reaper. Although the DuraDeck mat system did not experience any mat breakage, the non-rigid joint and lower section modulus of the mat are not suitable for protecting the subgrade from the load and pressure of the MQ-9A Reaper tire.

\subsubsection{P-19 lane}

A total of 5,400 passes of simulated P-19 truck traffic were applied to the PSA-FT, PSA-FT-R, and ALMATS test items. Traffic was stopped at 1,500 passes on the DuraDeck test item. All mat systems worked well in supporting at least 1,500 passes. Although the $\mathrm{P}-19$ load is higher than that of the MQ-9A Reaper, the load distribution on the wider tire makes it less damaging to mat surface components but more damaging to the subgrade because of the larger load that is distributed with a deeper zone of influence. The DuraDeck mat system, however, is not ideal for this load support condition because it allowed severe deformation of the subgrade well before 1,500 passes were applied. 


\section{Permanent deformation}

This chapter describes the permanent deformation results from data collected according to the activities described in section 3.5. The data for the MQ-9A Reaper lane are presented first, followed by the data for the P-19 lane.

\subsection{Permanent deformation results}

To limit the quantity of data presented in this section, graphs plotting the centerline profile on the mat, cross sections on the unloaded surface of the mats, and rut depth on the unloaded surface of the mats are shown in Appendix E and Appendix F for the MQ-9A Reaper and P-19 lanes, respectively. The data presented in this chapter are the plots of cross sections on the subgrade, cross sections on the loaded mat surface, rut depths on the subgrade, and rut depths on the loaded mat surface.

To show only the changes that occurred because of trafficking, the pretraffic data collected with the robotic total station along the centerlines and cross sections were subtracted from all subsequent data collected after trafficking began to normalize the data. The discussions that follow are based on normalized data. For the MQ-9A Reaper lane, Figure 5.1 through Figure 5.3 show the average deformation on the subgrade surface after the mats were removed. Figure 5.4 through Figure 5.7 show plots of the average cross sections on the loaded mat surface at different pass levels. For the P-19 lane, Figure 5.8 through Figure 5.10 show the average deformation on the subgrade surface. Figure 5.11 through Figure 5.14 show plots of average cross sections on the loaded mat surface at varying pass levels. To increase the level of clarity in these plots, some intermediate pass levels have been removed from the plots to promote readability, but the information presented is sufficient to evaluate the effect of traffic on the deformation of the test items.

Rut depth data collected on the subgrade and the mat surfaces were normalized against pretest data. Rut depth was plotted as a function of pass levels on a logarithmic scale to increase the resolution at the lower pass numbers. Figure 5.15 shows the average maximum rut depth on the subgrade for each of the test items for both test lanes. Figure 5.16 and Figure 5.17 show the average maximum rut depth measured on the loaded mat surface of each of the test items for both test lanes. 
Figure 5.1. Average deformation on the subgrade of PSA-FT - MQ-9A Reaper lane.

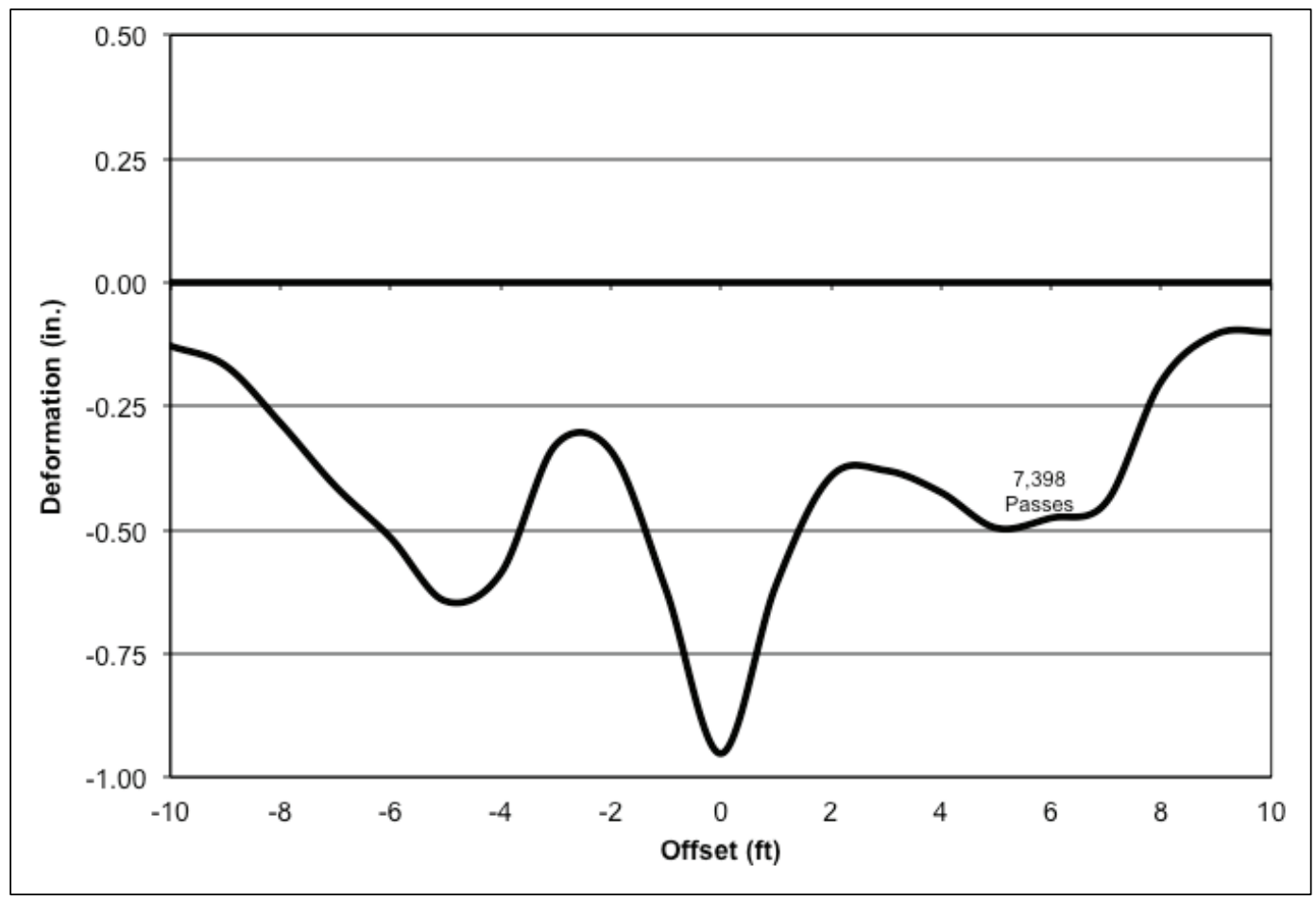

Figure 5.2. Average deformation on the subgrade of ALMATS - MQ-9A Reaper lane.

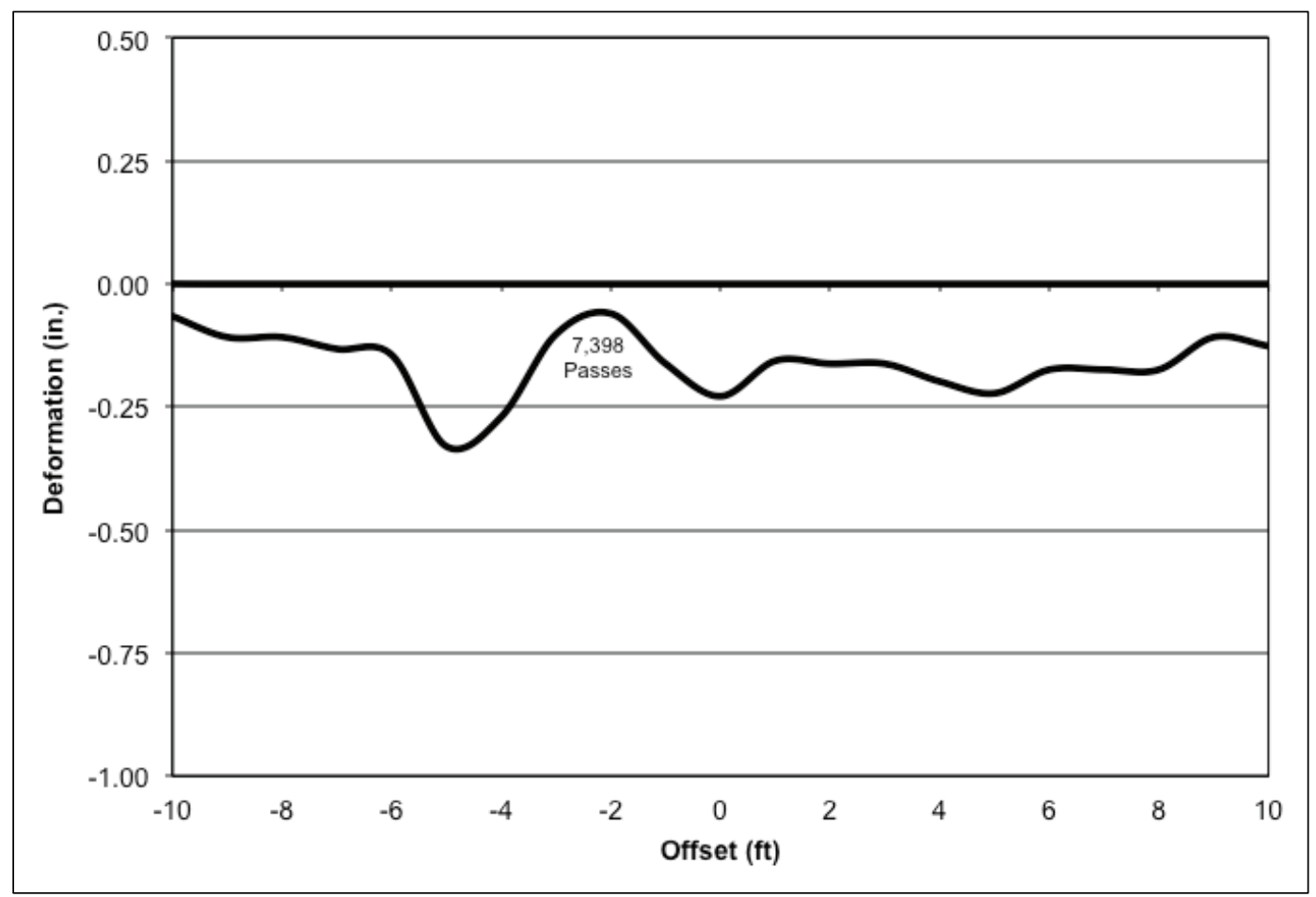


Figure 5.3. Average deformation on the subgrade of DuraDeck - MQ-9A Reaper lane.



Figure 5.4. Average deformation on the loaded mat surface of PSA-FT- MQ-9A Reaper lane.

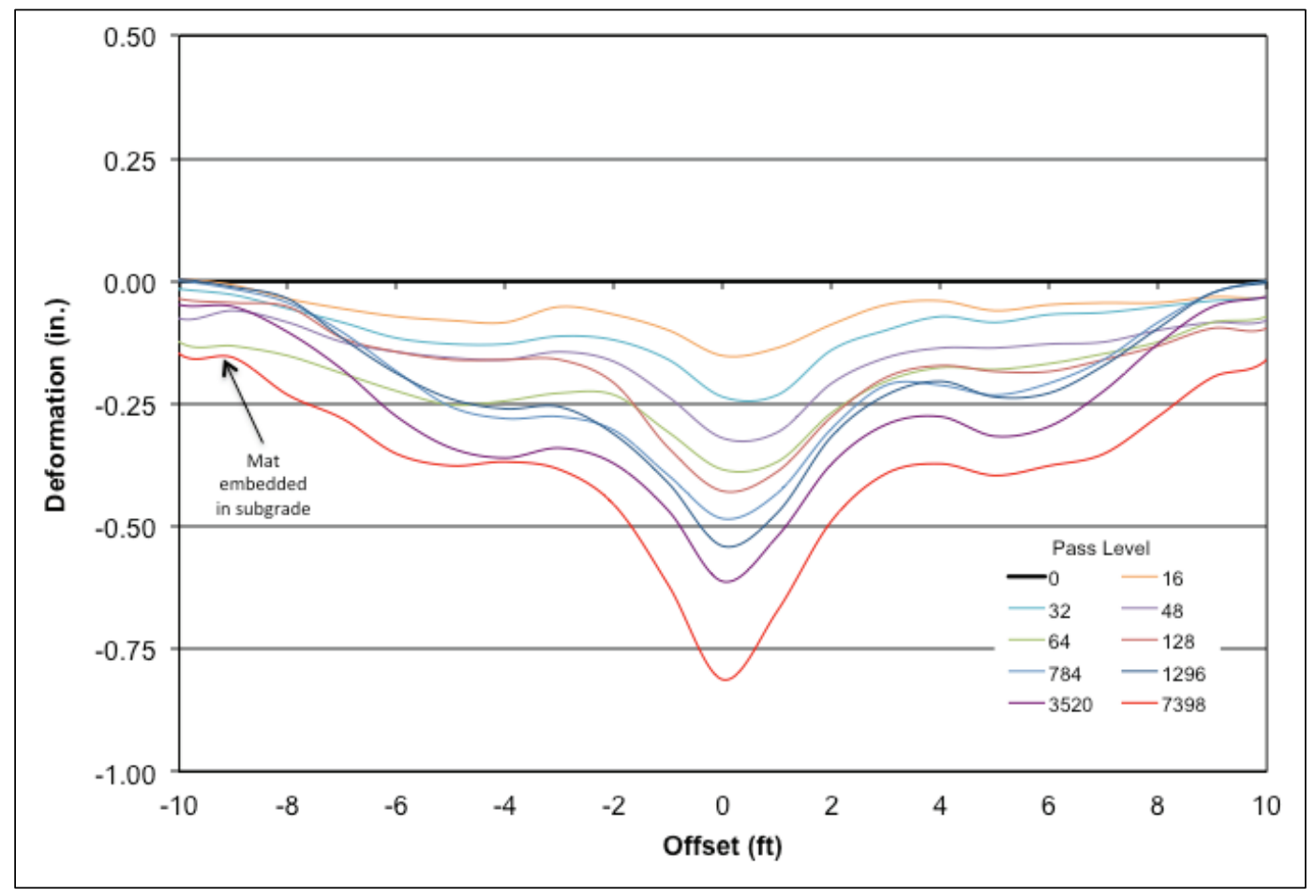


Figure 5.5. Average deformation on the loaded mat surface of PSA-FT-R - MQ-9A Reaper lane.

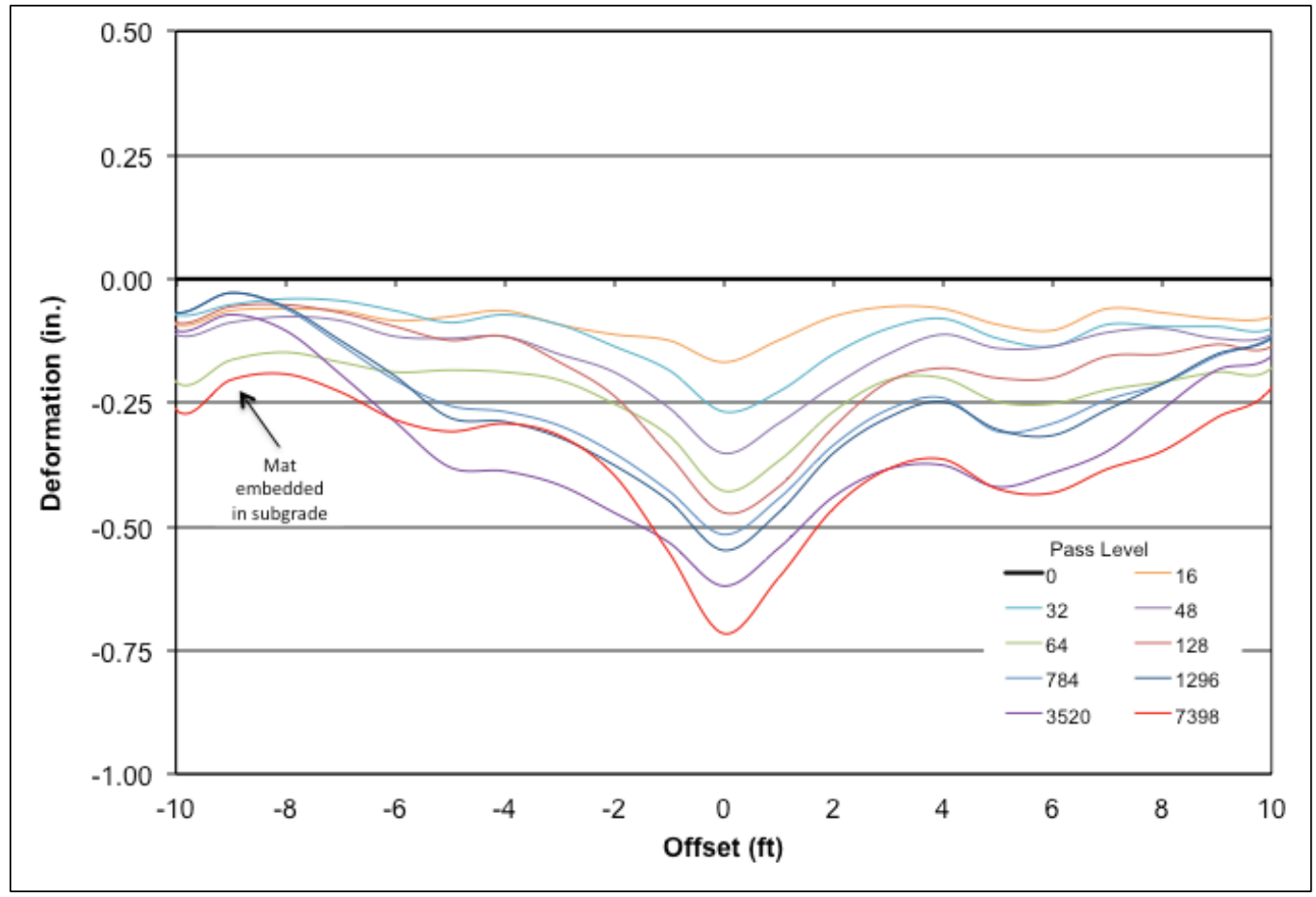

Figure 5.6. Average deformation on the loaded mat surface of ALMATS - MQ-9A Reaper lane.

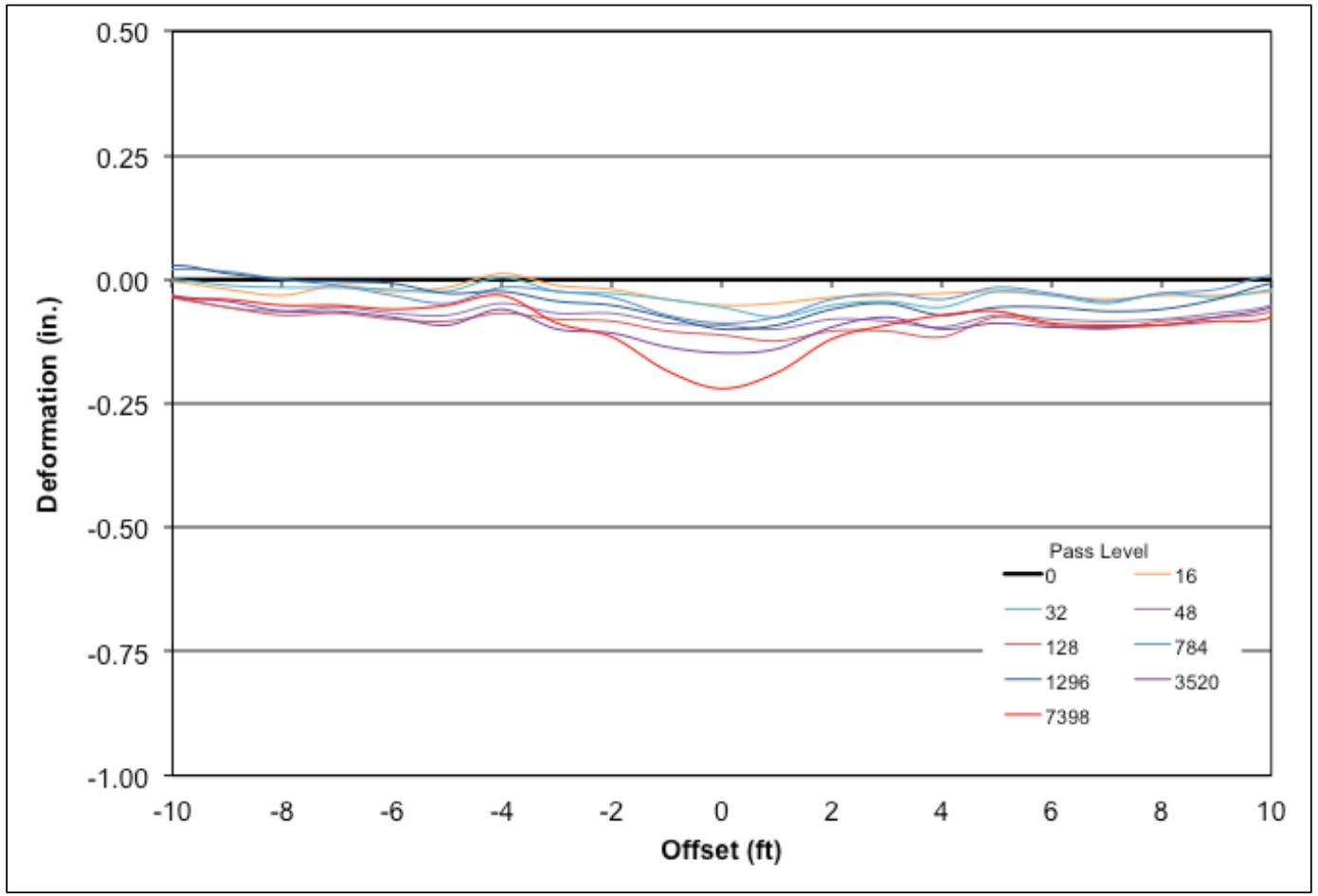


Figure 5.7. Average deformation on the loaded mat surface of DuraDeck - MQ-9A Reaper lane.

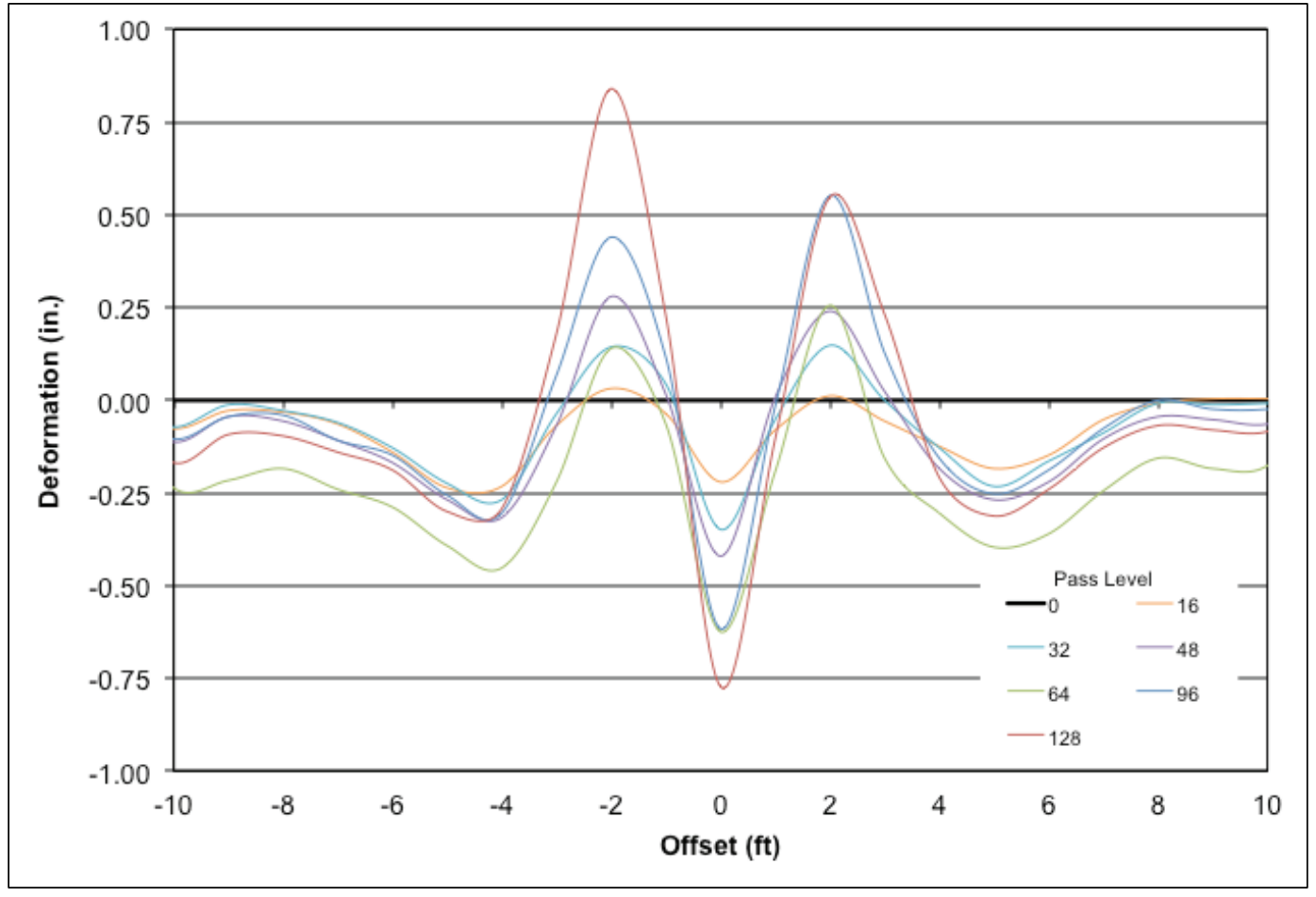

Figure 5.8. Average deformation on the subgrade of PSA-FT - P-19 lane.

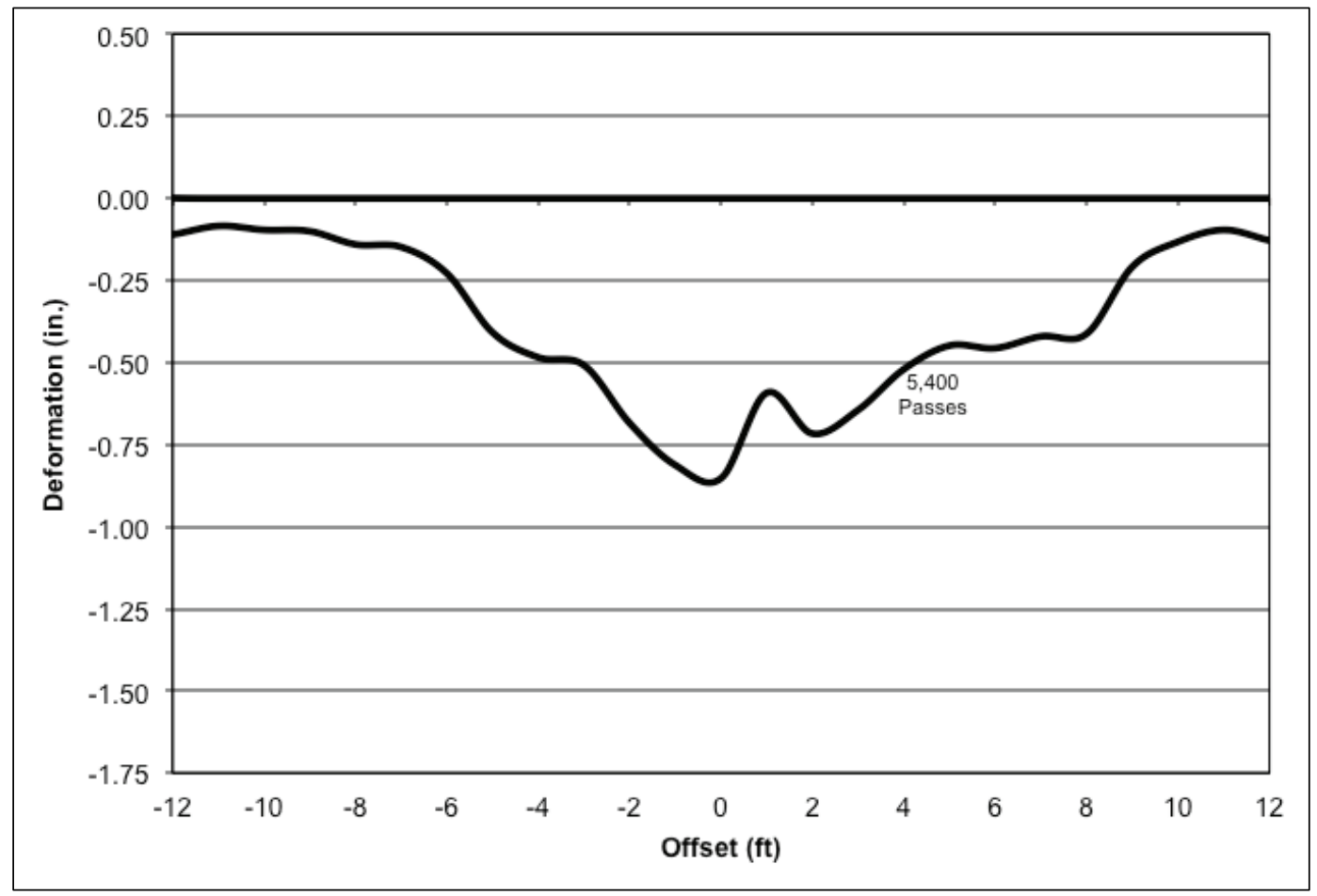


Figure 5.9. Average deformation on the subgrade of ALMATS - P-19 lane.

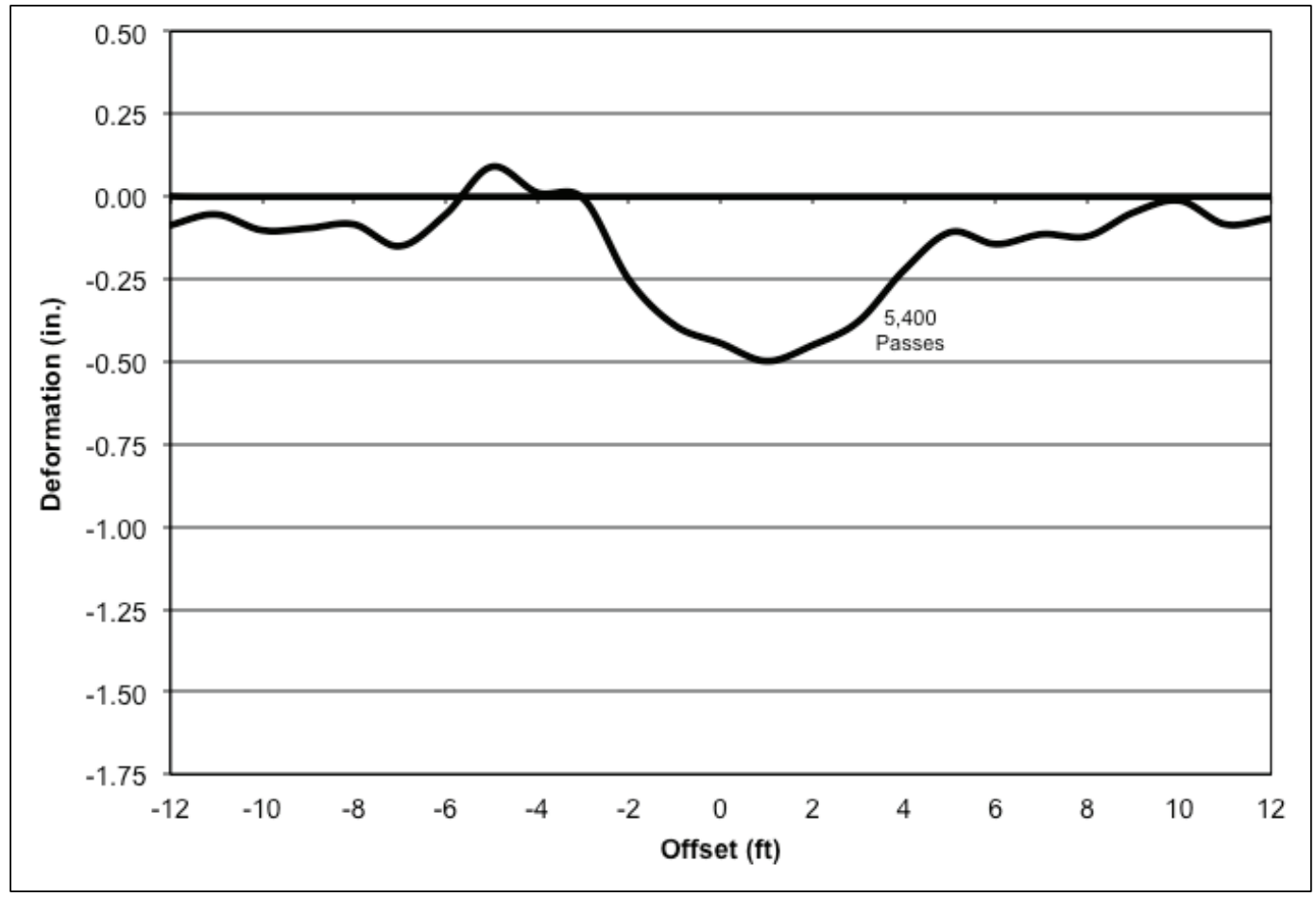

Figure 5.10. Average deformation on the subgrade of DuraDeck - P-19 lane.

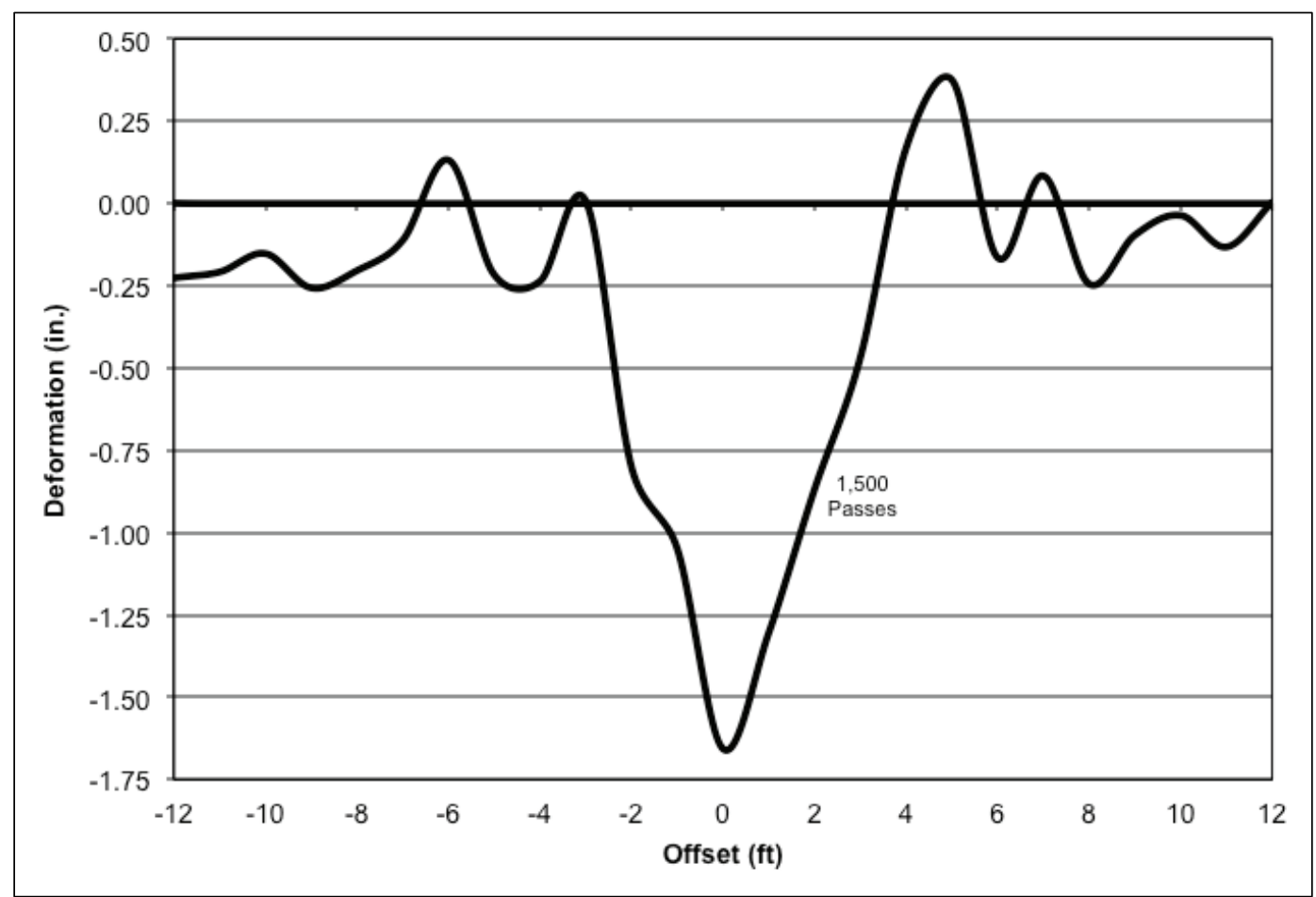


Figure 5.11. Average deformation on the loaded mat surface of PSA-FT - P-19 lane.

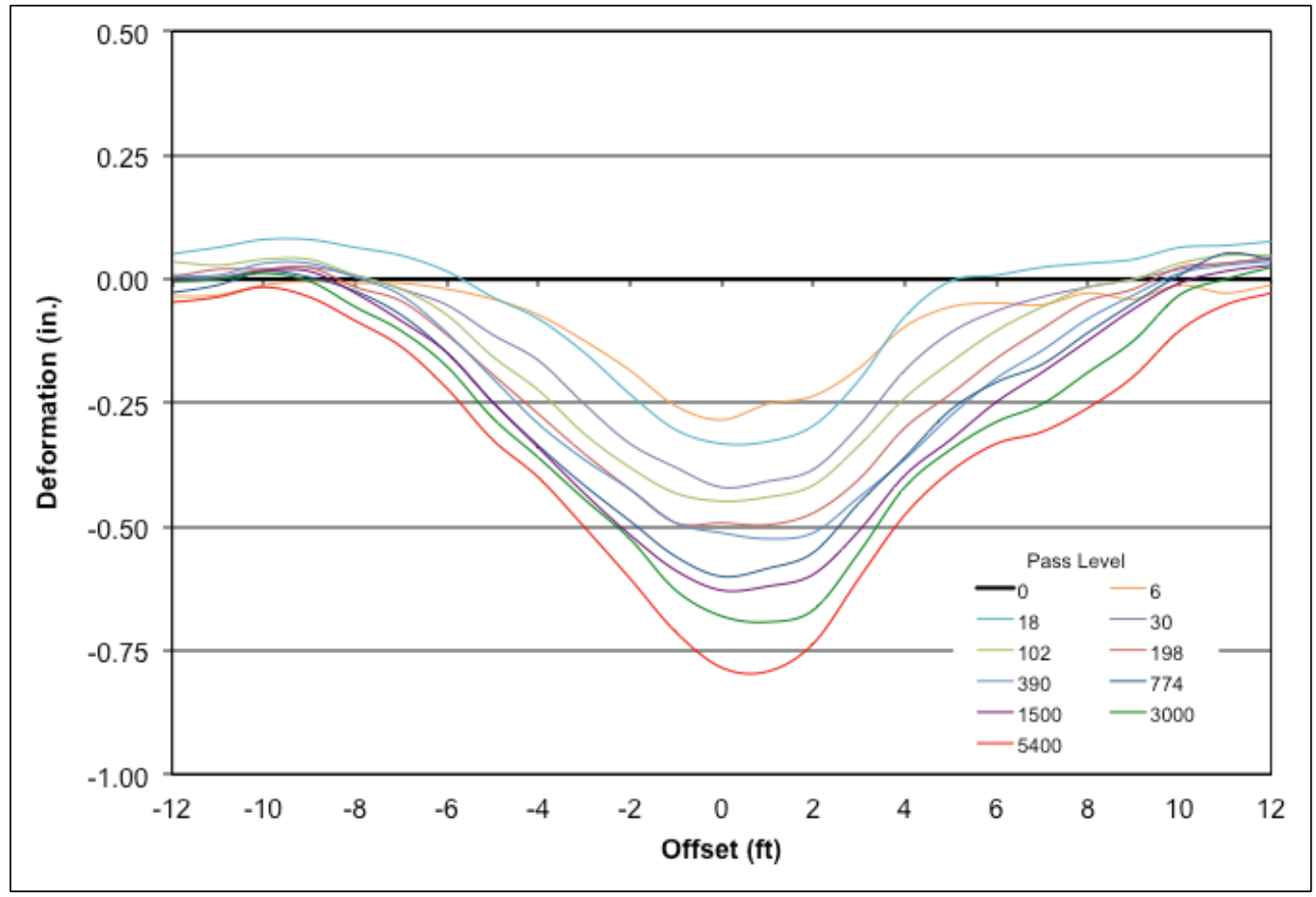

Figure 5.12. Average deformation on the loaded mat surface of PSA-FT-R - P-19 lane.

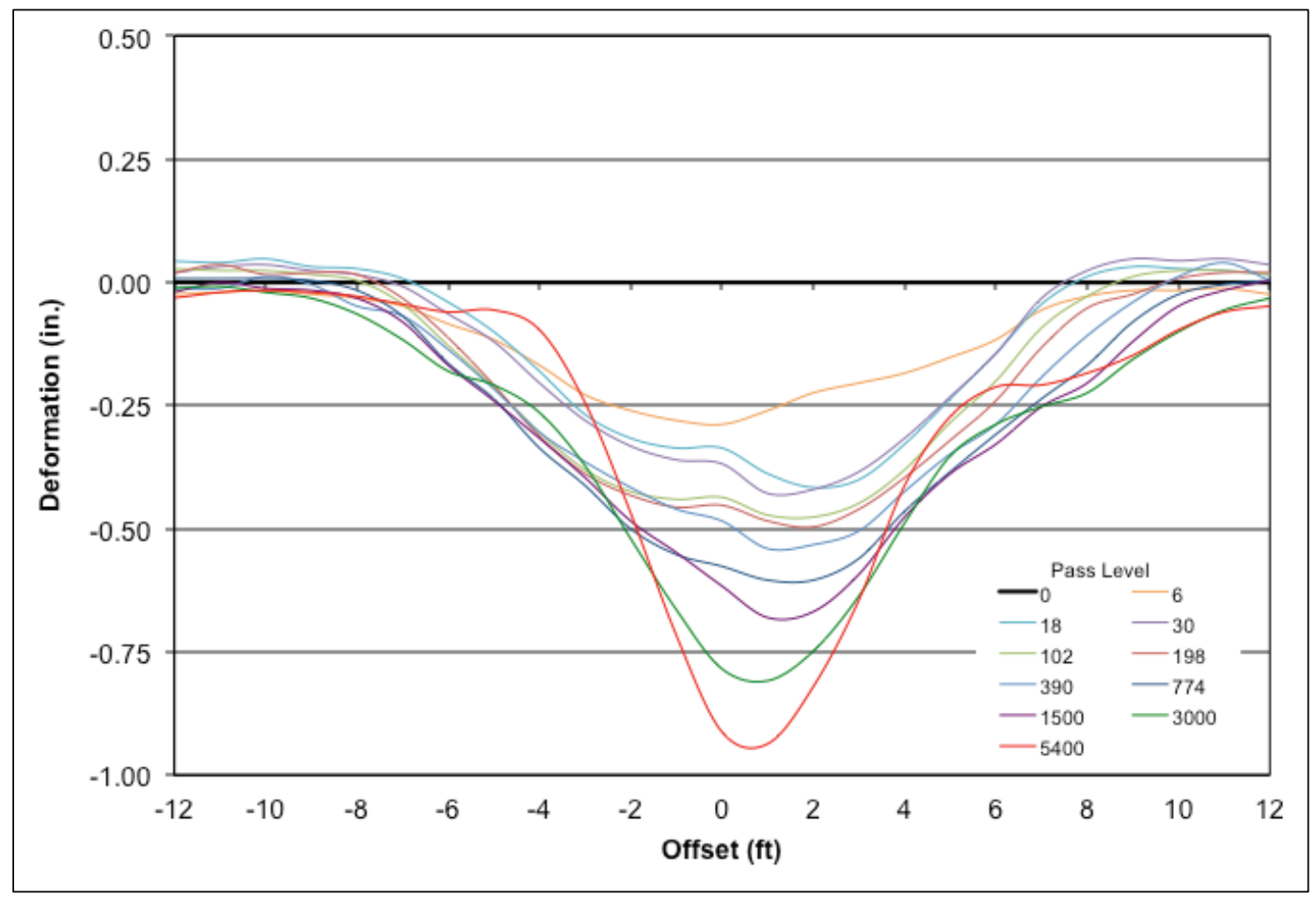


Figure 5.13. Average deformation on the loaded mat surface of ALMATS - P-19 lane.

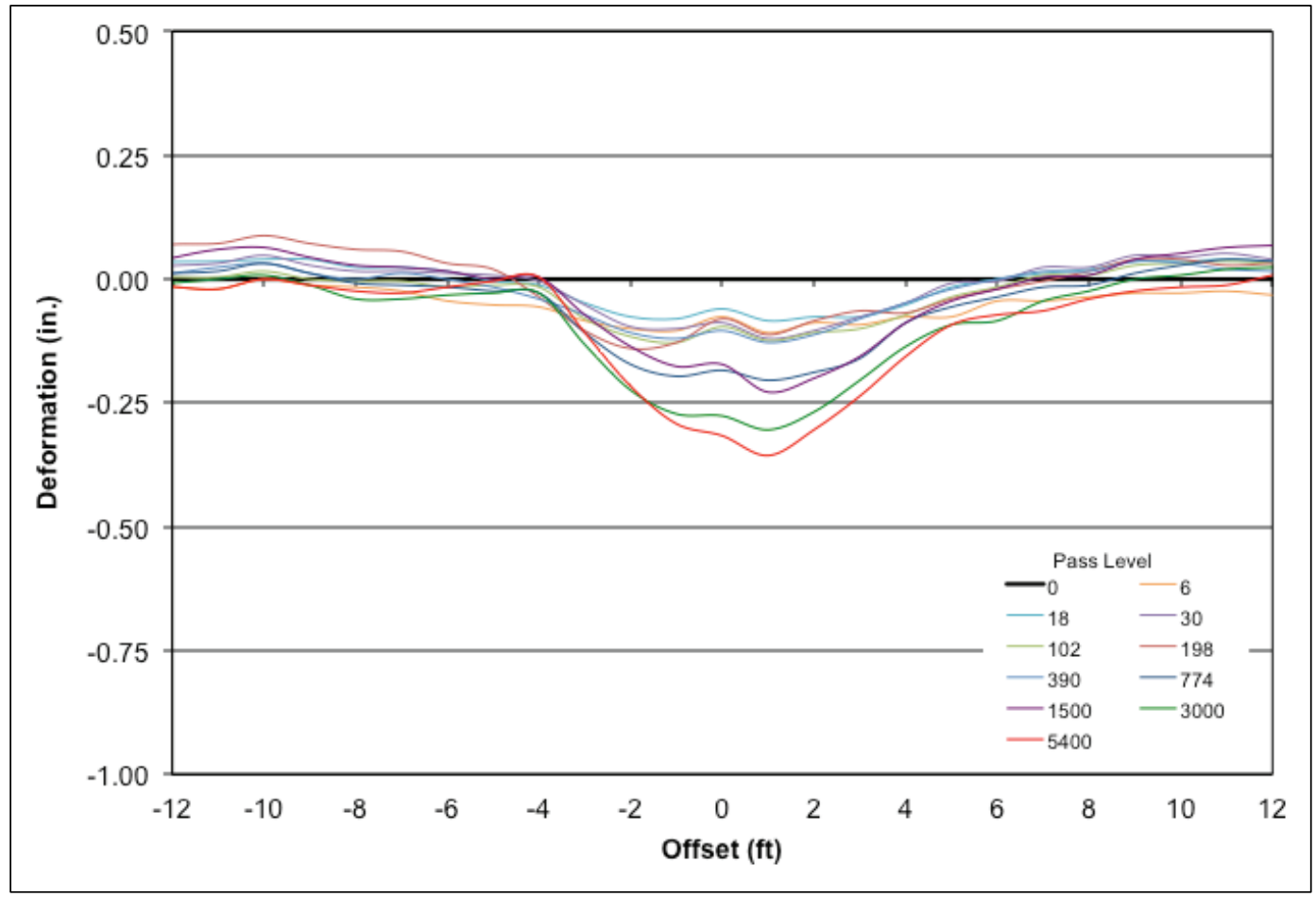

Figure 5.14. Average deformation on the loaded mat surface of DuraDeck - P-19 lane.

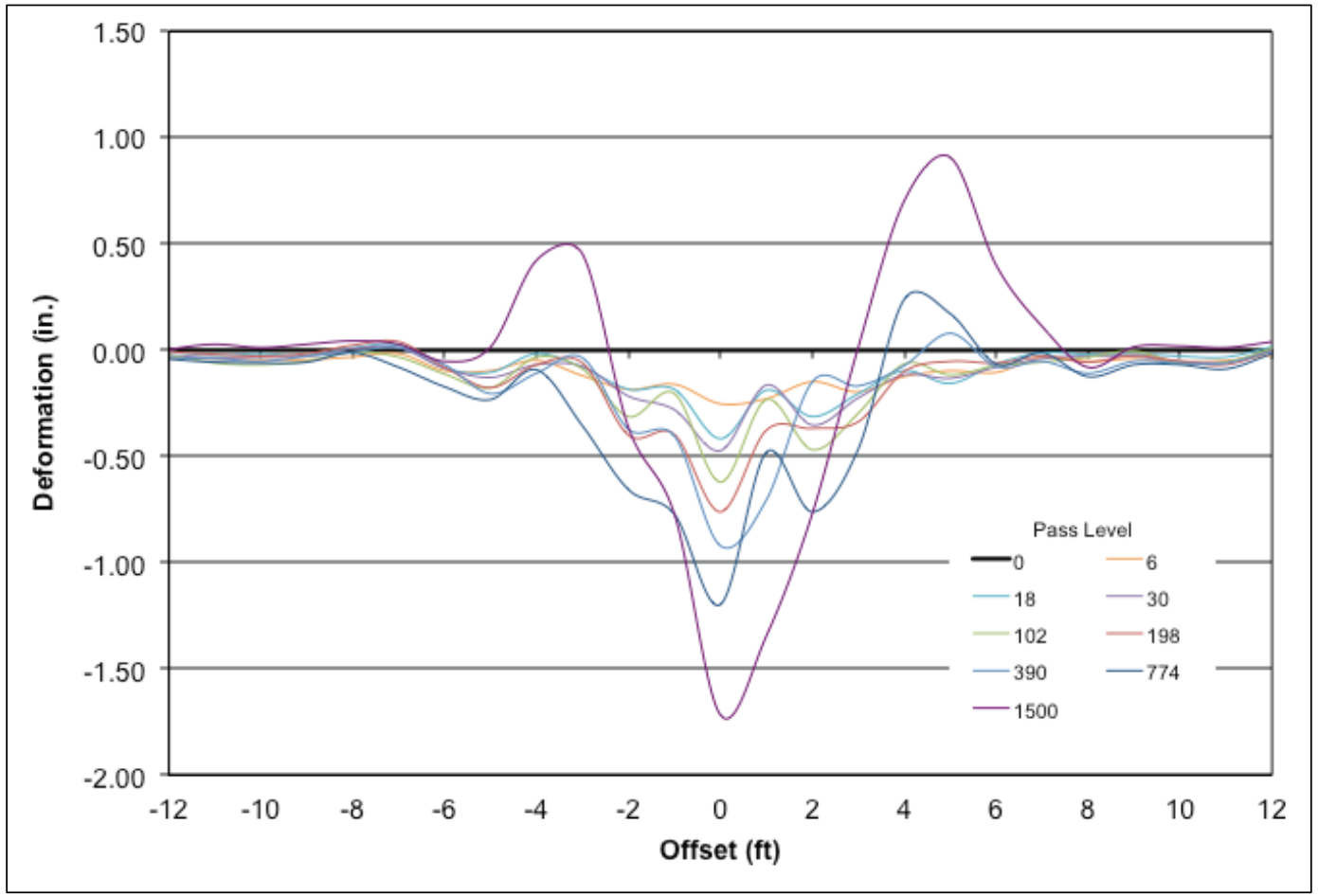


Figure 5.15. Average maximum rut depth on the subgrade.

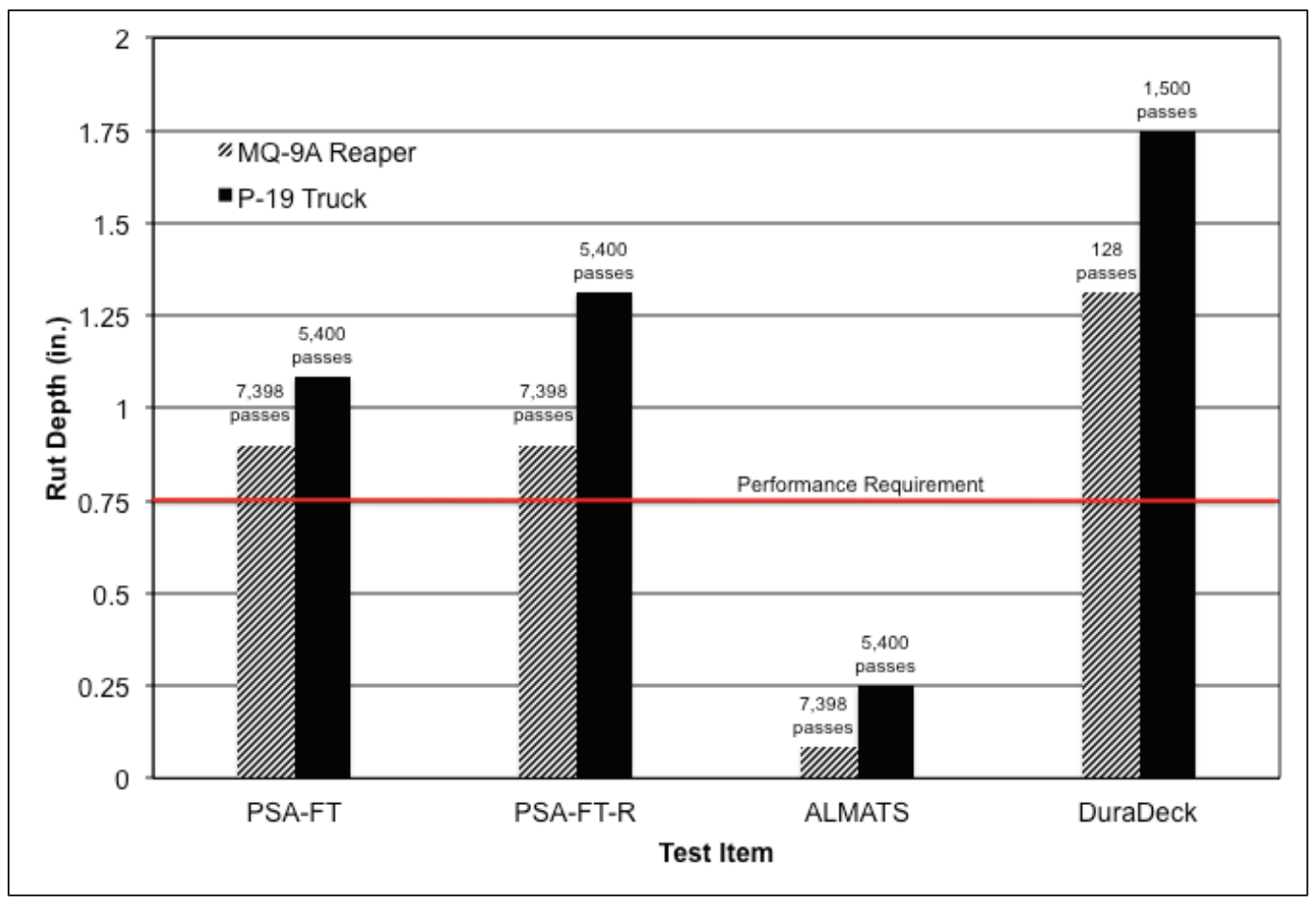

Figure 5.16. Average maximum rut depth on the loaded mat surface - MQ-9A Reaper lane.

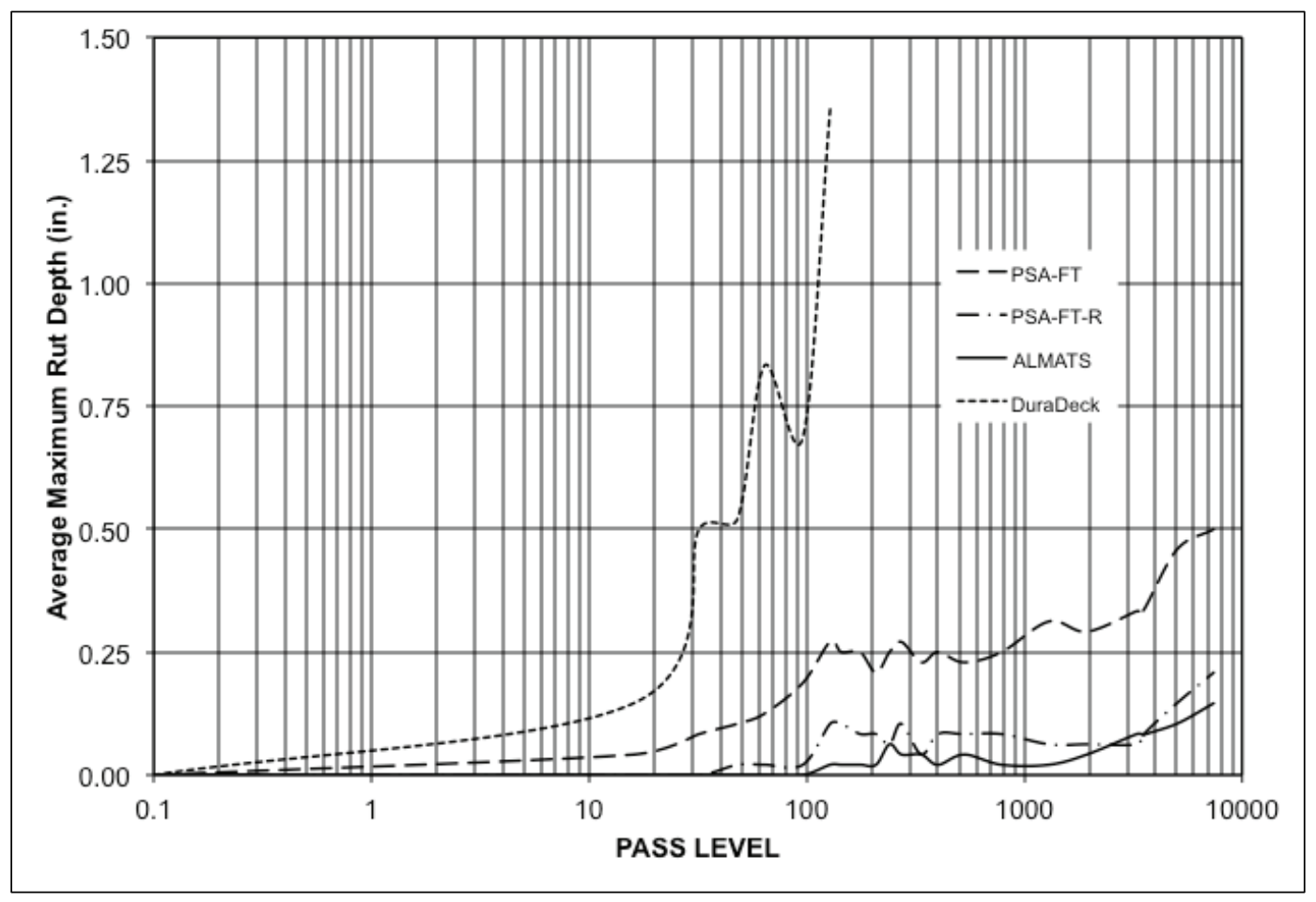


Figure 5.17. Average maximum rut depth on the loaded mat surface - P-19 lane.

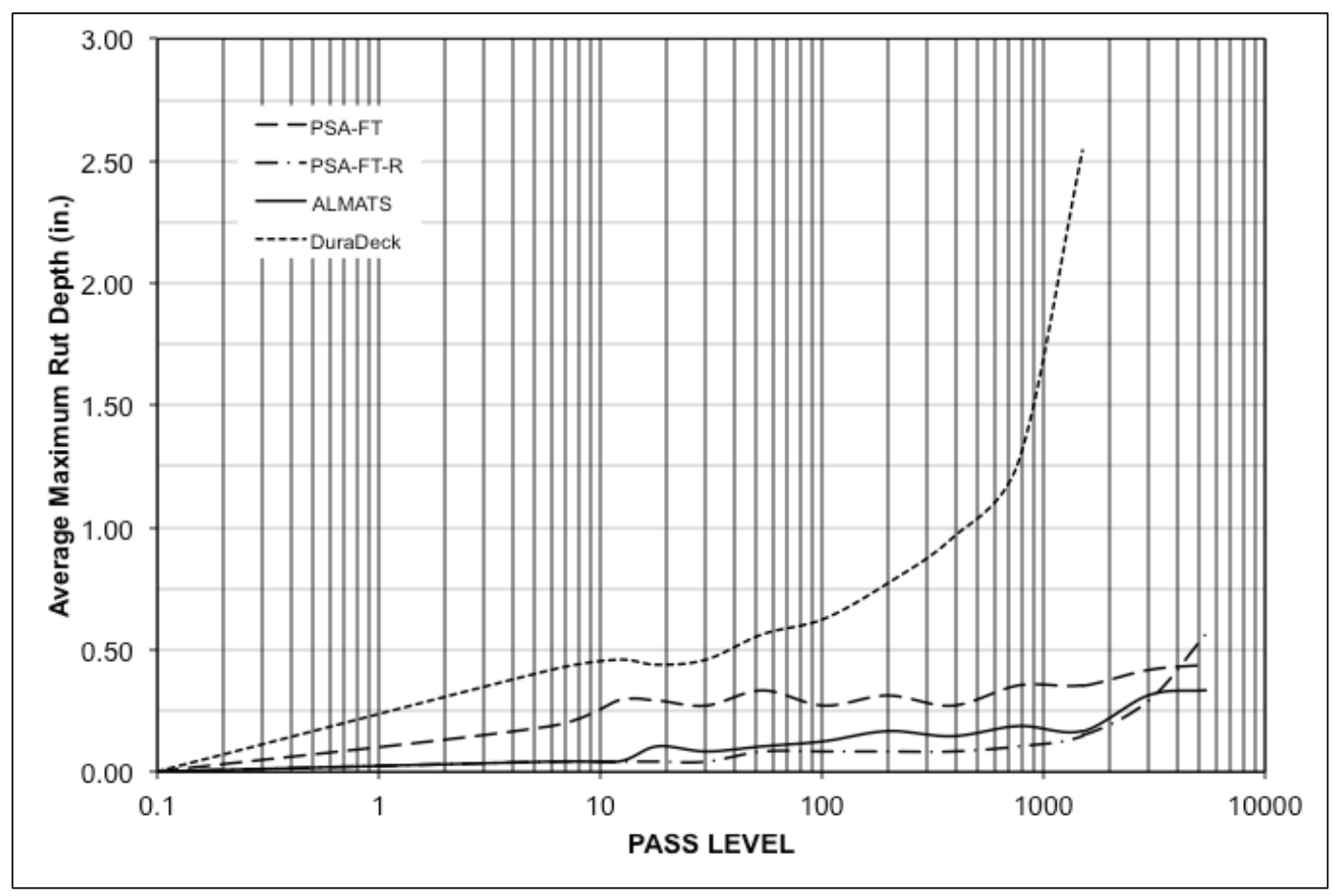

Due to discrepancies with robotic total station equipment, data collected along the pretest subgrade centerline of both test lanes were not usable. Data collected along the pretest subgrade cross sections of the PSA-FT-R test item were also unusable. All other pretest subgrade data were collected on different dates and are usable. For analyzing subgrade deformation along the cross sections of the PSA-FT-R test item, only rut depth data were used.

\subsection{Permanent deformation analysis}

The centerline profiles were analyzed to determine whether the roughness criterion was exceeded. The permanent deformation on the subgrade, the loaded mat surface, and the unloaded mat surface were also analyzed to determine whether the deformation criterion was exceeded. Table 5.1 summarizes the results of permanent deformation in terms of the pass level at which a mat system failed to meet the criterion. Except for the DuraDeck mat system, all other mat systems were able to sustain at least 1,500 passes without exceeding 0.75 in. of roughness along the centerlines or deformation at the cross sections. Note that deformation on the subgrade was measured after panels were removed. Therefore, if the rut depth on the subgrade exceeded 0.75 in., the pass number that is reported is the last pass level applied by the load cart, even if deformation was exceeded prior to that pass level. 
Table 5.1. Pass level at which permanent deformation criterion was exceeded.

\begin{tabular}{|l|l|l|l|l|l|l|l|l|}
\hline & \multicolumn{5}{|c|}{ MQ-9A Reaper } & \multicolumn{3}{c|}{} \\
\cline { 2 - 9 } & PSA-F & $\begin{array}{l}\text { PSA-FT } \\
\text { R }\end{array}$ & ALMATS & DuraDeck & PSA-FT & $\begin{array}{l}\text { PSA-FT- } \\
\text { R }\end{array}$ & ALMATS & DuraDeck \\
\hline $\begin{array}{l}\text { Mat surface } \\
\text { centerline } \\
\text { roughness }\end{array}$ & N/A & N/A & N/A & N/A & N/A & N/A & N/A & 1,500 \\
\hline $\begin{array}{l}\text { Deformation } \\
\text { on subgrade } \\
\text { surface }\end{array}$ & 7,398 & $-*$ & N/A & 128 & 5,400 & $-*$ & N/A & 1,500 \\
\hline $\begin{array}{l}\text { Loaded } \\
\text { deformation on } \\
\text { mat surface }\end{array}$ & N/A & N/A & N/A & 64 & 5,400 & 3,000 & N/A & 198 \\
\hline $\begin{array}{l}\text { Unloaded } \\
\text { deformation on } \\
\text { mat surface }\end{array}$ & N/A & N/A & N/A & 64 & 5,400 & 5,400 & N/A & 390 \\
\hline $\begin{array}{l}\text { Rut depth on } \\
\text { subgrade } \\
\text { surface }\end{array}$ & 7,398 & 7,398 & N/A & 128 & 5,400 & 5,400 & N/A & 1,500 \\
\hline $\begin{array}{l}\text { Rut depth on } \\
\text { loaded mat } \\
\text { surface }\end{array}$ & N/A & N/A & N/A & 64 & N/A & N/A & N/A & 198 \\
\hline $\begin{array}{l}\text { Rut depth on } \\
\text { unloaded mat } \\
\text { surface }\end{array}$ & N/A & N/A & N/A & 64 & N/A & N/A & N/A & 390 \\
\hline
\end{tabular}

*Data not available

Note: N/A indicates that criterion was not exceeded: $<0.75$ in. of deformation

Although slight differences can be seen between average cross-section deformation and rut depth data, the general characteristics of the rate of increase in deformation can be seen with both measurements. Sometimes these data differ because of varying features on the matting surface (type of joint, gap between joints, etc.), different personnel collecting the data, and precision of the equipment.

Apart from the DuraDeck test item on the P-19 lane, the mat systems worked well at preventing excessive roughness from occurring along the centerline. Mat systems tend to be forgiving on roughness along the centerline and typically meet roughness criteria. If a mat system fails by deformation, it will likely be due to deformation of the subgrade (Garcia et al. 2015).

Little movement was noted for the ALMATS system, making it the best performer in preventing deformation of the subgrade. This is likely due to 
tighter joint tolerances and stiffer joints relative to the other mat systems. The other systems were more flexible and deformed more easily at the traffic lane. The PSA-FT and PSA-FT-R systems in particular appear to have "settled" into the subgrade on the MQ-9A Reaper lane (Figure 5.4 and Figure 5.5). This may be associated with the corrugated bottom surface of the mats and lack of a bottom skin, allowing material to naturally move into the empty spaces. Deformation of PSA-FT-R on the P-19 lane was somewhat larger than for the PSA-FT, according to Figure 5.11 and Figure 5.12. This was unexpected since the end connector of the PSA-FT-R system should have better stiffness properties at the joint, therefore decreasing the rate of deformation compared to the PSA-FT mat system. Since the staggered pattern on the PSA-FT did not allow the joints of the system to align with that of the PSA-FT-R (because of the locations of the welded blocks on the male joint), the joints of the PSA-FT test item were offset 9 in. from the centerline of traffic in the P-19 lane. It was assumed that this would have little effect on the measurements on the mat surface of the PSA-FT test item because of the large width of the P-19 tire. However, this can explain the difference for the slightly better performance of the PSA-FT system on the P-19 lane. Regardless, both worked well and sustained over 1,500 passes.

In Figure 5.1 through Figure 5.7, approximately $5 \mathrm{ft}$ offset from each side of the centerline, there appear to be ruts that increased throughout the test. These were located where the outrigger tires of the MQ-9A Reaper test vehicle traveled along the test section, indicating an issue with the load distribution of the test vehicle. The ratio of this load relative to the load of the test tire was too high. Since the MQ-9A load cart was a new design and limited equipment was available, the test was continued, but it was noted that lighter equipment and a new design should be considered for future testing.

Generally, the rate of deformation was higher for simulated P-19 traffic than for MQ-9A Reaper traffic. The larger load and footprint of the P-19 tire tended to be more damaging to the foundation because of higher stress at a deeper zone of influence in the foundation. The exception to this is the DuraDeck mat system. The longitudinal joint of the DuraDeck mat system panels was $4 \mathrm{ft}$ long. Connection plates were placed only at the ends of the joint and not at the center, meaning the joint was unsupported for a length of $4 \mathrm{ft}$. Because the contact area of the MQ-9A Reaper tire is much smaller than the P-19 tire (approximately 80\% smaller in width), the tire was able to separate at the joint easily and cause severe rutting at the 
centerline. Although the P-19 test tire was heavier, the width of the tire allowed it to bridge over the joint and for rutting to spread throughout the traffic area. Two panels with a joint at the centerline were able to work together to prevent rutting on the P-19 lane, whereas on the MQ-9A Reaper lane, panels were separated by the small tire and could not work together to bridge the load. It is possible that the DuraDeck mat system could yield better load-bearing capabilities if a stronger substrate is used. This could require soil stabilization or the addition of suitable base material, such as crushed rock or gravel. However, additional testing would be needed to verify this. 


\section{Summary}

Table 6.1 summarizes the results and findings of the experimental program. A rank was given to each mat system to help make recommendations as to the suitability depending on several factors. Each of the mats was initially evaluated based on physical properties (weight and dimensions) and whether they met the criteria of the program. User feedback and ease of installation were also considered in ranking. The results from testing under simulated MQ-9A Reaper and P-19 trafficking in terms of the failure criteria discussed in Chapter 3 are shown, and each of the mat systems was ranked based on performance. A combination of all of the factors was used to determine an overall rank, where a rank of 1 was assigned to the mat system that is highly recommended, and a rank of 4 was given to the system that is not recommended.

From Table 6.1, the PSA-FT-R system was the highest ranked mat system for RPA operations because of its ability to sustain both the RPA and support vehicle traffic with limited damage and deformation, and because of its ease of installation. ALMATS was assigned an overall rank of 2, even though it received negative feedback, was difficult to install, and halfpanels were slightly above the weight criterion. However, as long as physical properties were mostly met, performance outweighs these other factors because it is directly associated with safety of both aircraft/vehicle and personnel. DuraDeck was given an overall rank of 4 because of poor performance and mostly negative feedback with regards to installation.

Note the tradeoff of mat characteristics versus performance shown in Table 6.1. While ALMATS seemed to be cumbersome and a burden on personnel, it provided excellent load-bearing performance. PSA-FT was very simple to install because it did not have an end connector and was also very lightweight, but the unsupported joint was an issue for stability and eventually posed a risk to the tire.

A trend was noted in the data for MQ-9A Reaper versus P-19 traffic. The MQ-9A Reaper seems to control mat breakage failure, while the P-19 tends to cause higher rates of increase in deformation. A similarity can be seen with the F-15E and $\mathrm{C}-17$ aircraft. The $\mathrm{F}-15 \mathrm{E}$ has a high tire pressure and a small footprint that causes severe surface damage, and the $\mathrm{C}-17$ has a large load carried by a 6 -wheel main landing gear that causes rapid subgrade deformation due to the size and depth of the stress in the foundation soil. 
Considering this relationship, the data collected in this test program could potentially be used to create curves for predicting subgrade soil deformation resulting from the MQ-9A Reaper and P-19 truck on a 6 CBR. A basis for this is provided by Garcia and Howard (2016), where the authors developed relationships for predicting subgrade deformation for different mat systems as a function of mat stiffness and F-15E passes. Rushing and Howard (2015) and Rushing and Howard (2017) performed similar work for the AM2 mat system for a range of CBRs. The test program is encouraging for performing additional investigations on different soil conditions. 
Table 6.1. Summary of experimental program.

\begin{tabular}{|c|c|c|c|c|c|c|c|c|c|c|}
\hline \multirow[b]{3}{*}{$\begin{array}{l}\text { Test } \\
\text { Item }\end{array}$} & \multirow{2}{*}{\multicolumn{4}{|c|}{ General Characteristics }} & \multicolumn{5}{|c|}{ Performance } & \multirow[b]{3}{*}{$\begin{array}{l}\text { Overall } \\
\text { Rank }\end{array}$} \\
\hline & & & & & \multicolumn{2}{|c|}{$\begin{array}{c}\text { MQ-9A Reaper } \\
\text { (after 7,398 passes) }\end{array}$} & \multicolumn{2}{|c|}{$\begin{array}{c}\text { P-19 Truck } \\
\text { (after } 5,400 \text { passes) }\end{array}$} & \multirow[b]{2}{*}{ Rank } & \\
\hline & $\begin{array}{l}\text { Physical } \\
\text { Properties }\end{array}$ & Installation & $\begin{array}{l}\text { User } \\
\text { feedback }\end{array}$ & Rank & Mat Breakage & Deformation & $\begin{array}{l}\text { Mat } \\
\text { Breakage }\end{array}$ & Deformation & & \\
\hline PSA-FT & Met criteria & Easy and efficient & Positive & 1 & $\begin{array}{l}\text { Extensive cracking } \\
\text { at joint }\end{array}$ & $<0.75$ in. & None & $>0.75 \mathrm{in}$. & 3 & 3 \\
\hline PSA-FT-R & Met criteria & $\begin{array}{l}\text { Easy, but minor } \\
\text { changes needed } \\
\text { at end connector }\end{array}$ & $\begin{array}{l}\text { Mostly } \\
\text { positive }\end{array}$ & 2 & $\begin{array}{l}\text { Minor panel skin } \\
\text { deformation and } \\
\text { minor cracks at } \\
\text { weld }\end{array}$ & $<0.75$ in. & None & $>0.75$ in. & 2 & 1 \\
\hline ALMATS & $\begin{array}{l}\text { Half panels } \\
>4 \text { psf }\end{array}$ & $\begin{array}{l}\text { Very difficult. } \\
\text { Changes needed } \\
\text { at all joints }\end{array}$ & Negative & 4 & None & $<0.5$ in. & None & $<0.5$ in. & 1 & 2 \\
\hline DuraDeck & Met criteria & $\begin{array}{l}\text { Easy, but not } \\
\text { efficient }\end{array}$ & $\begin{array}{l}\text { Mostly } \\
\text { negative }\end{array}$ & 3 & None & $\begin{array}{l}>0.75 \text { in. after } \\
64 \text { passes }\end{array}$ & None & $\begin{array}{l}>0.75 \text { in. after } \\
198 \text { passes }\end{array}$ & 4 & 4 \\
\hline
\end{tabular}




\section{Conclusions and Recommendations}

The objectives of the effort described herein were to identify COTS matting systems potentially capable of supporting RPA and associated ground support vehicle operations. Four (4) matting systems were selected and evaluated in a full-scale test section consisting of a 6 CBR subgrade surfaced with each of the matting systems. The four COTS mat systems were PSA-FT, PSA-FT-R, ALMATS, and DuraDeck. The test section had two lanes, one for simulated MQ-9A Reaper traffic and the other for simulated P-19 traffic that were trafficked continuously over the length of the four test items. Permanent deformation and mat breakage were monitored. The performance of each of the COTS systems was analyzed based on the failure criteria, and the information was used to develop recommendations.

\subsection{Conclusions}

1. The PSA-FT mat system was able to sustain 7,398 passes of simulated MQ-9A Reaper traffic before failure by mat breakage and rut depth of the subgrade surface occurred. After the objective 1,500 passes were completed, the condition of the mat was good, meeting the performance requirements of the program.

2. The PSA-FT-R mat system was able to sustain 7,398 passes of simulated MQ-9A Reaper traffic before failure by rut depth of the subgrade surface occurred. After the objective 1,500 passes were completed, the condition of the mat was good, meeting the performance requirements of the program.

3. ALMATS was able to sustain 7,398 passes of simulated MQ-9A Reaper traffic with limited deformation and no mat breakage. After the objective 1,500 passes were completed, the condition of the mat was excellent, meeting the performance requirements of the program

4. The DuraDeck mat system was able to sustain only 64 passes of simulated MQ-9A Reaper traffic before failure by deformation occurred. Minimum test requirements were not met; therefore, the mat system is not suitable for RPA operations.

5. The PSA-FT mat system was able to sustain 5,400 passes of simulated P-19 truck traffic before failure by deformation occurred. After the objective 1,500 passes were completed, the condition of the mat was good, meeting the performance requirements of the program. 
6. The PSA-FT-R mat system was able to sustain 3,000 passes of simulated $\mathrm{P}-19$ truck traffic before failure by deformation occurred. After the objective 1,500 passes were completed, the condition of the mat was good, meeting the performance requirements of the program

7. ALMATS was able to sustain 5,400 passes of simulated P-19 truck traffic with limited deformation and no mat breakage. After the objective 1,500 passes were completed, the condition of the mat was excellent, meeting the performance requirements of the program

8. The DuraDeck mat system was only able to sustain 198 passes of simulated P-19 truck traffic before failure by deformation occurred. Minimum test requirements were not met; therefore, the mat system is not suitable for support vehicle operations.

9. The PSA-FT-R and ALMATS systems are highly recommended for RPA and support vehicle operations in term of their load-bearing capabilities. However, the ALMATS system requires changes at all joints to increase tolerances to improve ease-of-installation. The PSA-FT-R system requires minor changes at the end connector to allow installation from each direction.

\subsection{Recommendations}

1. Additional full-scale testing is recommended to verify the stability of the COTS systems when traffic occurs along the long dimension of the mats (i.e. 90 deg to the direction of traffic in this test). Similar testing was performed on the AM2 system, which yielded that the system was highly unstable after a limited number of passes of $\mathrm{F}-15 \mathrm{E}$ and $\mathrm{C}-17$ aircraft traffic.

2. This test program showed that the rate of permanent deformation caused by the P-19 is higher than that caused by the MQ-9A Reaper, which tended to control general failure of the COTS systems by rutting at a lower number of passes. It is recommended to limit traffic of heavy ground support vehicles on the mat system, if possible, to reduce maintenance and repair activity frequency on the subgrade (lengthening the life of the mats).

3. Additional testing could be performed to develop relationships that can predict subgrade deformation as a function of aircraft passes and CBRs. Similar curves have already been developed for the AM2 mat system.

4. It is recommended that a MQ-9A load cart be designed for future testing to reduce the load on the outrigger tires. 


\section{References}

ASTM International. 2007a. Standard test method for California Bearing Ratio (CBR) of laboratory-compacted soils. Standard D1883. West Conshohocken, PA: ASTM International.

ASTM International. 2007b. Standard test method for particle-size analysis of soils. Standard D422. West Conshohocken, PA: ASTM International.

ASTM International. 2009. Standard test method for use of the dynamic cone penetrometer in shallow pavement applications. Designation: D 6951. West Conshohocken, PA: ASTM International.

ASTM International. 2010a. Standard test method for in-place density and water content of soil and soil aggregate by nuclear methods (shallow depth). Standard D6938. West Conshohocken, PA: ASTM International.

ASTM International. 2010b. Standard test method for laboratory determination of water (moisture) content of soil and rock by mass. Standard D2216. West Conshohocken, PA: ASTM International.

ASTM International. 2011. Standard practice for classification of soils for engineering purposes (Unified Soil Classification System). Standard D2487. West Conshohocken, PA: ASTM International.

ASTM International. 2012. Standard test methods for laboratory compaction characteristics of soil using modified effort $\left(56,000 \mathrm{ft}-\mathrm{lbf} / \mathrm{ft} 3\left(2,700 \mathrm{kN}-\mathrm{m} / \mathrm{m}_{3}\right)\right)$. Standard D1557. West Conshohocken, PA: ASTM International.

ASTM International. 2014. Standard test methods for liquid limit, plastic limit, and plasticity index of soils. Standard D4318. West Conshohocken, PA: ASTM International.

Department of the Army. 2013. Aviation complex planning and design criteria for unmanned aircraft systems (UAS). ETL 1110-3-510. Washington, DC: U.S. Army Corps of Engineers.

Garcia, L. and I. L. Howard. 2016. Full-scale instrumented testing of multiple airfield matting systems on soft soil to characterize permanent deformation. Transportation Geotechnics 9:80-95.

Garcia. L., T. W. Rushing, Q. Mason, J. S. Tingle, and C. A. Rutland. 2015. AM2 mat end connector modeling and performance validation. ERDC TR-15-28. Vicksburg, MS: U.S. Army Engineer Research and Development Center.

Rushing, T. W. and I. L. Howard. 2015. Prediction of soil deformation rate beneath temporary airfield matting systems based on full-scale testing. Journal of Terramechanics 58:1-9.

Rushing, T. W. and I. L. Howard. 2017. Analysis of AM2 airfield matting performance under six-wheel Boeing C-17 gear loading. Journal of Terramechanics 58:1-9. 
Rushing, T. W., and J. S. Tingle. 2007. AM2 and M19 airfield mat evaluation for the rapid parking ramp expansion program. ERDC/GSL TR-07-5. Vicksburg, MS: U.S. Army Engineer Research and Development Center.

Rushing, T. W., and L. Garcia. 2013. Full-scale evaluation of DuraDeck and MegaDeck matting systems. ERDC/GSL TR-13-27. Vicksburg, MS: U.S. Army Engineer Research and Development Center.

Rushing, T. W., L. Garcia, and Q. S. Mason. 2012. Evaluation of faun aluminum mat systems. ERDC/GSL TR-12-32. Vicksburg, MS: U.S. Army Engineer Research and Development Center.

U.S. Army Engineer Research and Development Center. 1995. Standard test method for California Bearing Ratio of soils in place. Designation: CRD-C654-95. Vicksburg, MS: ERDC. 


\title{
Appendix A: Request for Information for an RPA Mat System
}

\author{
Solicitation Number: W81EWF43234193
}

\section{A.1 Background}

The U.S. Military has identified preliminary requirements for matting systems required to support Remote Piloted Aircraft (RPA). Information is being requested from potential providers of mat surfaces that may be used to construct RPA runway, taxiway, and parking apron surfaces as large as 5,000 ft long x $100 \mathrm{ft}$ wide. The following sections define the preliminary requirements for matting systems to be considered for RPA operations. Submissions will be considered based on their ability to meet the requirements described below, cost, and projected performance over a variety of subgrade soil conditions. After submissions have been reviewed, systems meeting the requirements may be invited to participate in fullscale validation testing to support future acquisitions.

\section{A.2 Key requirements}

The most important criteria for acceptable matting are twofold:

(1) support the most critical loading without catastrophic failure or damage, and (2) maintain operational integrity over time so as to minimize the need for repairs.

\section{A.3 Minimum number of required operations}

The objective of this effort is to find a matting system capable of sustaining 1,500 operations (passes) of the most critical vehicle loading while adhering to all requirements listed in the sections below. However, systems included in the full-scale validation phase will be evaluated based on their cost and performance under traffic to determine the system(s) most suited to meet the customer's needs.

\section{A.4 Load capacity}

Controlling loads for load-bearing design and evaluation will be dependent on mat usage. The mats may be used by both RPAs and support vehicles. The matting system must be able to support a) an RPA with a maximum single-wheel gear load of 5,00o lb and maximum tire pressure of 170 psi 
and b) a ground support vehicle with a maximum single-wheel gear load of $12,000 \mathrm{lb}$ and a maximum tire pressure of $90 \mathrm{psi}$.

\section{A.5 Subgrade requirements}

The objective of this effort is to find a matting system capable of being placed directly on top of a semi-prepared soil surface with a California bearing ratio (CBR) of 6 and meet requirements listed in this document. However, full-scale validation experiments may be conducted over multiple soil conditions (i.e. CBR 6, 10, and 25) to determine the most cost-effective solution that meets all other requirements. Consideration may be given to systems that require additional subgrade preparation to achieve the 1,500-pass requirement based on a cost-benefit analysis.

\section{A.6 Foreign Object Damage (FOD) protection}

The matting system must provide FOD cover/protection. The mat system must not be a source of FOD and must also prevent small rocks/debris on the ground underneath from being sucked into engines.

\section{A.7 Deflection limits}

Maximum mat surface deflections under aircraft load must not exceed 0.75 in. at anytime during the application of the first 1,500 passes when placed directly over a subgrade.

\section{A.8 Mat panel breakage limits}

The system must also be capable of supporting the requirements above without more than a $10 \%$ mat component failure. Component failure is defined as any condition rendering the component unserviceable or a safety hazard to equipment or personnel.

\section{A.9 Panel replacement}

Interior panels and assembled mat sub-systems must be removable to allow the replacement of damaged panels or to allow for maintenance of the subgrade below groups of panels. The matting system must be repairable as panels are damaged, or the subgrade under the panels fails. In order to minimize repair time and maximize usable space during repair operations, repairs should be made without extensive removal of existing panels. 


\section{A.10 Reusable panels}

Matting system panels without extensive damage must be recoverable and suitable for reuse after being cleaned and repacked.

\section{A.11 Weight}

The matting system's weight must be no more than $4.0 \mathrm{lb} / \mathrm{ft}^{2}$, not including any shipping containers/restraints. This represents a $40 \%$ reduction in the weight of the current AM2 aluminum matting system. The total panel weight, including any paint, coatings, or non-skid material (if required), must be less than or equal to $120 \mathrm{lb}$.

\section{A.12 Dimensions}

The matting system dimensions, to include ancillary connectors and parts, must be optimized for transport using a standard $463 \mathrm{~L}$ master pallet and 20-ft ISO flat rack. Panel thickness must be minimized to the greatest extent possible to reduce shipping volume, but must be less than or equal to 1.5 in.

\section{A.13 Non-slip surface}

The matting must be surfaced with a minimum nonskid profile capable of producing a coefficient of friction of at least $0.50 \mathrm{mu}$ when measured using a Griptester device at $60 \mathrm{mph}$. Correlations to other devices may be found in Section 3-19 of FAA Advisory Circular AC 150/5320-12C. The non-skid coating must be durable and must remain in satisfactory condition after 1,500 aircraft operations, including braking and turning. The non-skid surface must not be easily degraded by routine sweeping for FOD removal.

\section{A.14 Vertical bump limitations}

The maximum vertical change at a joint or panel connection is limited to $\leq$ 0.50 in. for runway and taxiway surfaces and $<1.0$ in. for apron surfaces. Ramps may be designed as required for panels with thickness $\geq 1.0 \mathrm{in}$. to transition to adjacent operating surfaces. 


\section{A.15 Horizontal gap between panels}

The maximum horizontal gap allowed between panels is limited to $\leq 0.25$ in. to prevent RPA gear damage. This is equivalent to the maximum gap between AM2 matting panels.

\section{A.16 Installation rate}

Construction personnel must be able to install the matting system at a minimum rate of $250 \mathrm{ft}^{2}$ per man-hour. System should require few, if any, tools to assemble.

\section{A.17 Edge anchoring}

The matting system must be designed to accommodate stakes and anchors on the edges and ends of assembled arrays to resist horizontal movement and vertical uplift from propwash and rotorwash of aircraft operating on or adjacent to matted surface. The system may be designed to accommodate either commercially available anchor and stake systems or AM2 cruciform stakes. Adapters, bushings, bolts, etc. are allowable.

\section{A.18 Aircraft/flightline fluids and liquid oxygen (LOX) resistance}

The matting system must be able to withstand exposure to LOX, JP series fuels, hydraulic fluids, firefighting agents, detergents, and other liquids typically found in an airfield environment, as well as being able to withstand exposure to NBC decontamination agents.

\section{A.19 Transportability}

The matting system must be delivered from the manufacturer bundled for inter-modal transportability. Gaining agencies will provide the specific bundling configurations required. Basic configurations are: (1) 463L and (2) ISO, $8 \mathrm{ft} \times 8.5 \mathrm{ft} \times 20 \mathrm{ft}$ flatrack containers. Bundles in the $463 \mathrm{~L}$ configuration must be capable of being placed on a 463L pallet system and should be maximized for C-130 transportation with an Allowable Cabin Load (ACL) of 25,000 lb, where a single pallet load cannot exceed 10,000 lb. Matting systems, when packaged for shipment in the $463 \mathrm{~L}$ configuration, must be able to be moved by a $10 \mathrm{~K}$ forklift. Mats must be compatible with standard Joint Service transportation systems and shipping configurations, and standard materiel handling equipment available in deployment packages likely to be resident where mats are to be used. 


\section{A.20 Surface temperature and solar radiation:}

When installed, the matting system must be capable of withstanding a peak ambient surface temperature of at least $205^{\circ} \mathrm{F}$ and withstand ultraviolet effects for 5 years' continuous use with minimal degradation of components, including permanent deformation, delaminating, or loss of material strength.

\section{A.21 Storage and reconstitution}

The matting system must be capable of outdoor storage to achieve a minimum 20-yr service life. Protective packaging may be used to meet this requirement. The mat must not become deformed if stored on dunnage. After use, the material must be capable of being reconditioned, if necessary, to allow a 20-yr service life.

\section{A.22 Support equipment (SE)}

The matting system must not require specialized tools to assemble and maintain (with the exception of simple hand-held devices designed to expedite assembly). Assembly of the matting system must be achievable using only common hand tools contained in Civil Engineer Unit Type Code (UTC) Equipment and Supply Listing (ESL). Engineers deploy with a substantial tool and equipment inventory in order to accomplish their many airfield support tasks. Adding specialized tools will increase logistics footprint.

\section{A.23 Operating temperature range}

The matting system must be able to perform its designed function in all climate types (e.g., hot, basic, cold, and extremely cold) and in induced operating temperatures between $-40^{\circ} \mathrm{F}$ and $+140^{\circ} \mathrm{F}$.

\section{A.24 Flammability}

The matting surface must not be flammable. Inflammability shall be defined as having a burning rate slower than $0.087 \mathrm{in}$. per sec when tested in accordance with UN Manual of Tests and Criteria. 


\section{A.25 All weather capability}

The matting surface must be suitable for operations in all weather conditions.

\section{A.26 Unplanned stimuli}

Matting systems and components must not be susceptible to static-charge build-up.

\section{A.27 Mooring and grounding}

The matting system should be designed to accommodate mooring or ground point installation without significant degradation to the structural integrity of the mat. Typical installation requires an 8- to 12-in.-diameter hole. If necessary, mat panels should be marked to show preferred installation locations.

\section{A.28 Paint and markings}

The matting system should be designed to accommodate painting of airfield markings using commercial paint and paint application systems commonly used for airfields without requiring special surface preparation or materials.

\section{A.29 Non-reflective surface}

The matting system's upper surface should be painted/colored/coated to achieve a non-reflective surface. Custom coloring to meet the user's preference is desired, but not required.

\section{A.30 Environment, safety, and occupational health}

The matting system developer will ensure that environment, safety, and occupational health $(\mathrm{ESOH})$ risks are considered consistent with operational needs and cost. Identified environmental, safety, and health risks will be eliminated, minimized, or controlled to acceptable levels within cost, schedule, and performance constraints. ESOH concerns are important to the user community. Operations, maintenance, support, and disposal activities require a system with minimal hazardous materials (HAZMATs); minimal health risks; minimal safety risks; and minimal environmental life cycle costs. Any HAZMATs used as part of the system's 
operations, maintenance, support, and disposal activities must be identified and adequate procedures and equipment (to include engineering controls/appropriate personal protective equipment or administrative controls) must be included with the delivered system to minimize environmental, personnel safety, and health risks. The application and its support will not present uncontrolled safety, health, or environmental hazards throughout its life cycle.

The matting program will use the Standard Practice for System Safety to identify, assess, mitigate, and then formally accept residual ESOH risks. The matting system developer will review hazard tracking information, mishaps, and environmental impact information of the current AM-2 Mat to identify potential ESOH hazards associated with materiel shortcomings, system performance, or predictable human error that need to be eliminated or reduced through engineering design and manufacturing of the mats. The matting system developer will reduce ESOH risks that could result in death, illness, or injury to personnel, or in damage to or loss of property, equipment, or environment to a Medium or Low level. The matting system developer will not allow the acceptance of High or Serious ESOH risks. The matting system developer will provide ESOH risk assessment information to testers, operators, and maintainers and to support National Environmental Policy Act (NEPA)/Executive Order 12114, Environmental Effects Abroad of Major Federal Actions, analyses.

\section{A.31 Safety and occupational health considerations}

The matting system developer should use the order of precedence for risk mitigation measures identified in the Standard Practice for System Safety. The first alternative should be to try to design out ESOH hazards, but, if that is not possible, then the developer should use engineering controls to mitigate the risk. Only when the developer cannot eliminate risks or mitigate risks with engineering controls should the developer use warning devices and safety labels as mitigation measures to help prevent injury during system operations and disposal. Normally, the developer should only use warnings and labels to augment engineering controls to mitigate ESOH risks.

Since matting systems and components may be placed in the proximity of aircraft refueling and/or ordnance loading/unloading, subsystems and components must not be a conduit for electromagnetic radiation. 


\section{A.32 Human Systems Integration (HSI)}

The matting system should be designed with the standard base civil engineer and installation crew in mind. Operators and maintainers will be capable of safely and effectively operating and maintaining the system while wearing the field duty uniform and chemical protective gear. The matting system will be designed to meet applicable industry and government Human Factors Engineering (HFE) requirements and practices. The applicable nine HSI domains (i.e., manpower, personnel, training, environment, safety, occupational health, human factors, habitability, and personnel survivability) will be optimized to ensure total system performance during operation, maintenance, and construction, thereby reducing life-cycle costs through upfront consideration.

\section{A.33 Environmental quality}

The matting system will be designed to eliminate or minimize impacts to the environment so that minimal, if any, mitigation is identified in NEPA/E.O. 12114 documentation required as a result of the testing and use of the mats. The design of the mats will reduce or eliminate the use of hazardous materials and the generation of hazardous wastes during manufacture, use, and disposal of the system to the extent that is technically and economically feasible. 


\section{Appendix B: Layouts of Test Items}

This appendix shows detailed drawings of the mat layout in each of the test items individually, with data collection locations marked and labeled. 
Figure B.1. Data collection locations on PSA-FT test item.

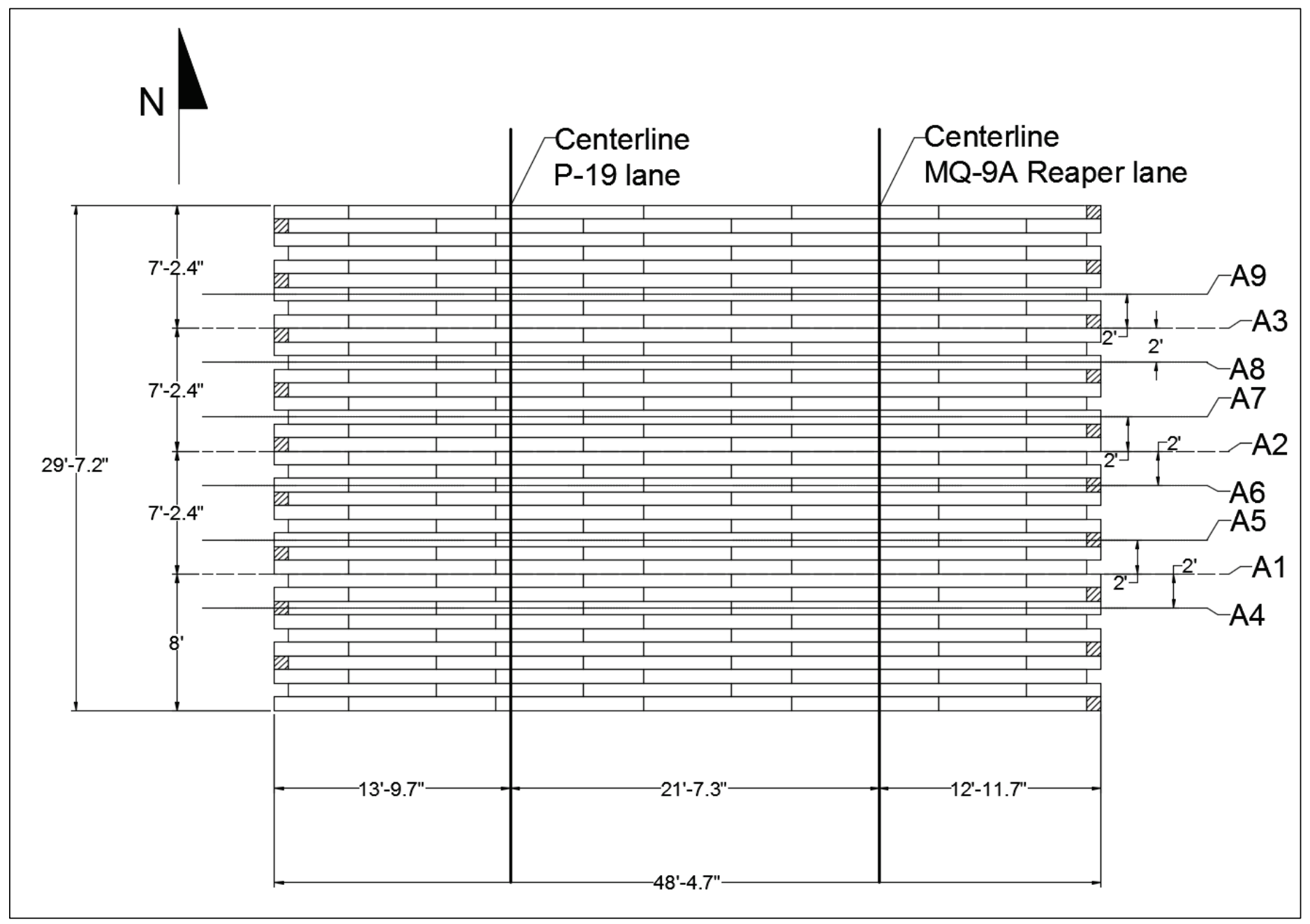


Figure B.2. Data collection locations on PSA-FT-R test item.

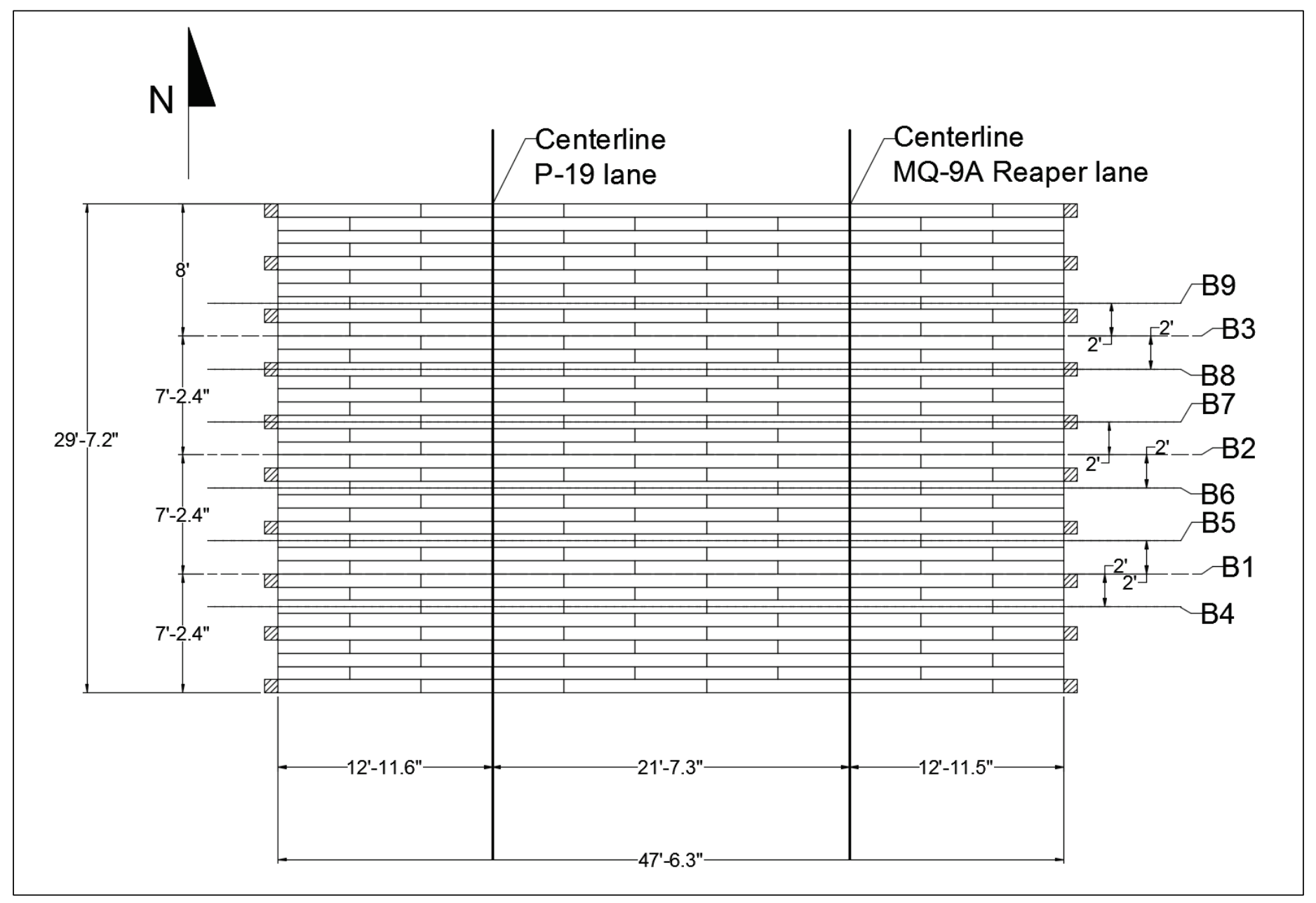


Figure B.3. Data collection locations on ALMATS test item.

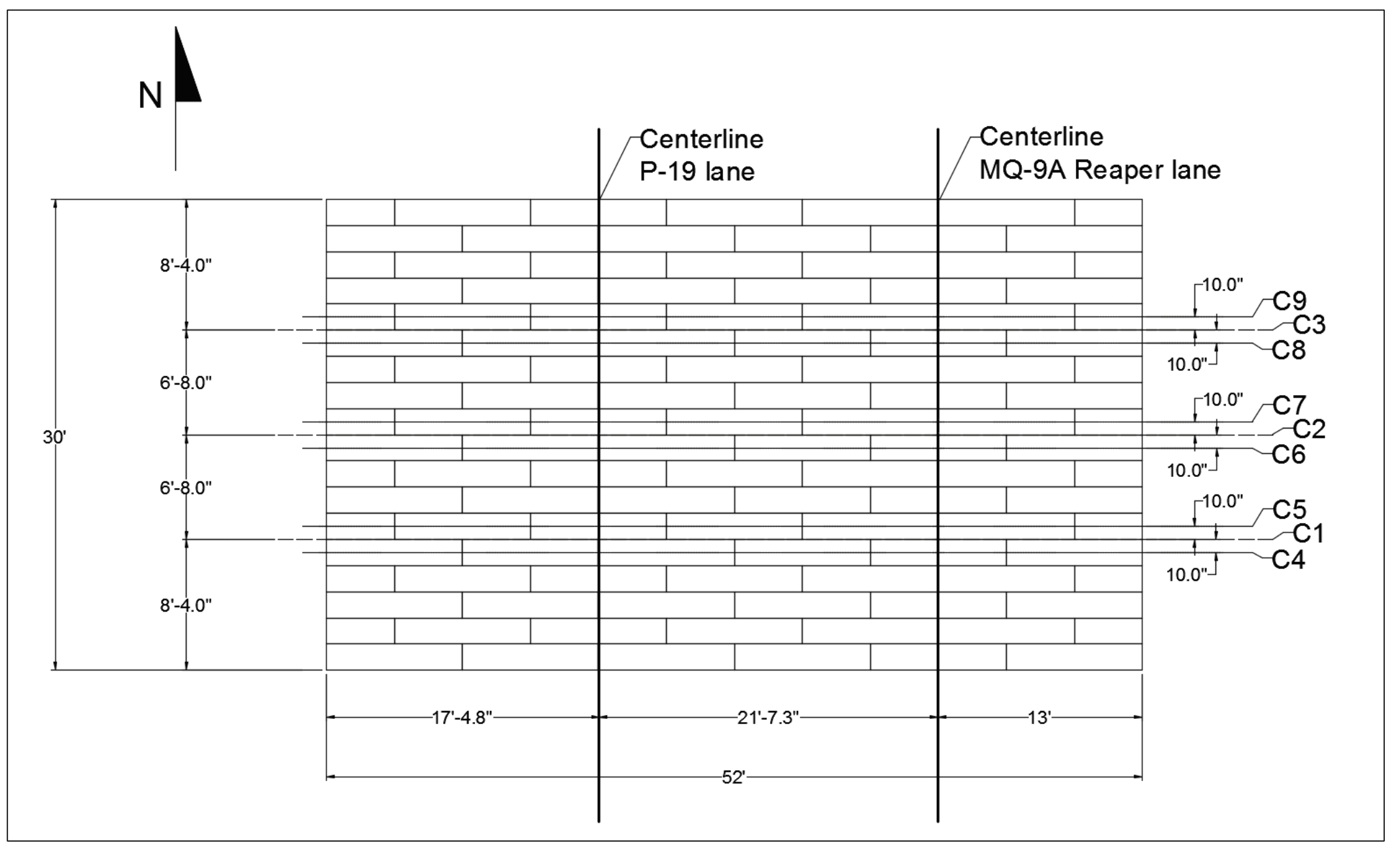


Figure B.4. Data collection locations on DuraDeck test item.

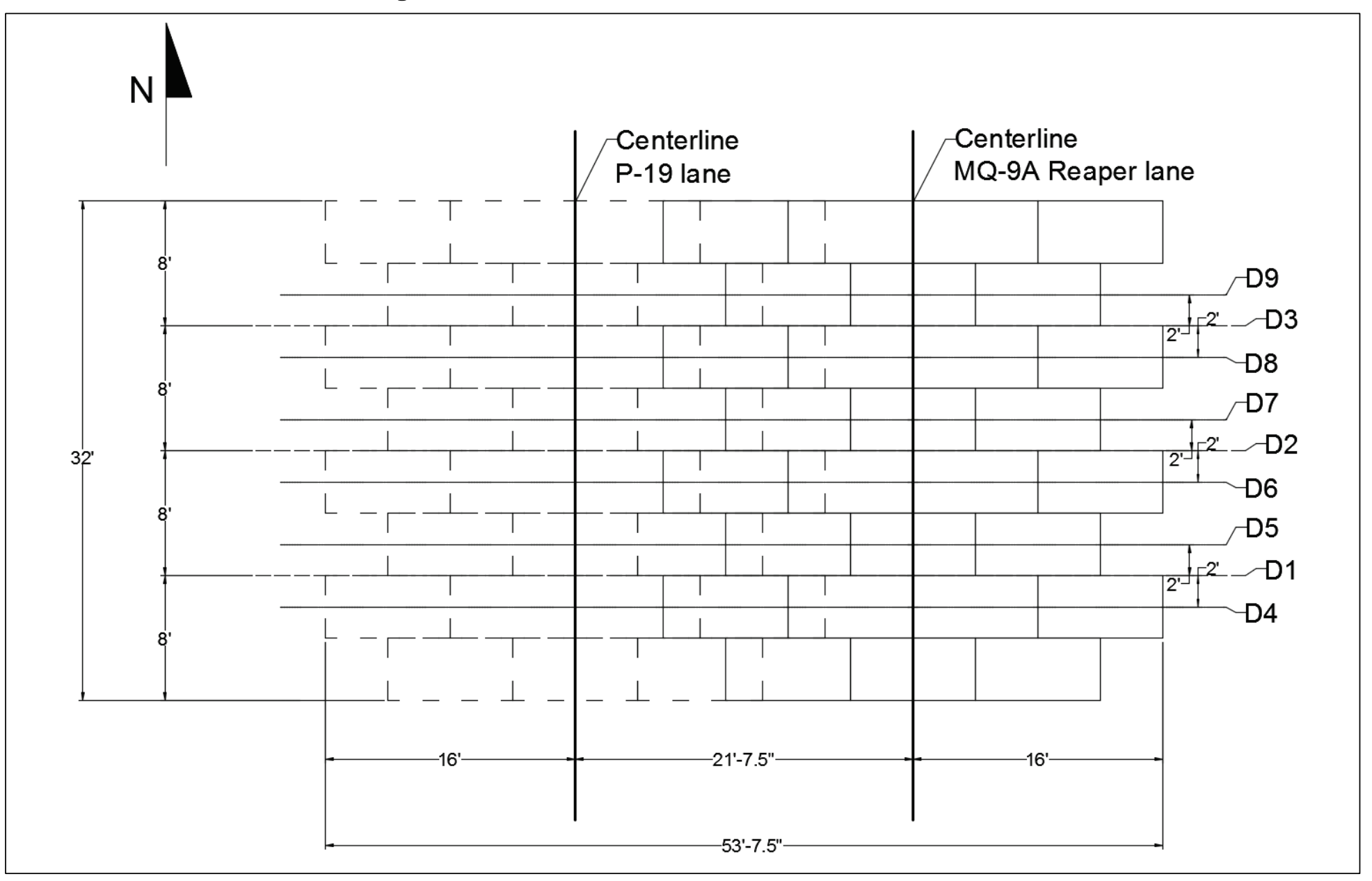




\section{Appendix C: Hangar 2 Foundation DCP Data}

This appendix shows DCP data collected on the Hangar 2 natural foundation. Material classification, strength, and other properties are provided in Chapter 2.

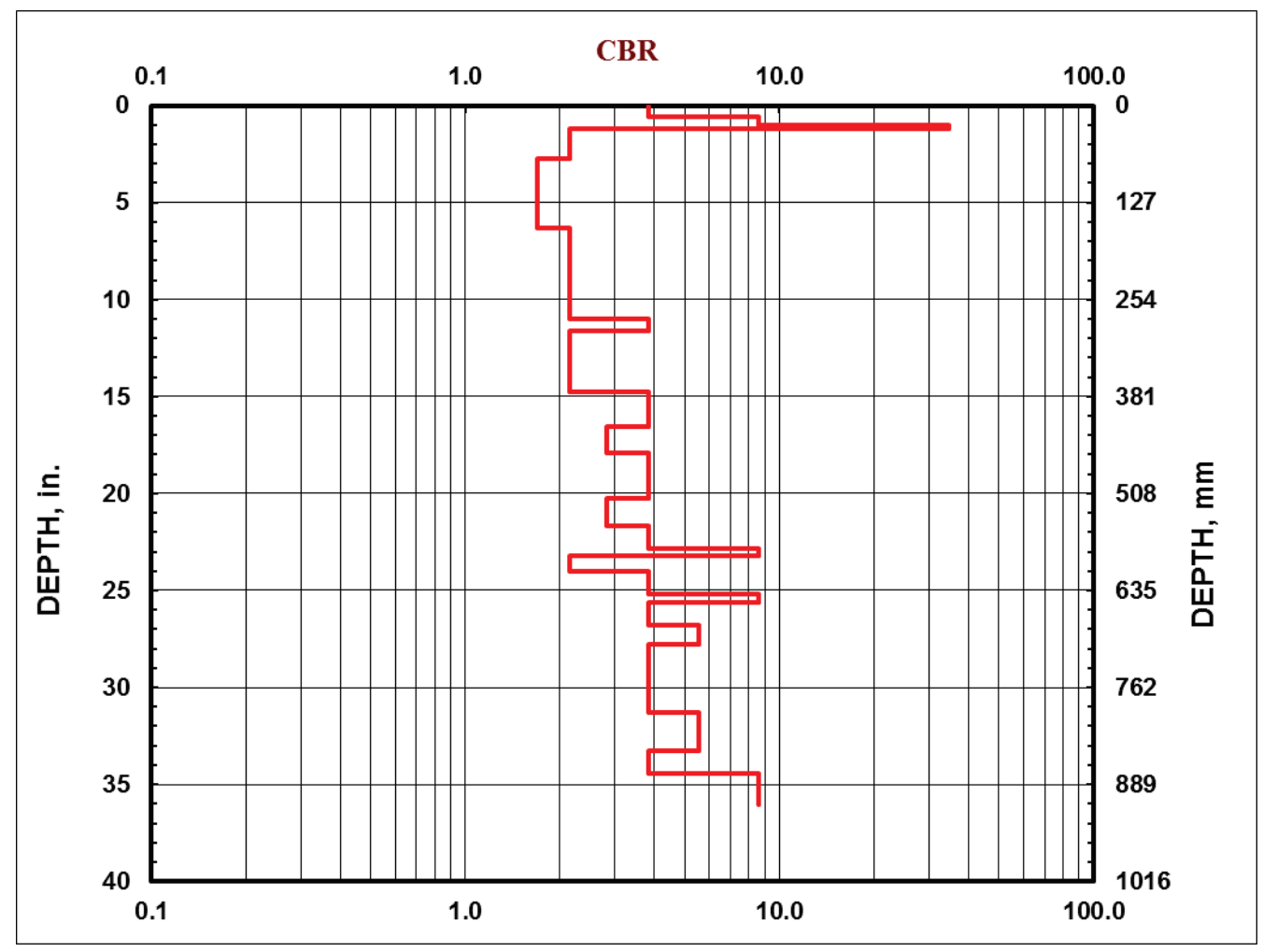



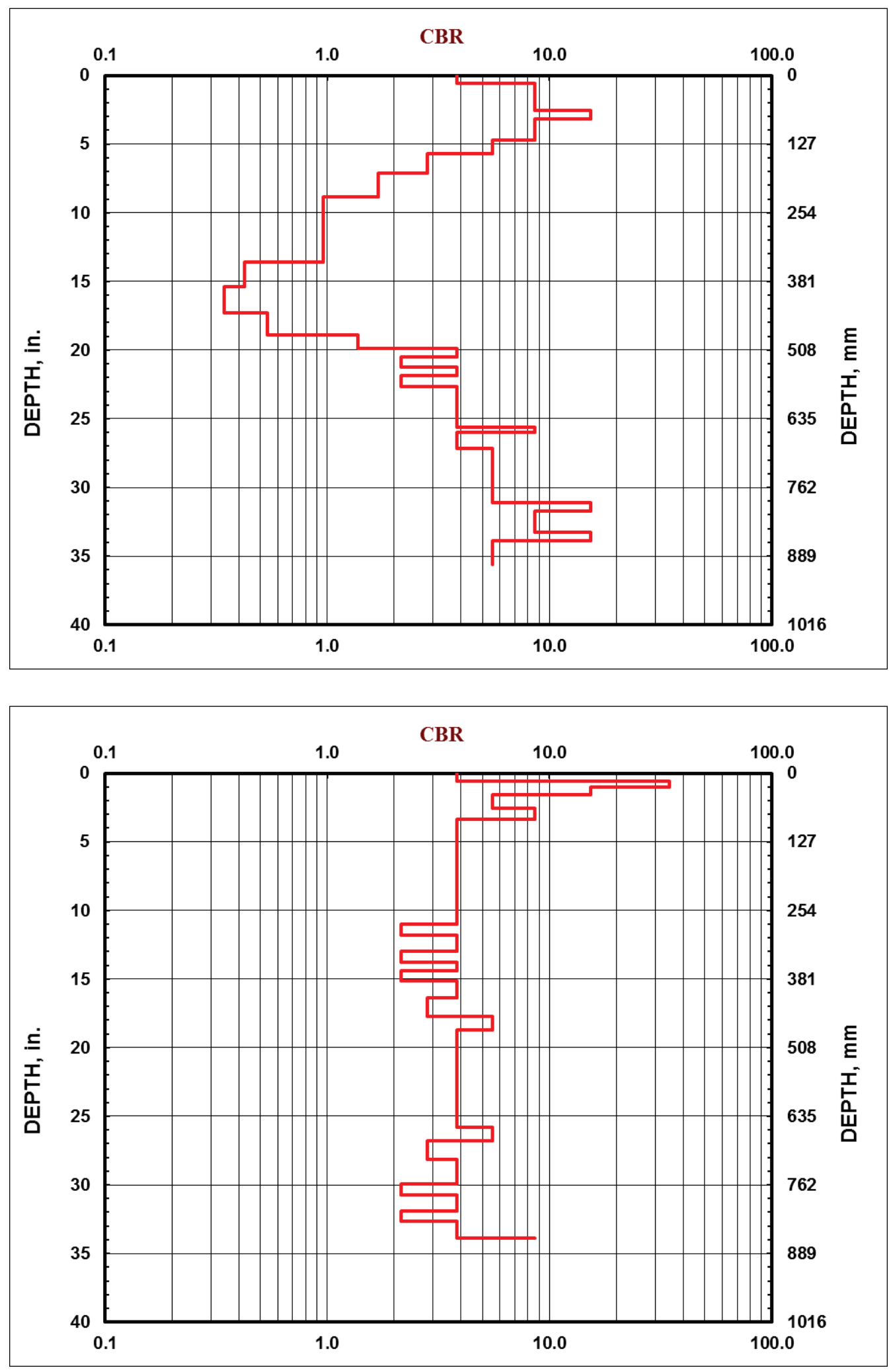

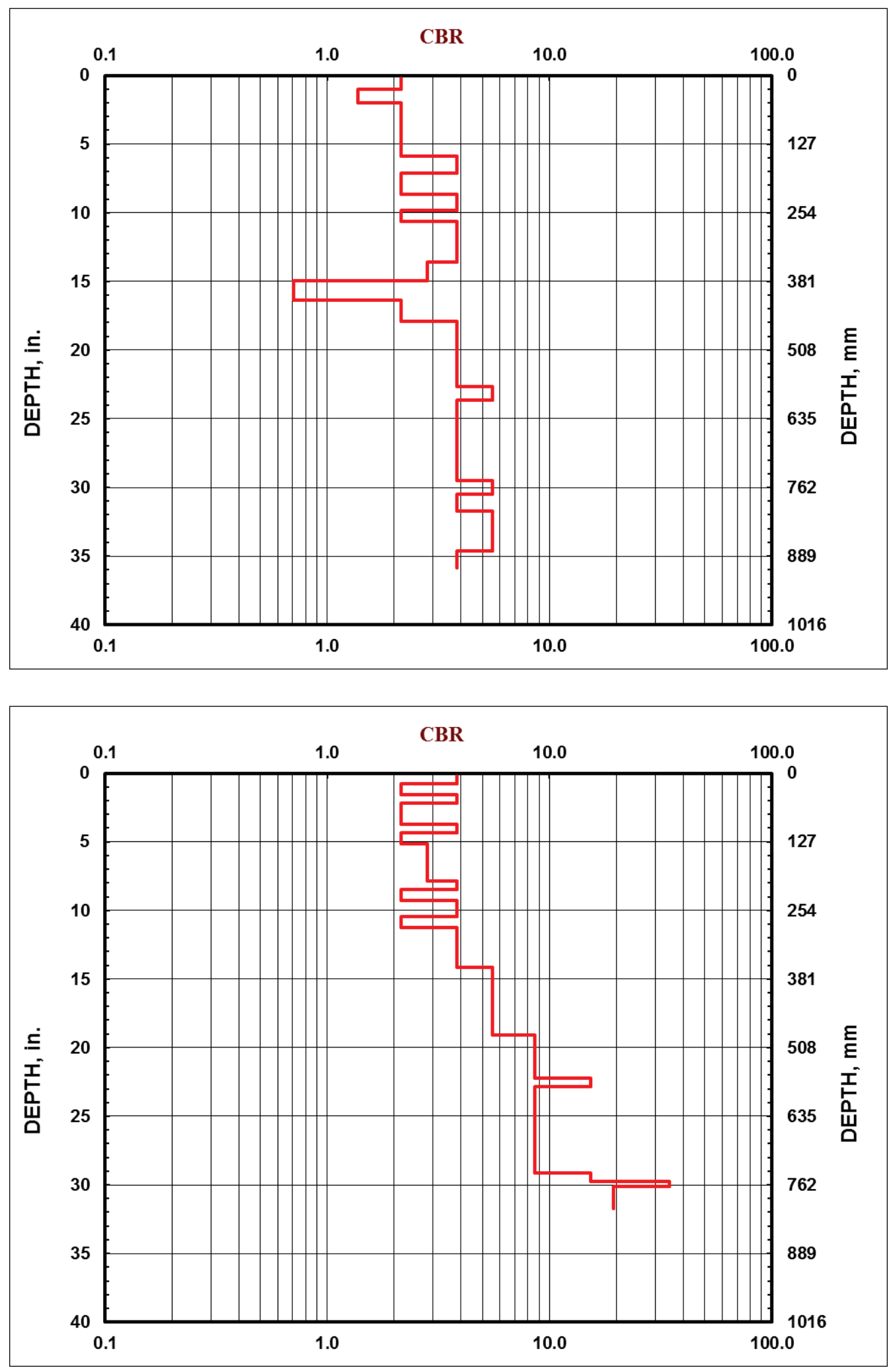


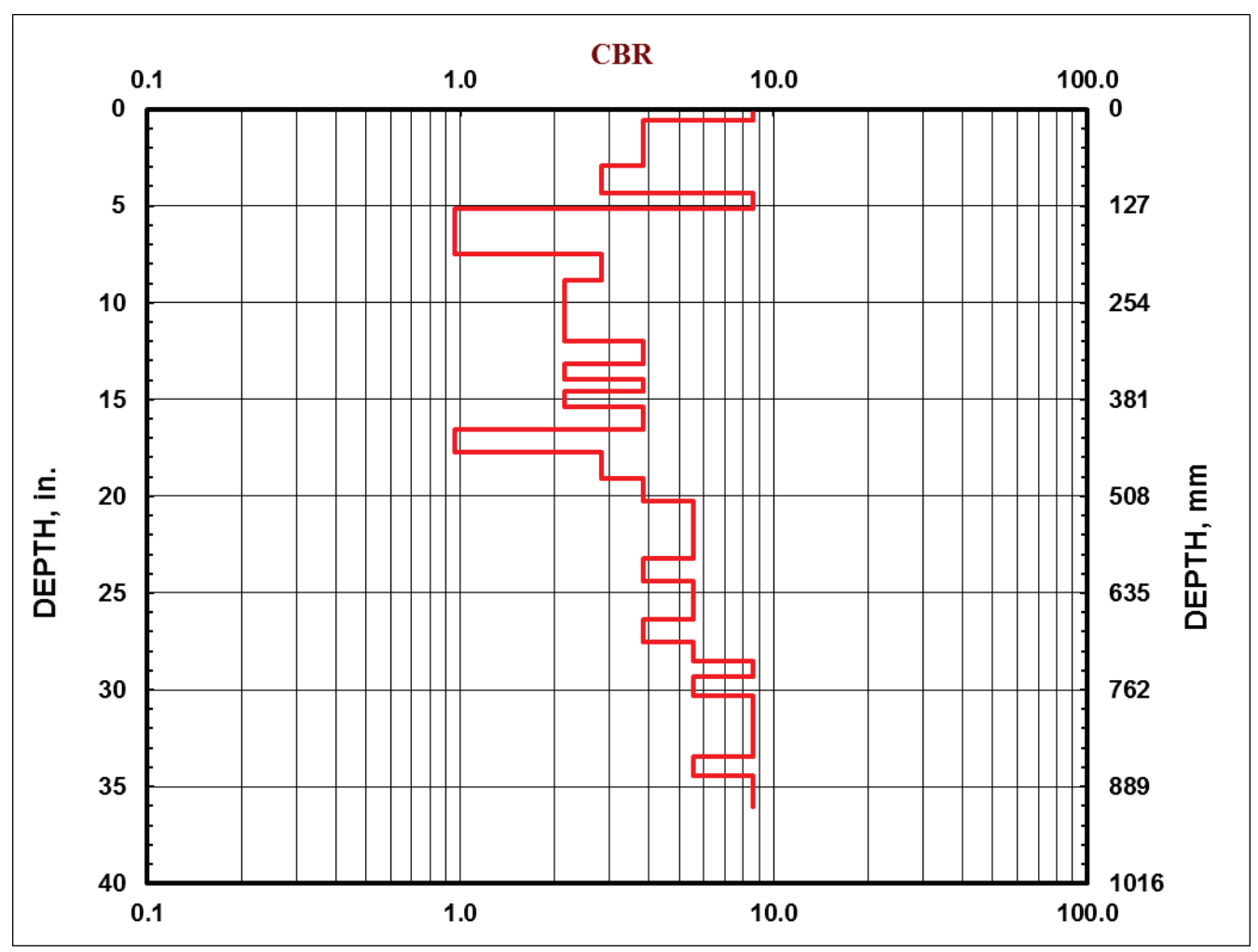




\section{Appendix D: ML Backfill DCP Data}

This appendix shows DCP data collected on the Hangar 2 low plasticity silt (ML) compacted backfill. Material classification, strength, and other properties are provided in Chapter 2. Note that the ML backfill was $2 \mathrm{ft}$ thick, and the material underneath is the natural material at Hangar 2.
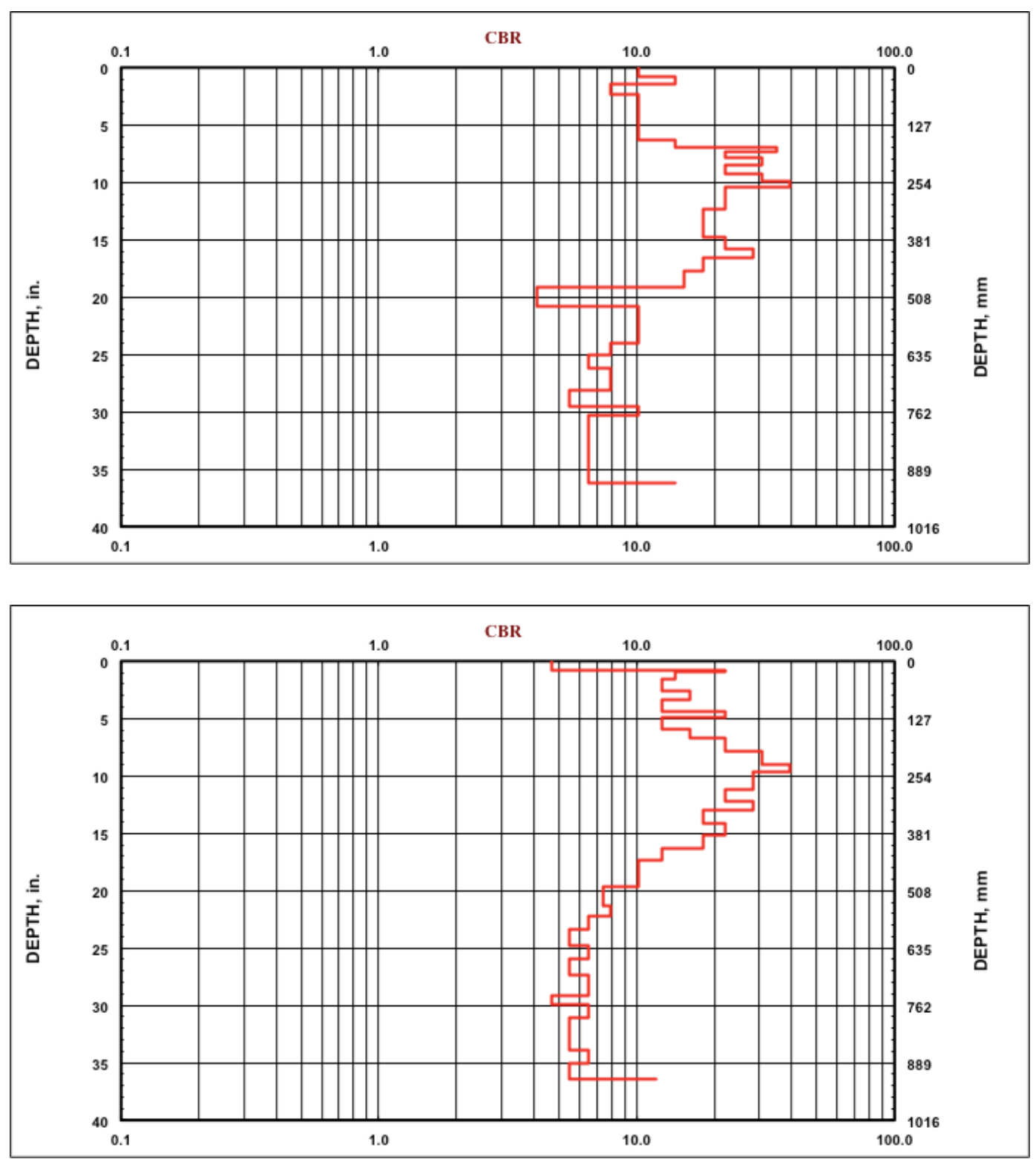

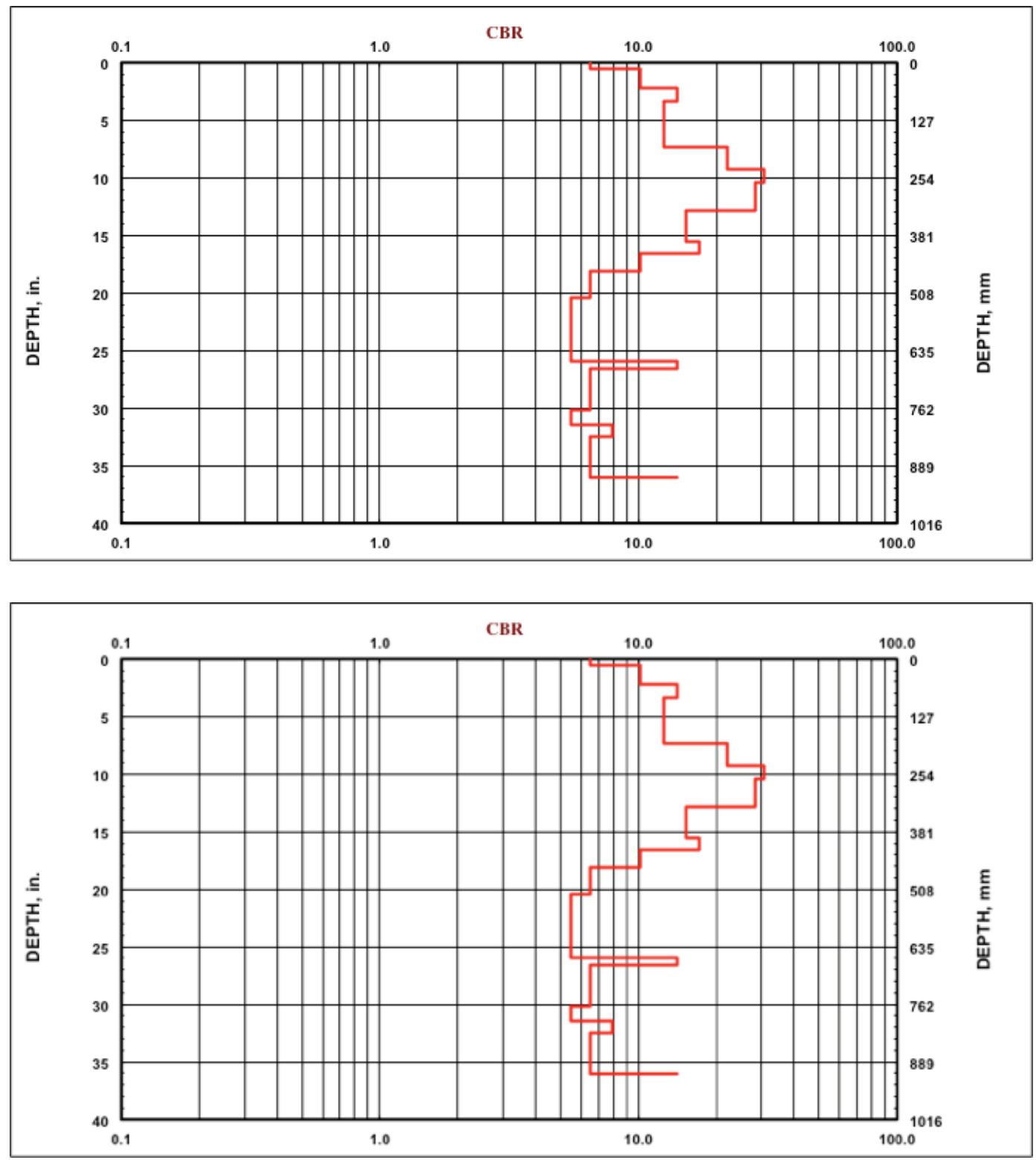

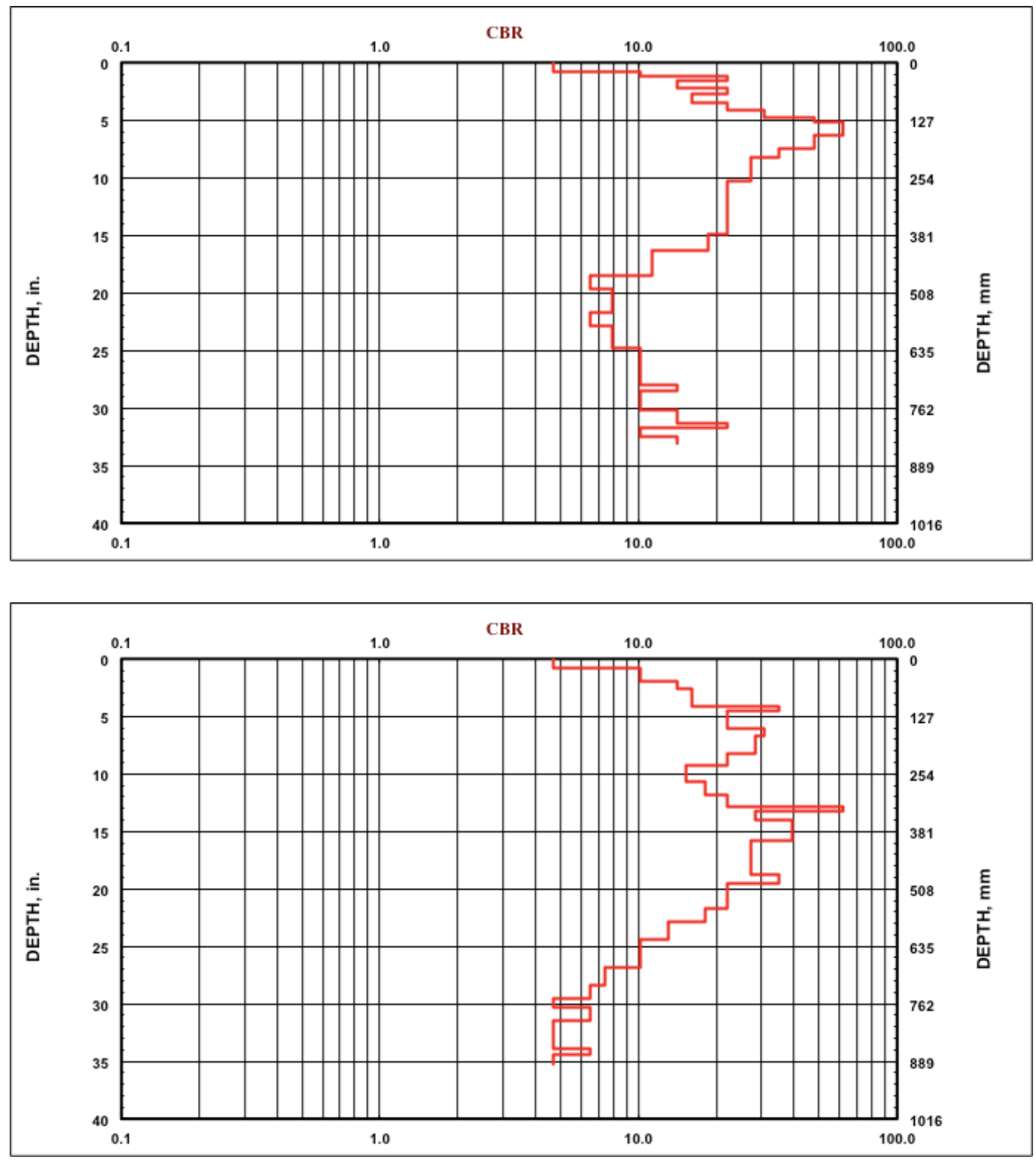

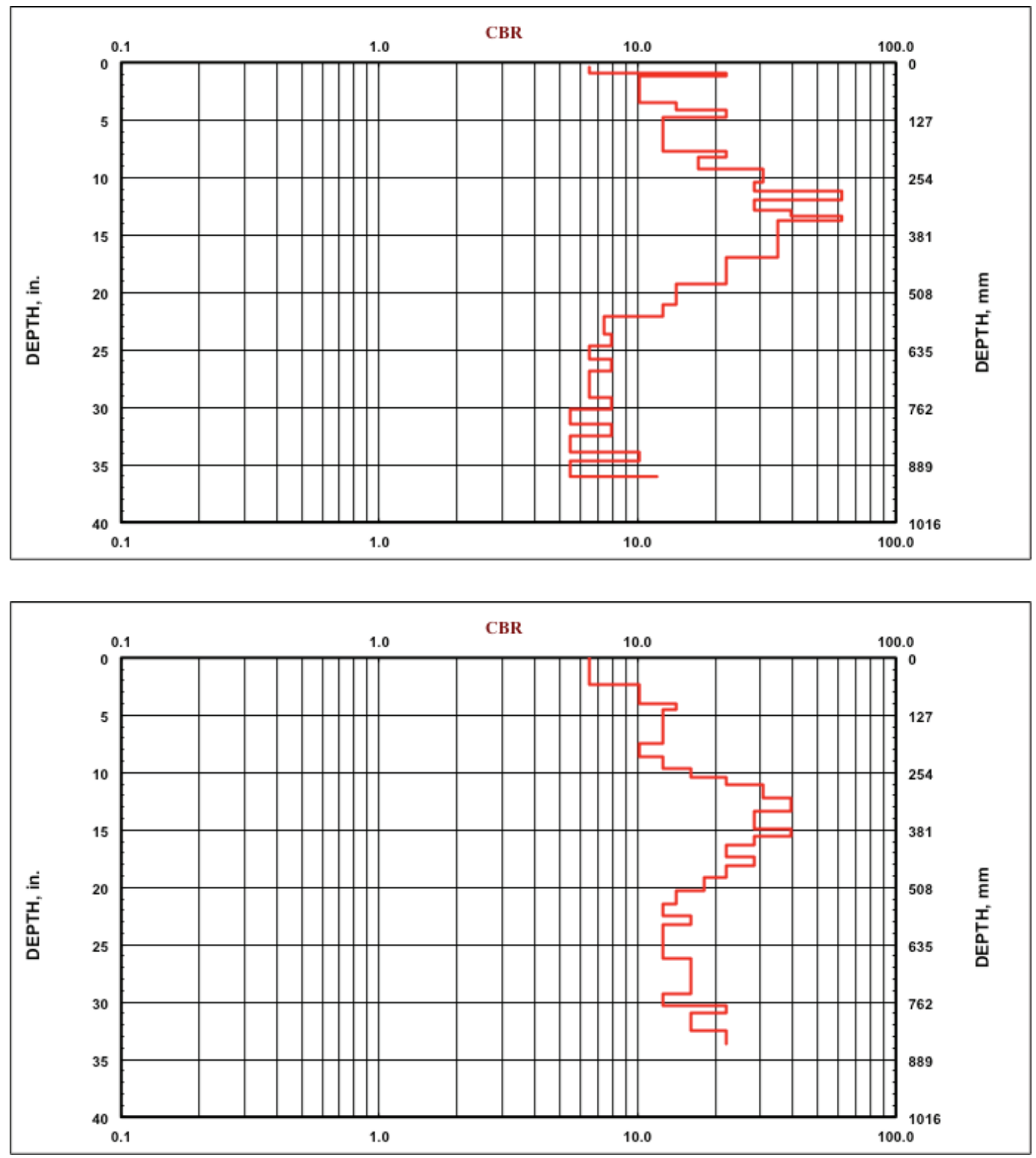


\section{Appendix E: MQ-9A Reaper Lane Trafficking Data}

This appendix shows data collected along the centerline on the mat surface and along the cross sections of the unloaded mat surface for each of the test items in the MQ-9A Reaper lane. The remainder of the data is in Chapter 5 .

Figure E.1. Average deformation along centerline of PSA-FT mat surface - MQ-9A Reaper lane.

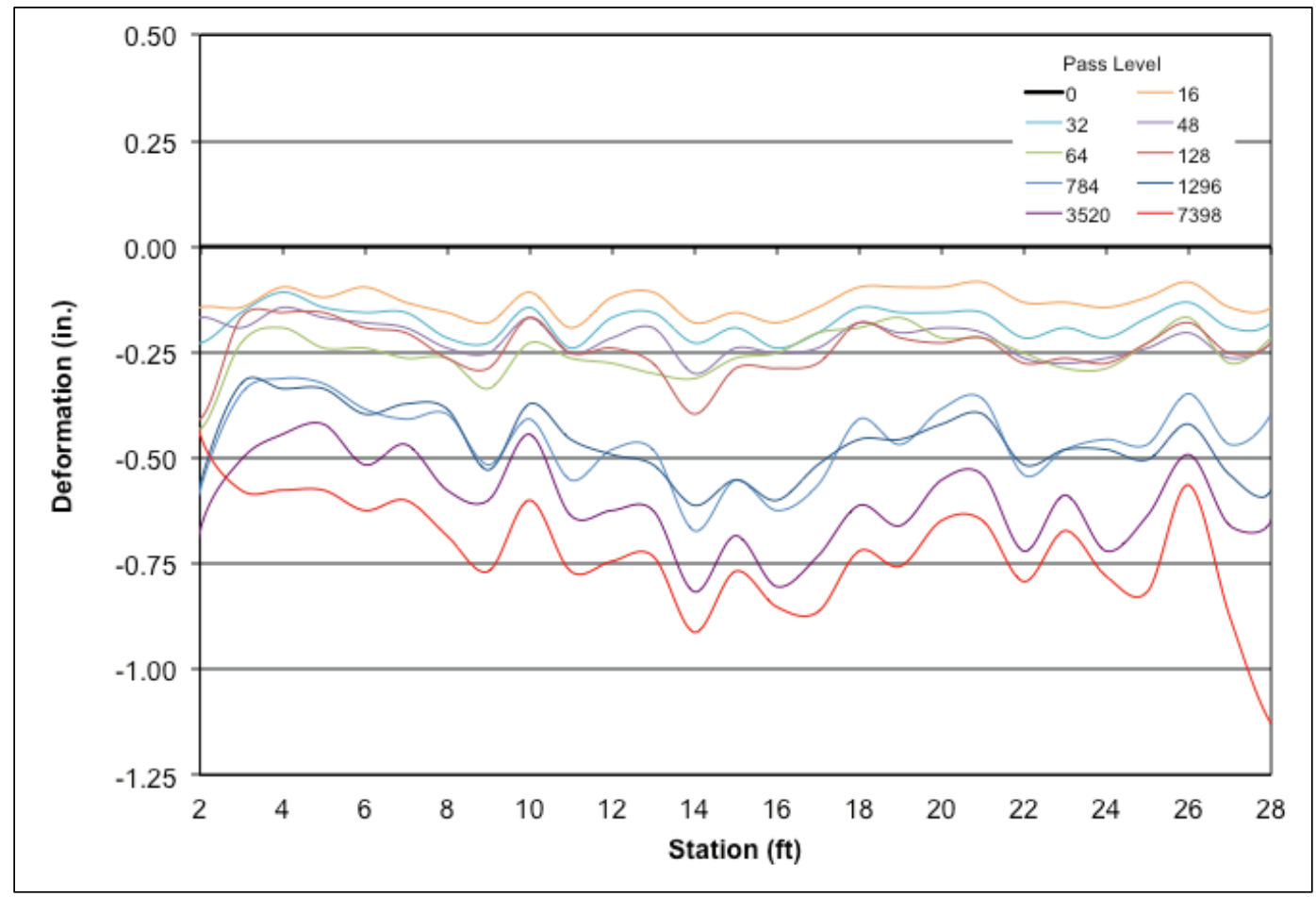


Figure E.2. Average deformation along centerline of PSA-FT-R mat surface - MQ-9A Reaper lane.

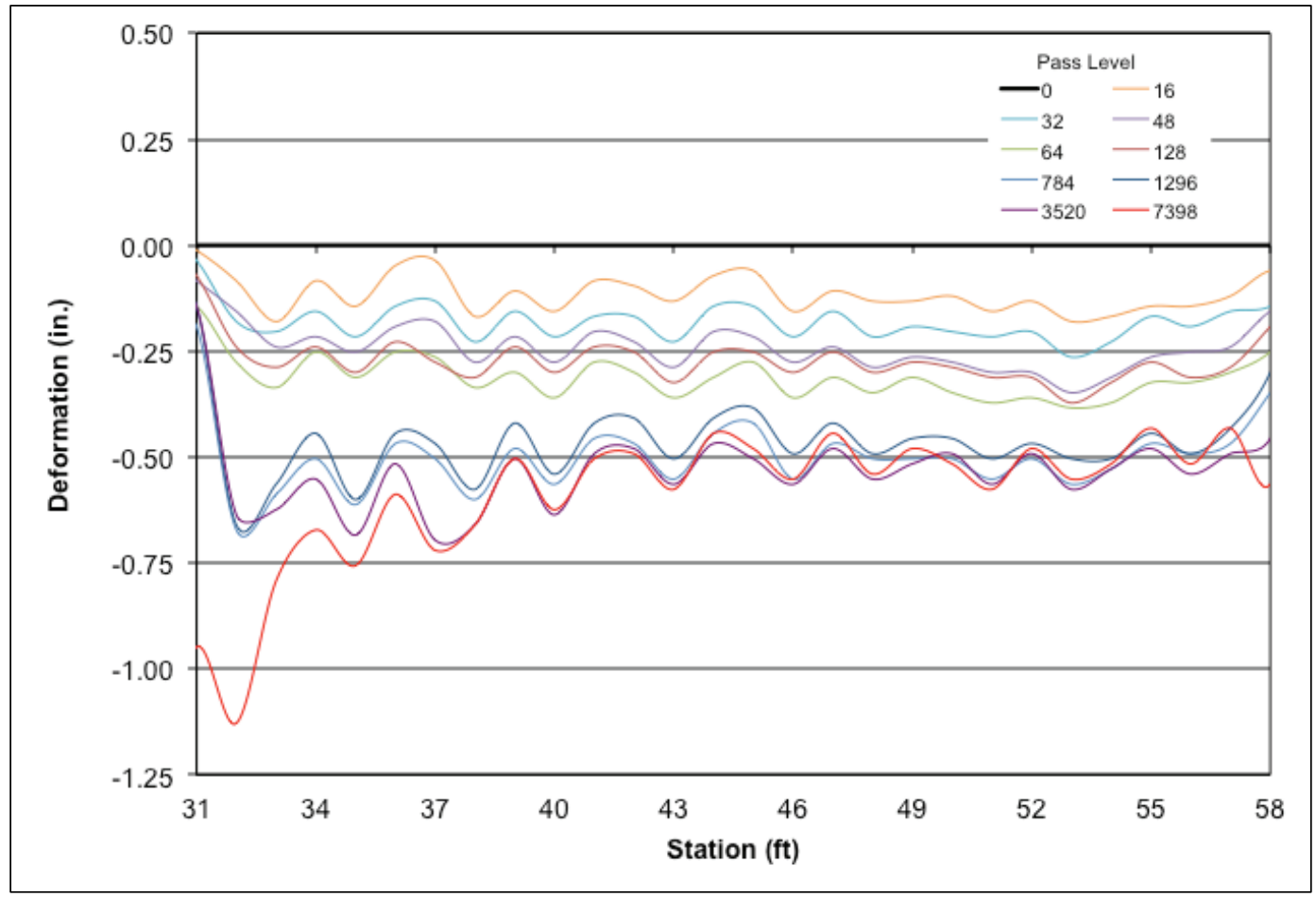

Figure E.3. Average deformation along centerline profile of ALMATS mat surface - MQ-9A Reaper lane.

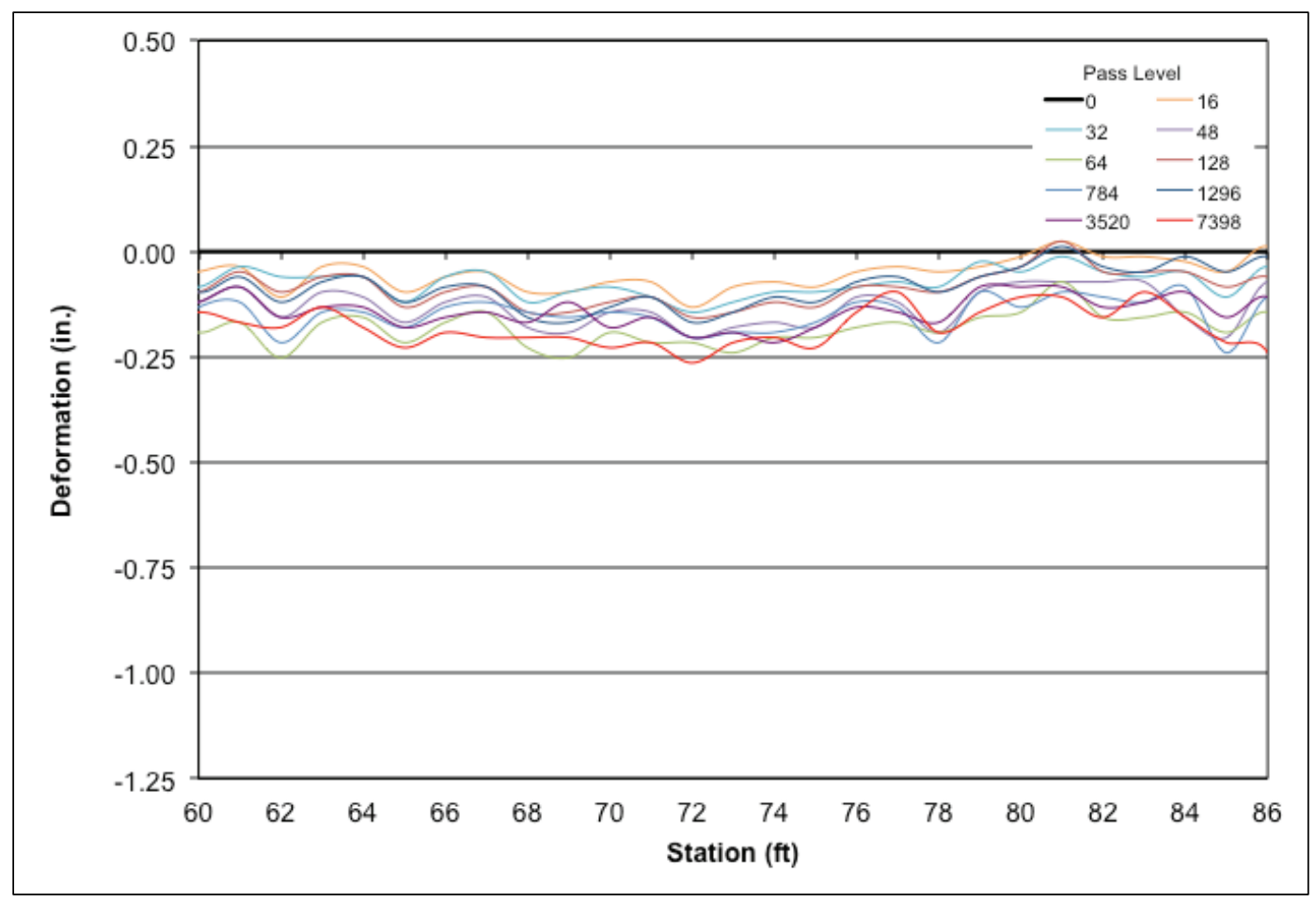


Figure E.4. Average deformation along centerline of DuraDeck mat surface- MQ-9A Reaper lane.

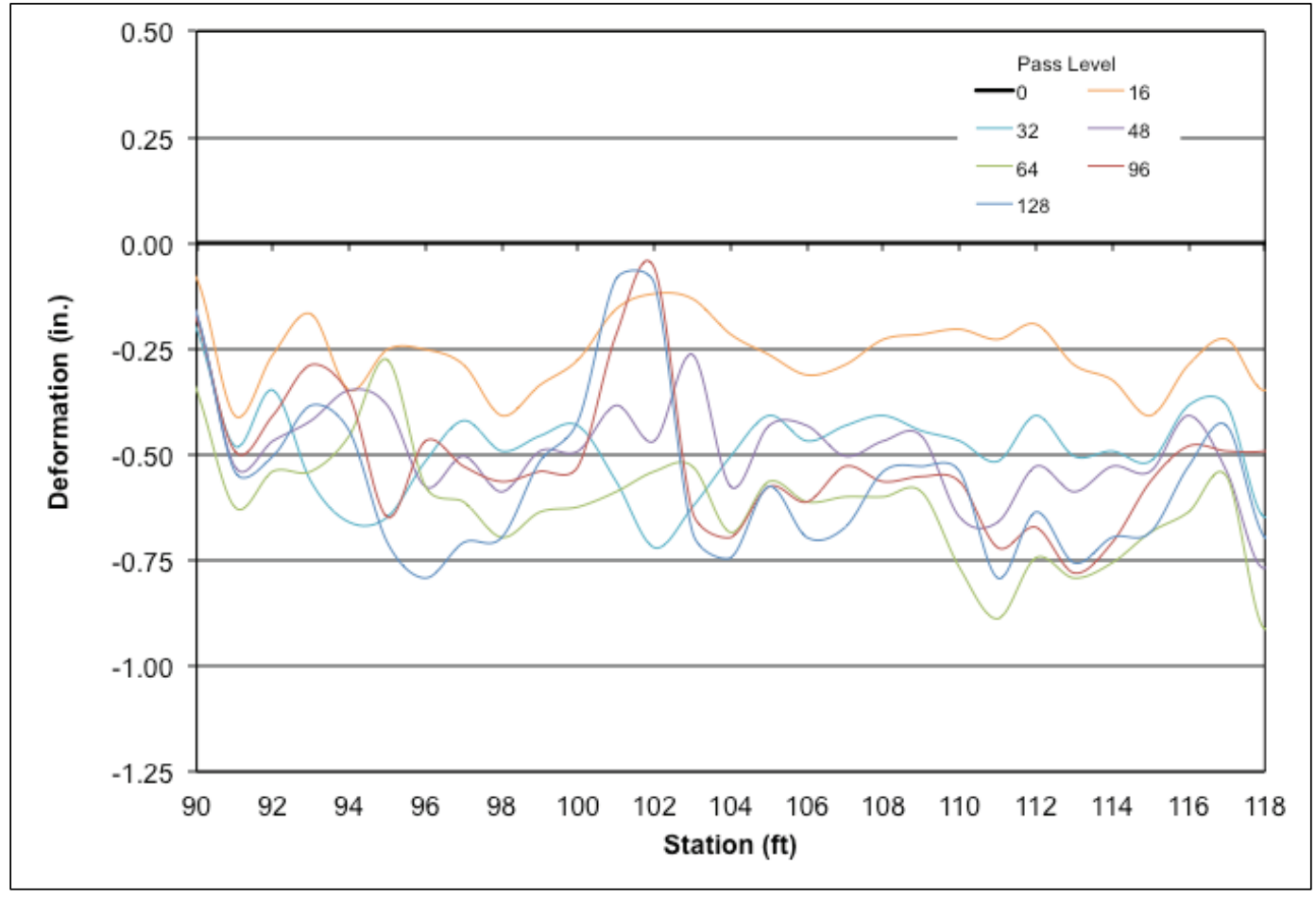

Figure E.5. Average deformation on the unloaded mat surface of PSA-FT - MQ-9A Reaper lane.

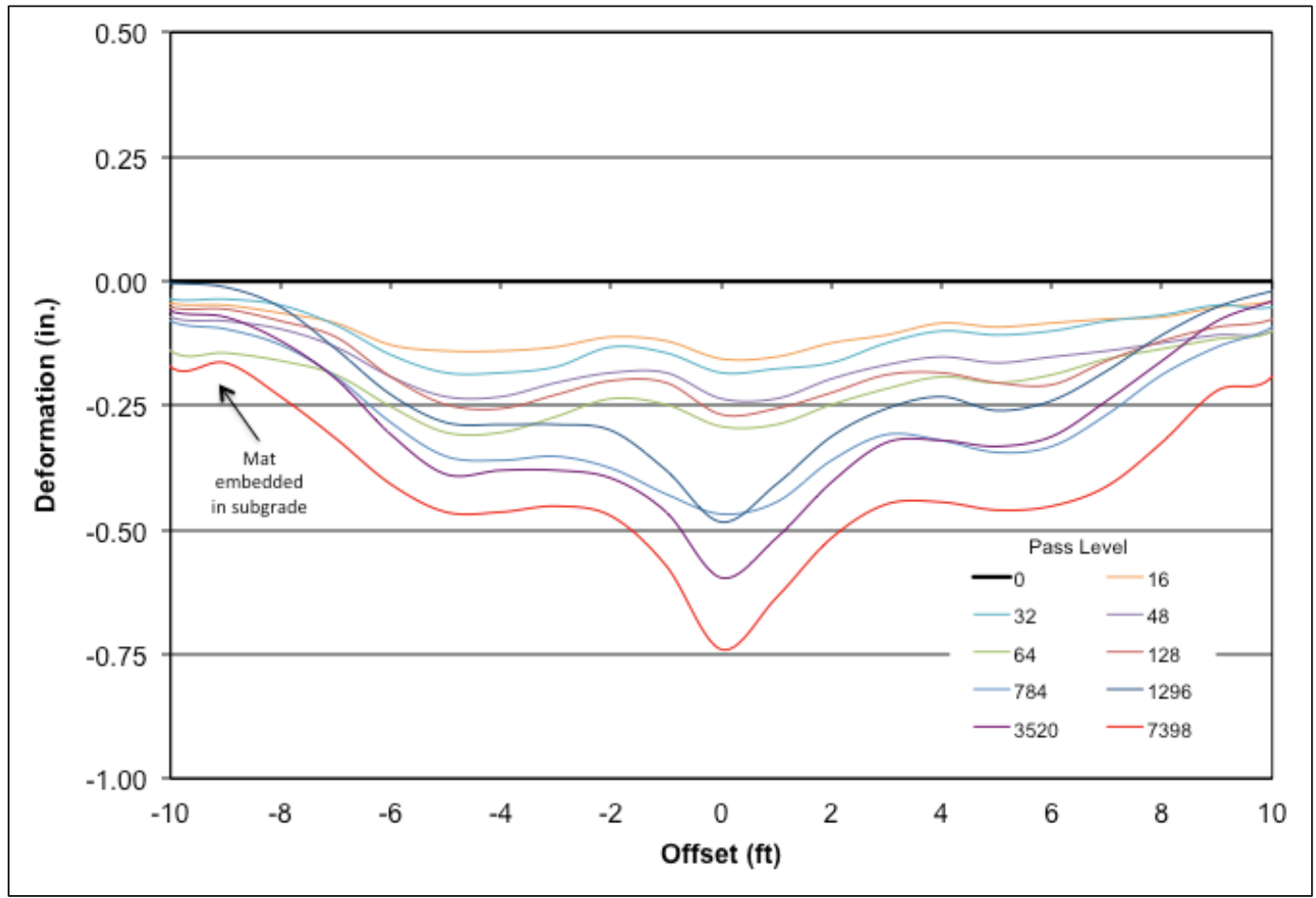


Figure E.6. Average deformation on the unloaded mat surface of PSA-FT-R - MQ-9A Reaper lane.

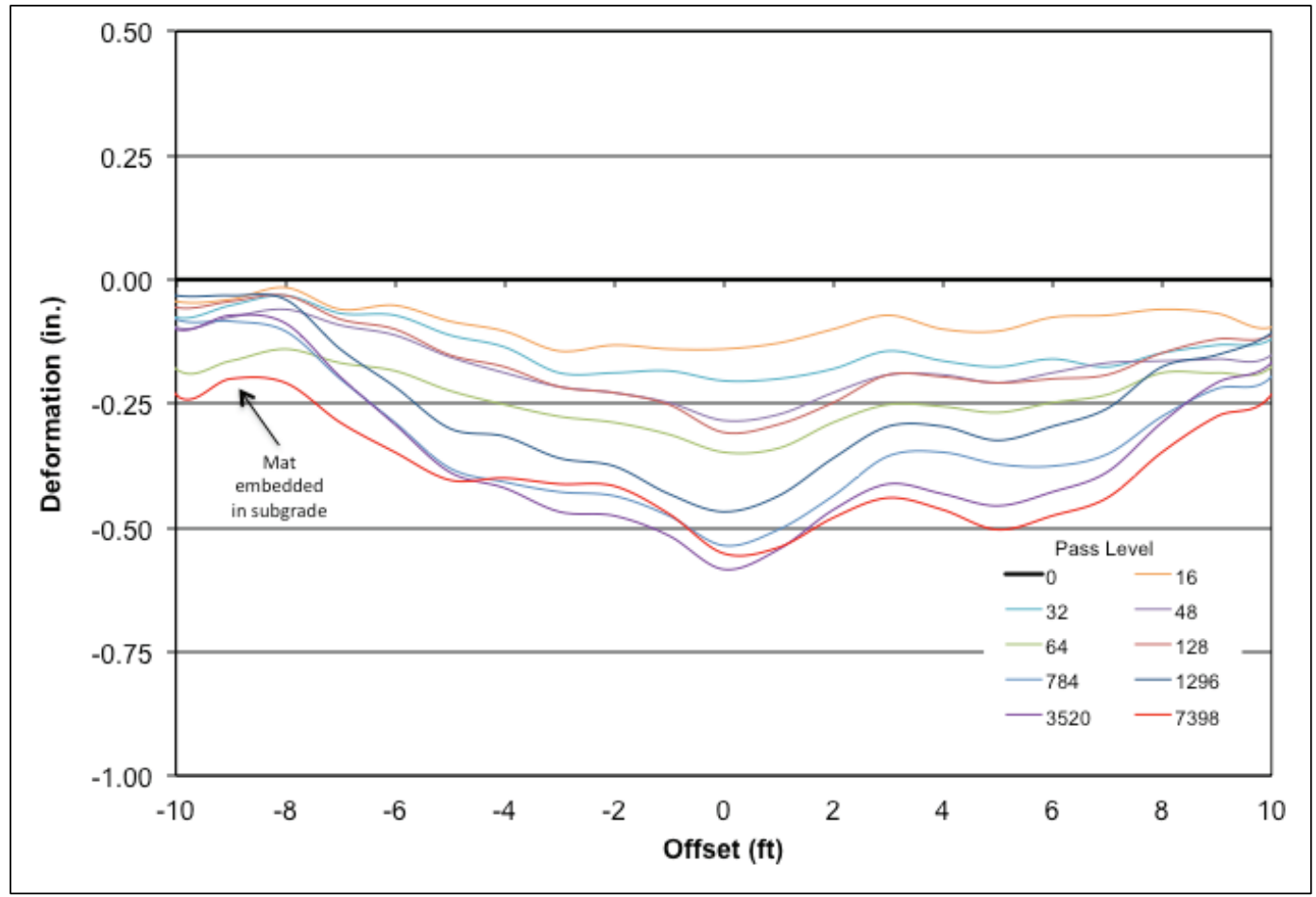

Figure E.7. Average deformation on the unloaded mat surface of ALMATS - MQ-9A Reaper lane.

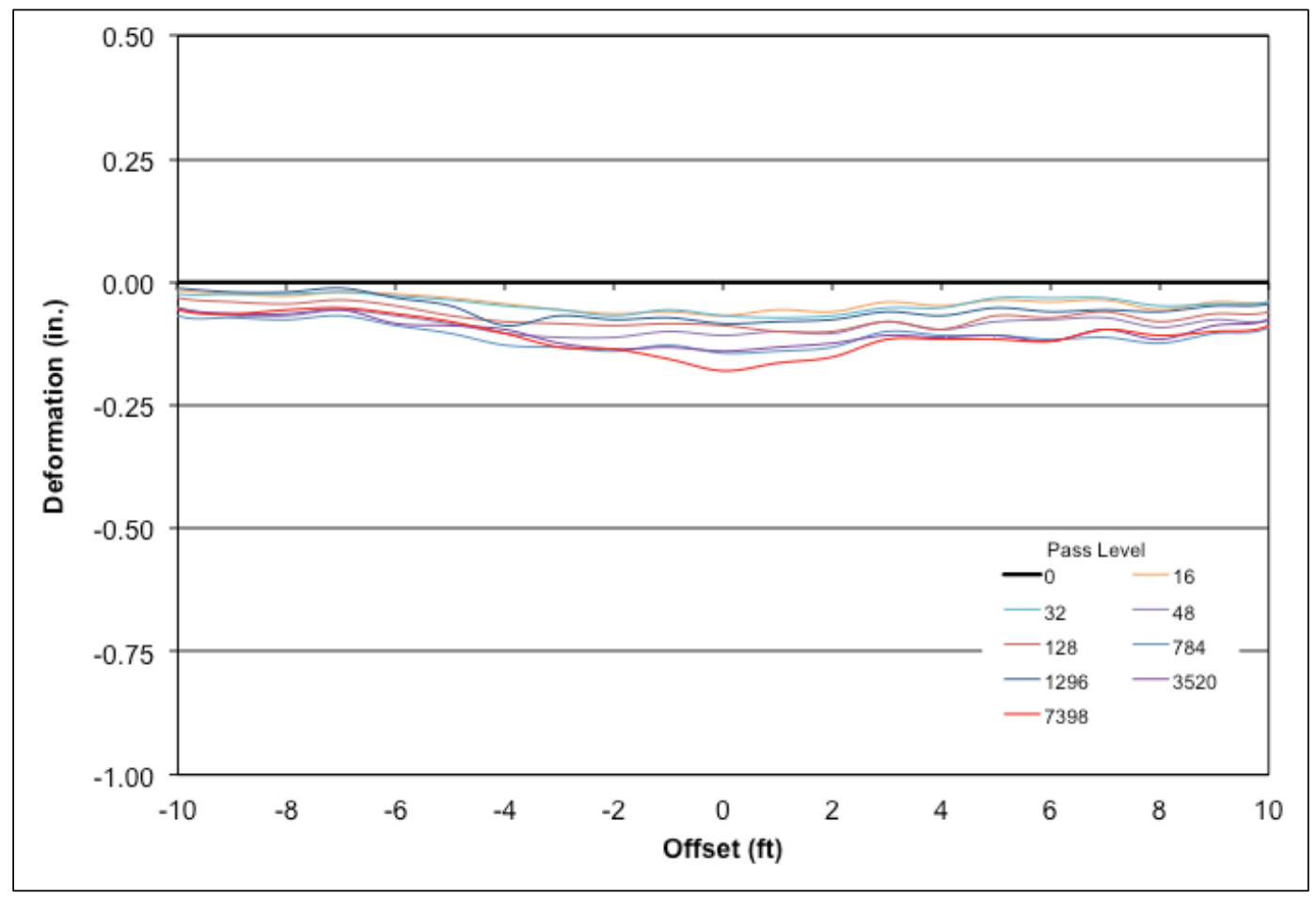


Figure E.8. Average deformation on the unloaded mat surface of DuraDeck - MQ-9A Reaper lane.

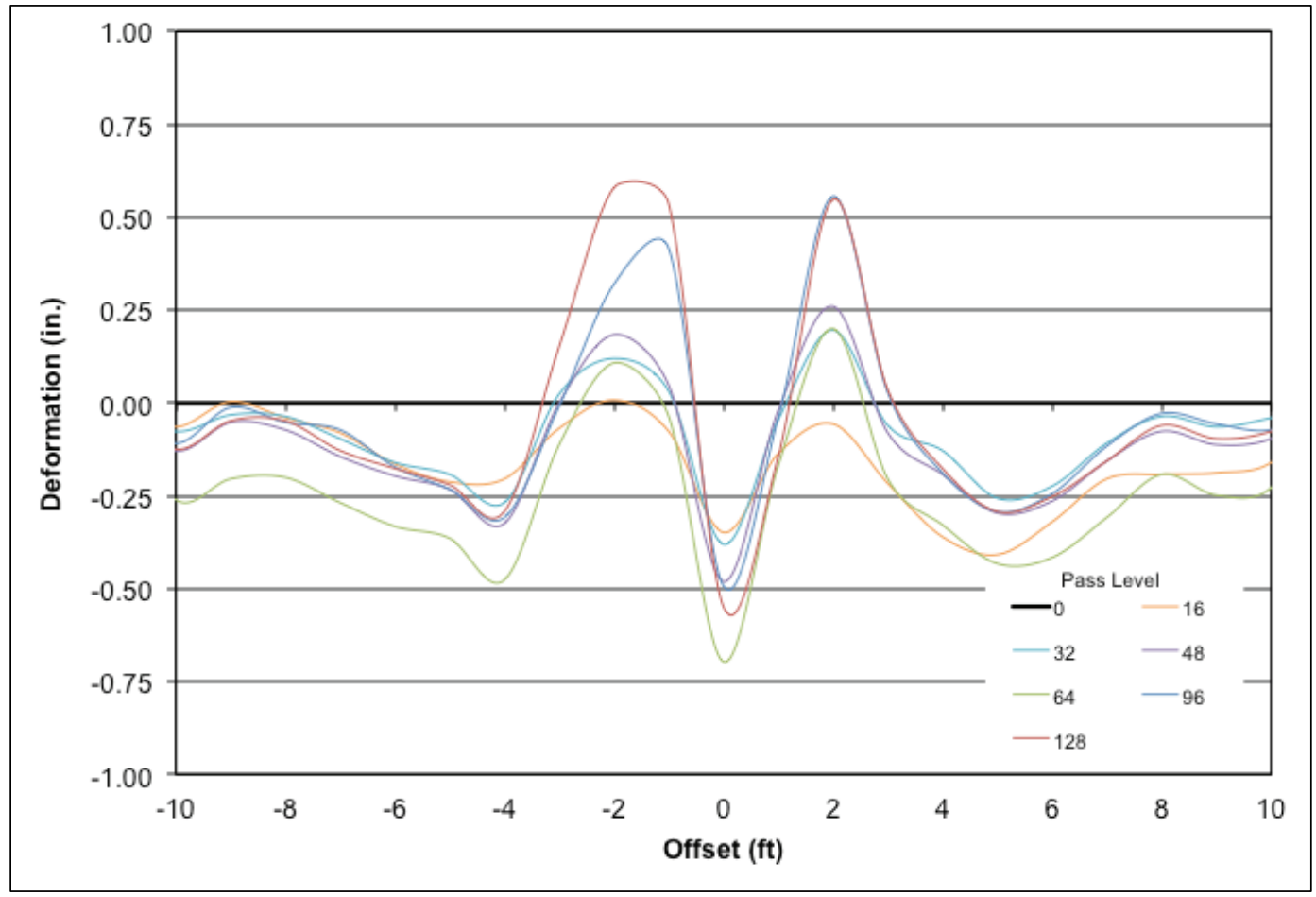

Figure E.9. Average maximum rut depth on the unloaded mat surface - MQ-9A Reaper lane.

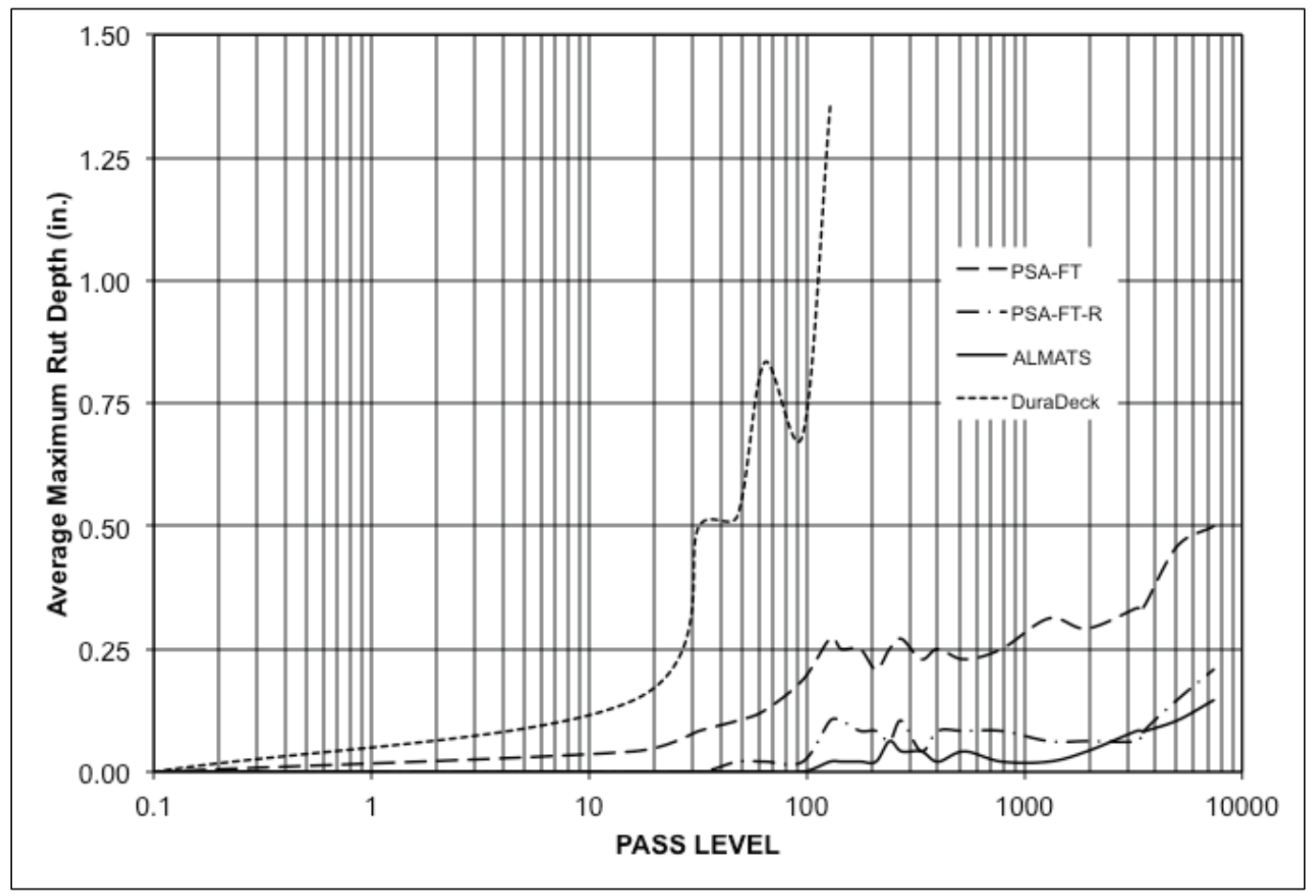




\section{Appendix F: P-19 Trafficking Data}

This appendix shows data collected along the centerline on the mat surface and along the cross sections of the unloaded mat surface for each of the test items in the P-19 lane. The remainder of the data is in Chapter 5 .

Figure F.1. Average deformation along centerline of PSA-FT mat surface - P-19 lane.

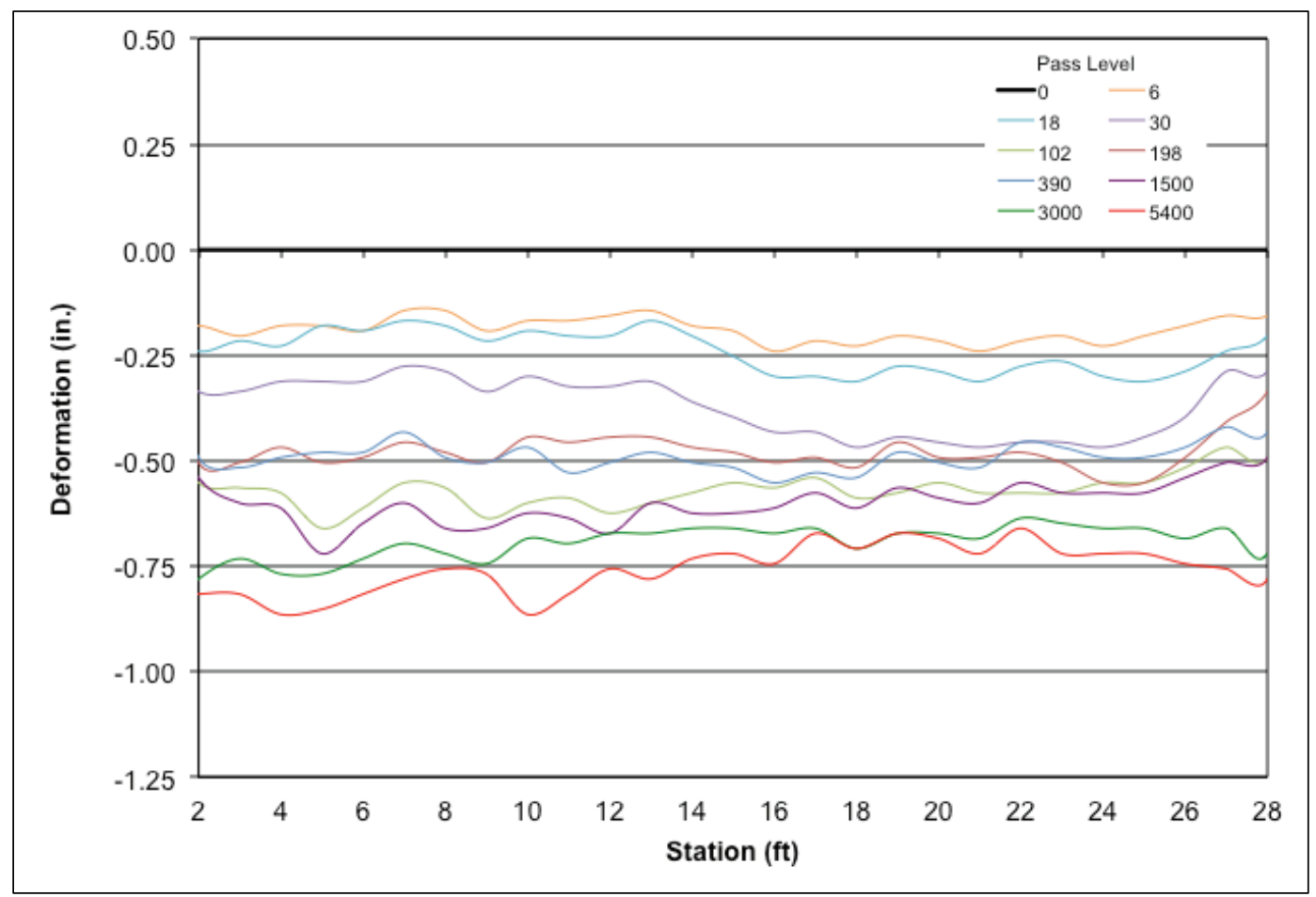


Figure F.2. Average deformation along centerline of PSA-FT-R mat surface - P-19 lane.

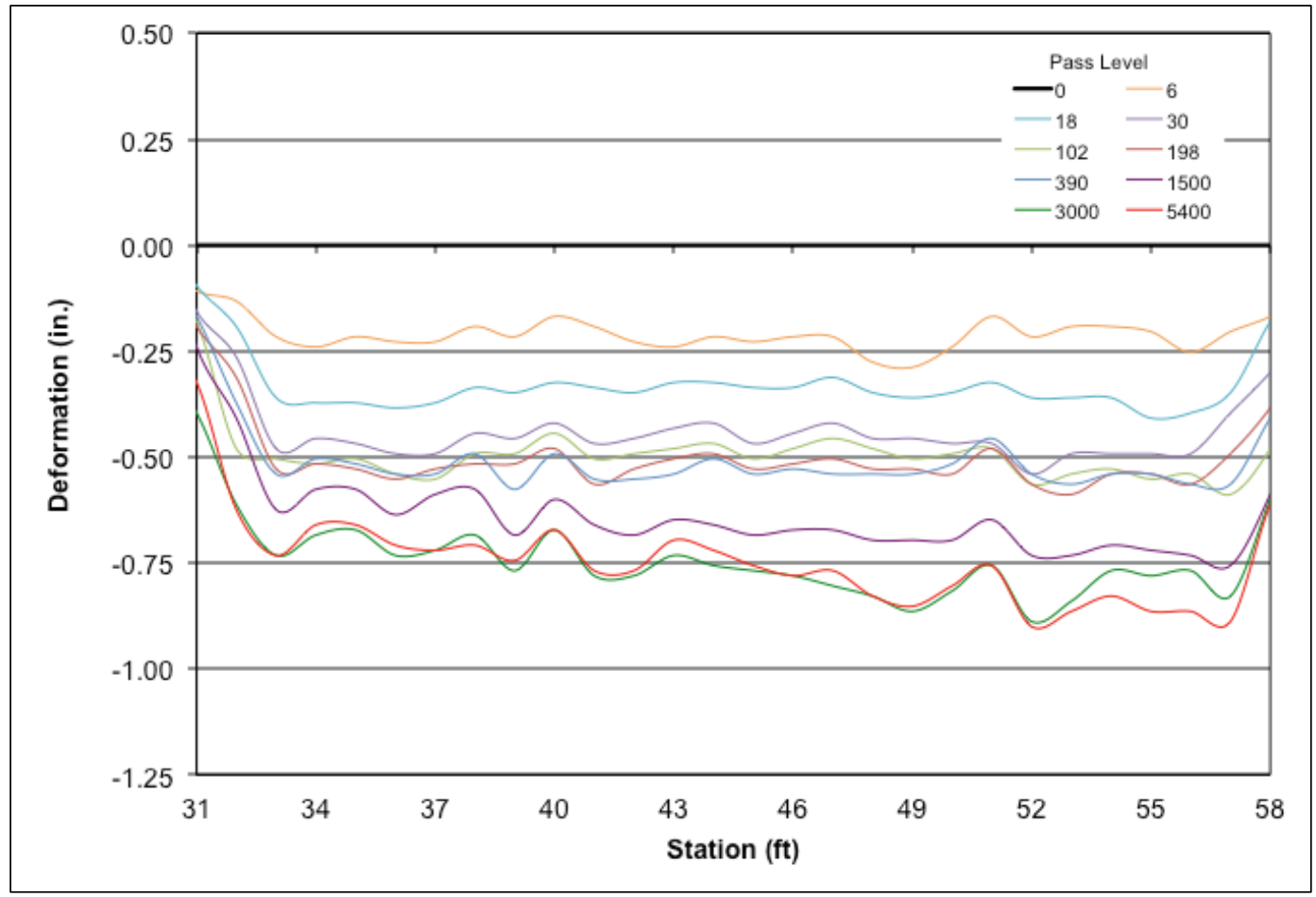

Figure F.3. Average deformation along centerline of ALMATS mat surface - P-19 lane.

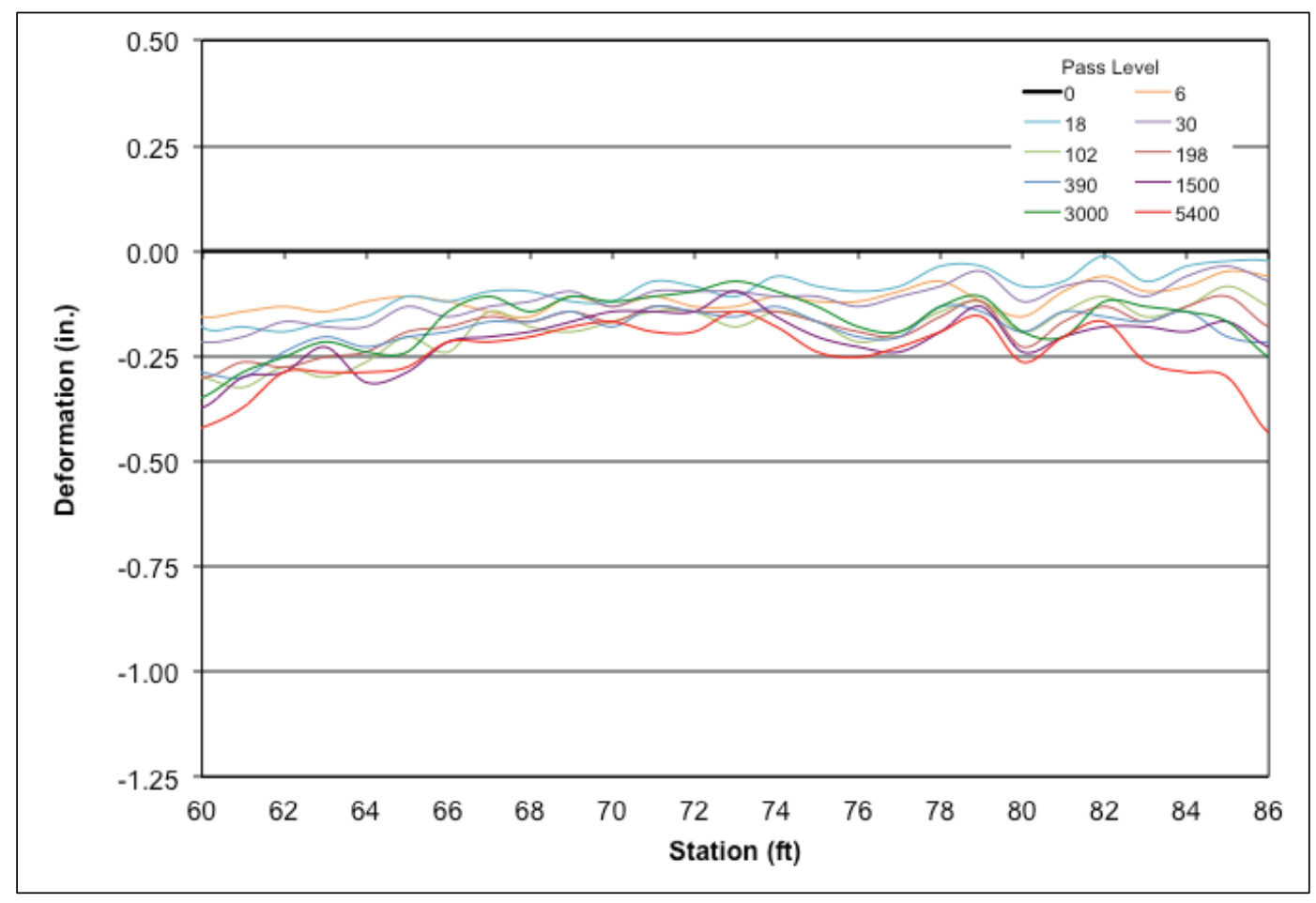


Figure F.4. Average deformation along centerline of DuraDeck mat surface - P-19 lane.

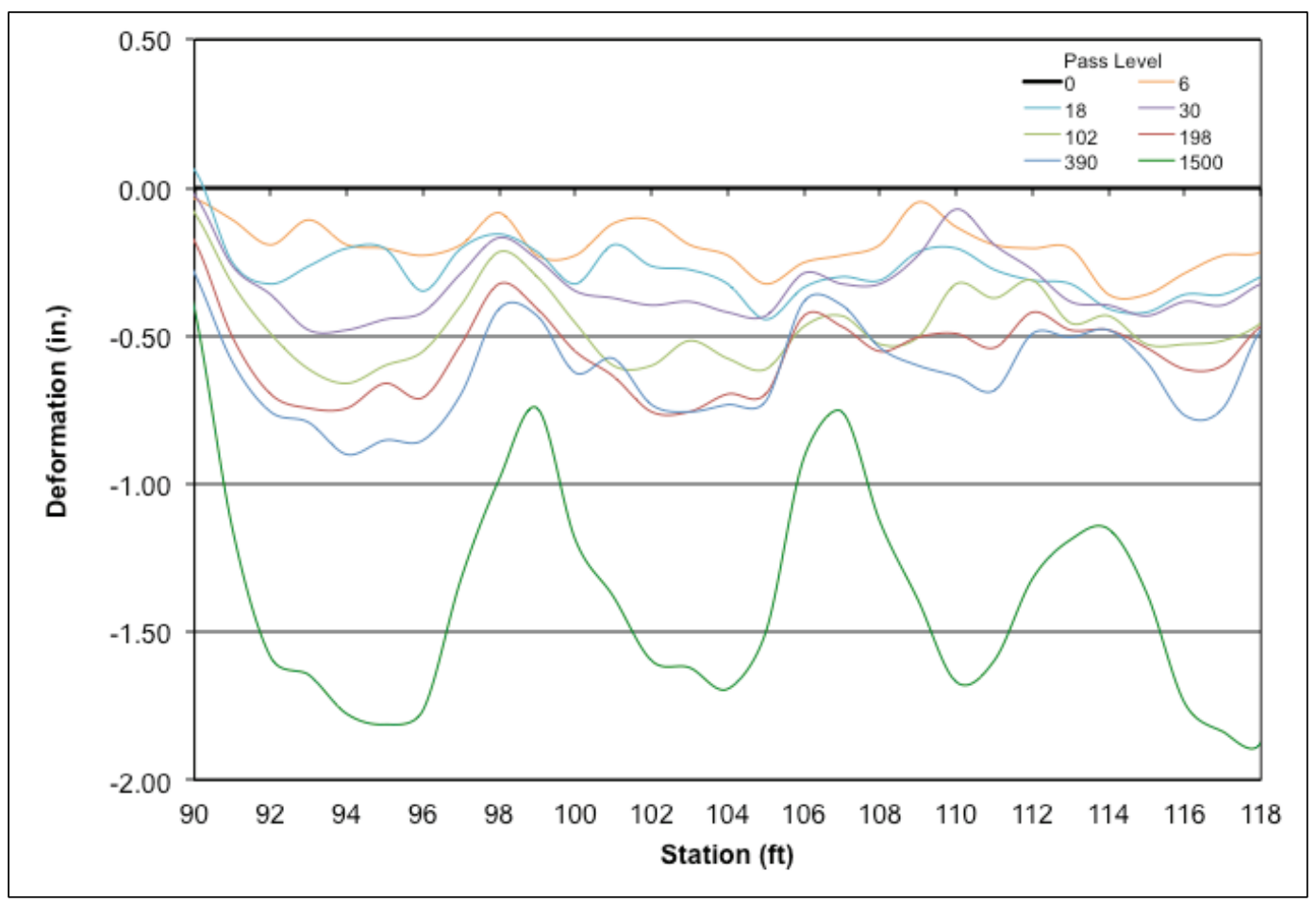

Figure F.5. Average deformation on the unloaded mat surface of PSA-FT - P-19 lane.

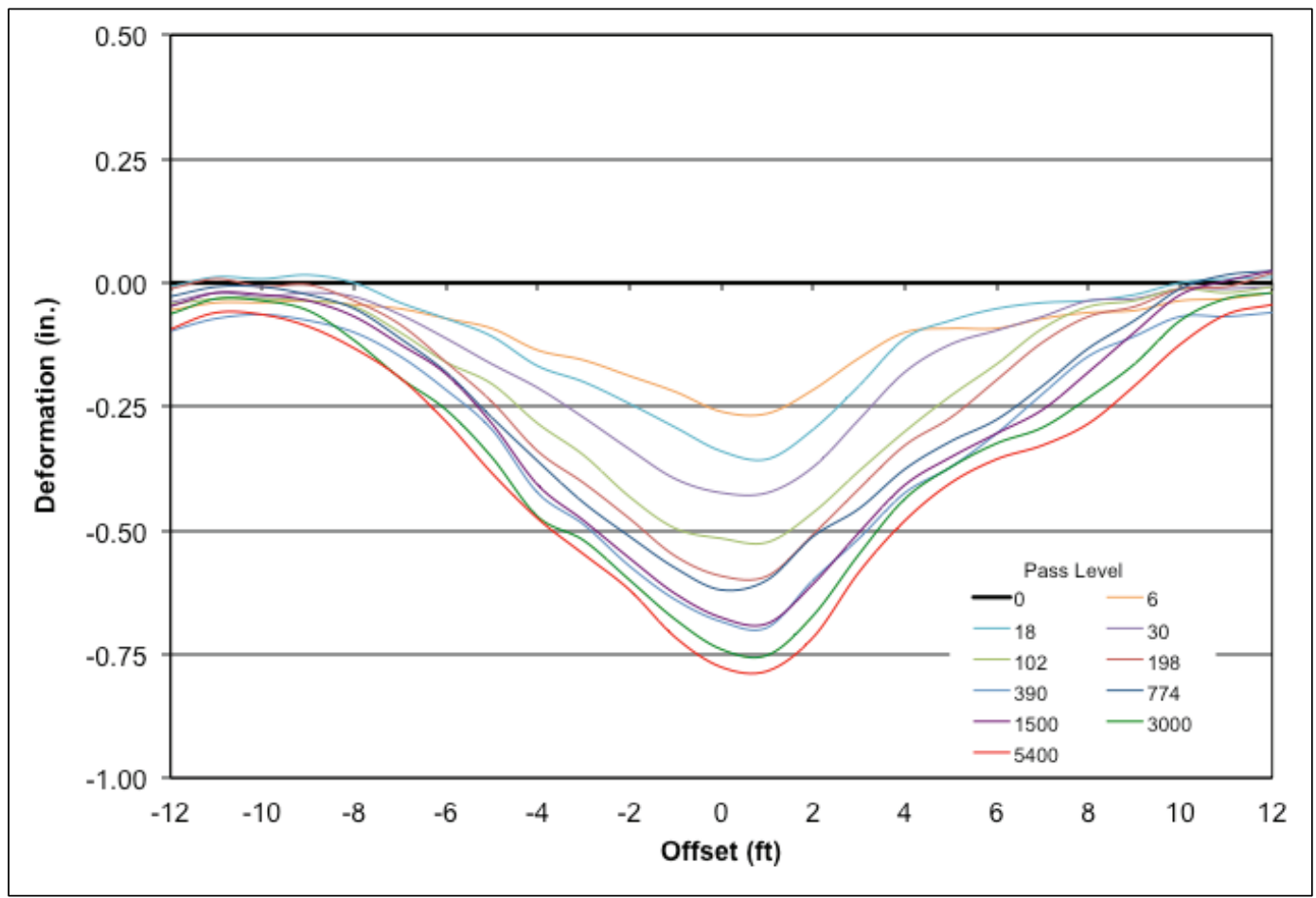


Figure F.6. Average deformation on the unloaded mat surface of PSA-FT-R - P-19 lane.

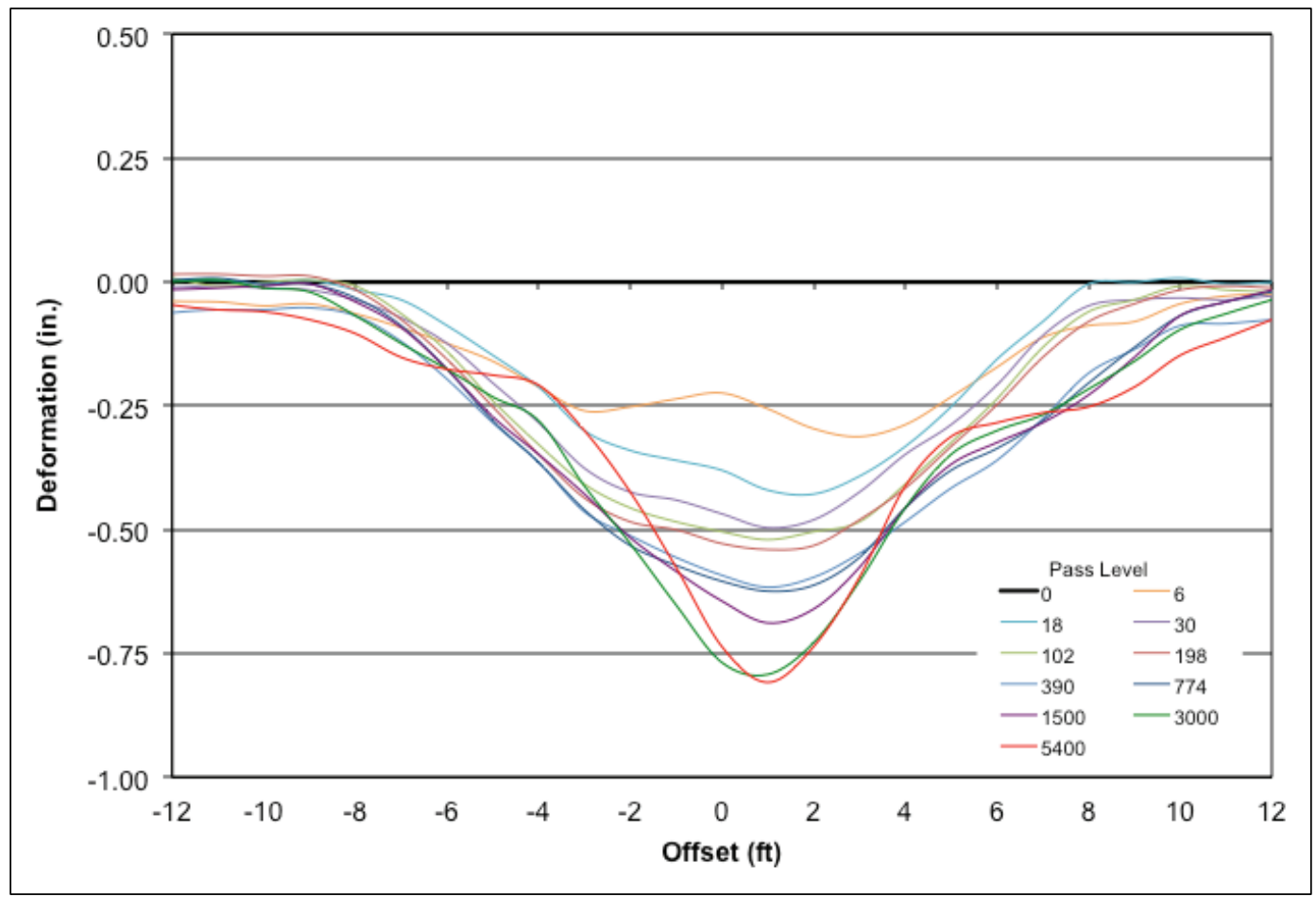

Figure F.7. Average deformation on the unloaded mat surface of ALMATS - P-19 lane.

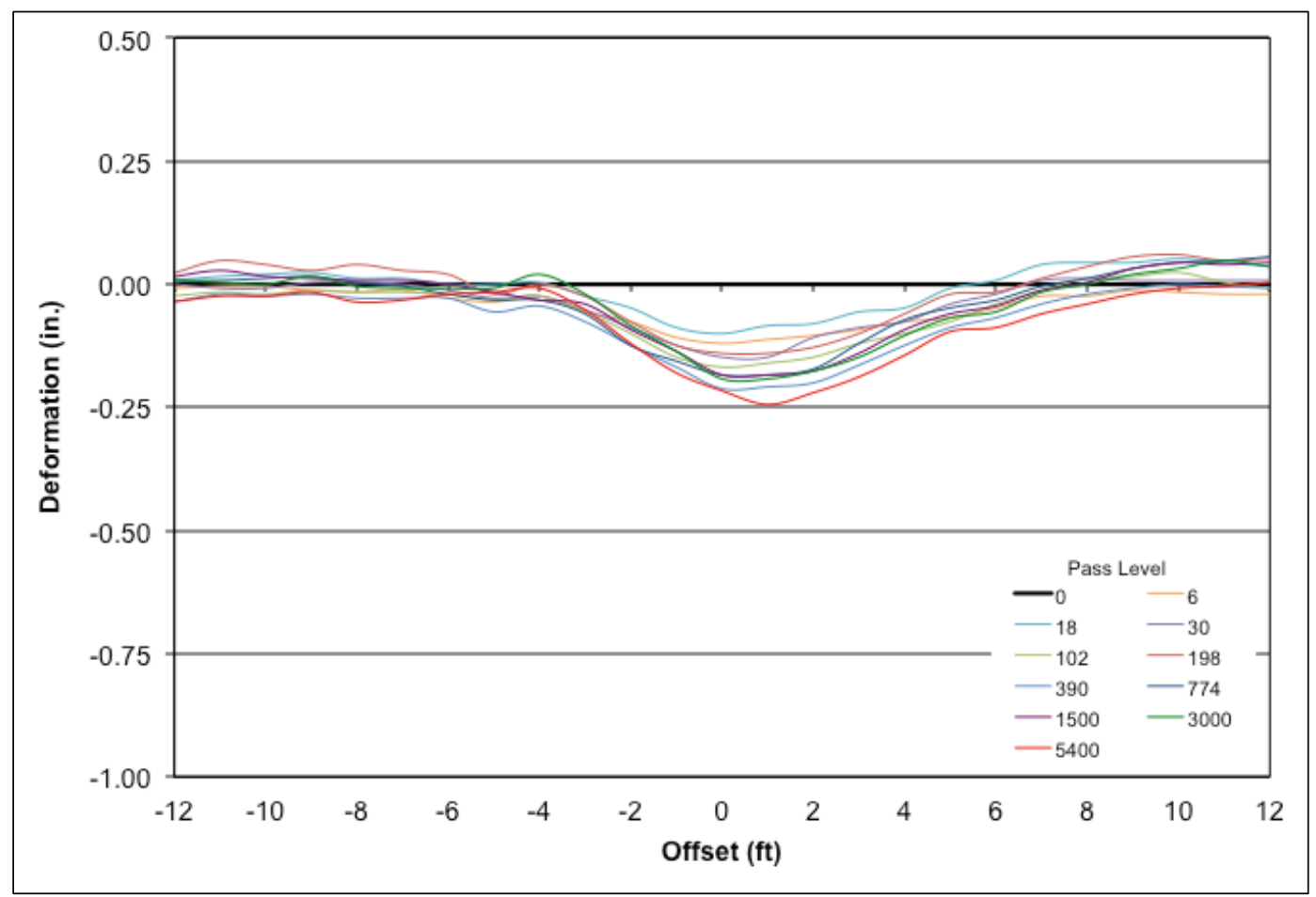


Figure F.8. Average deformation on the unloaded mat surface of DuraDeck - P-19 lane.

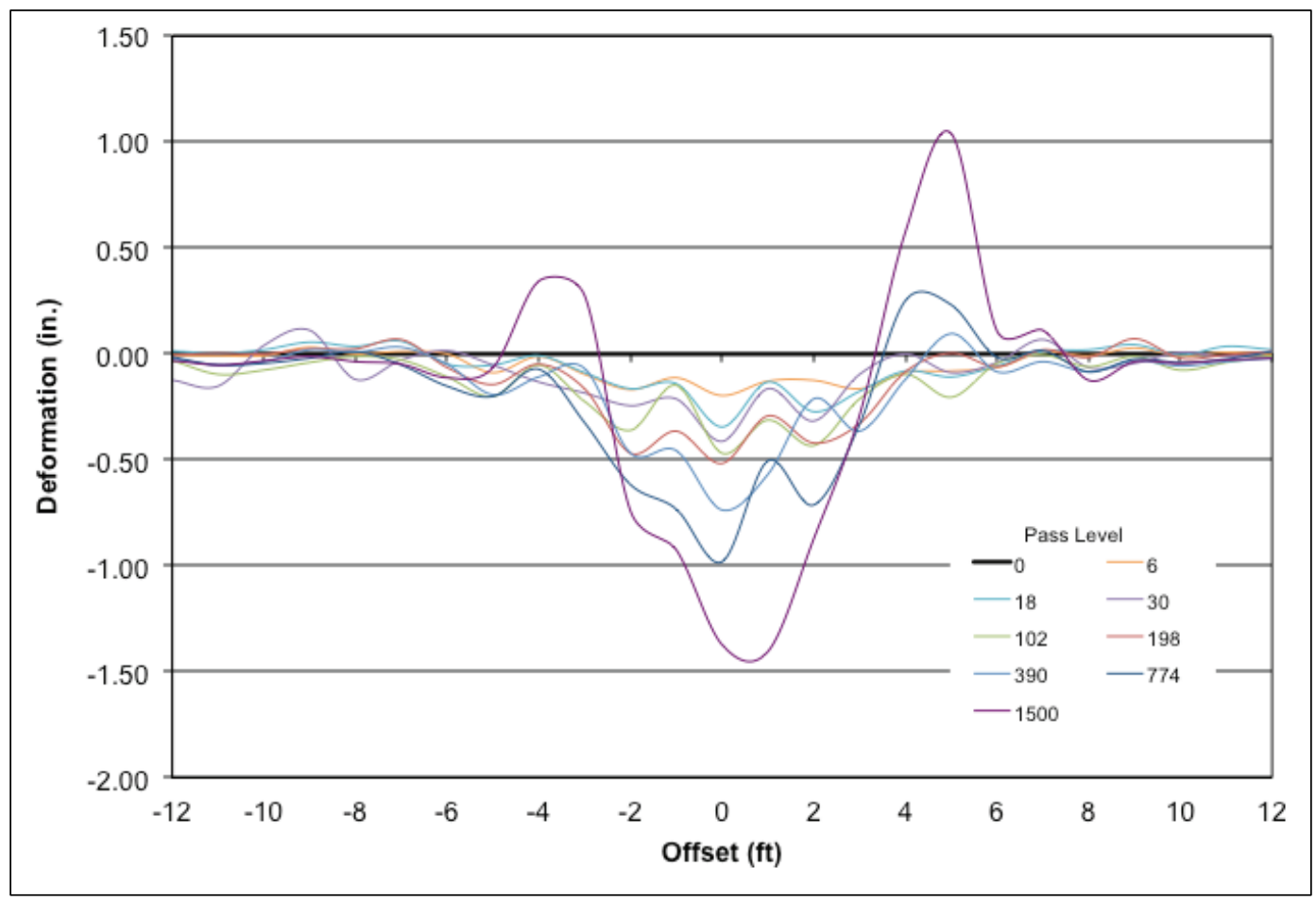

Figure F.9. Average maximum rut depth on the unloaded mat surface - P-19 lane.

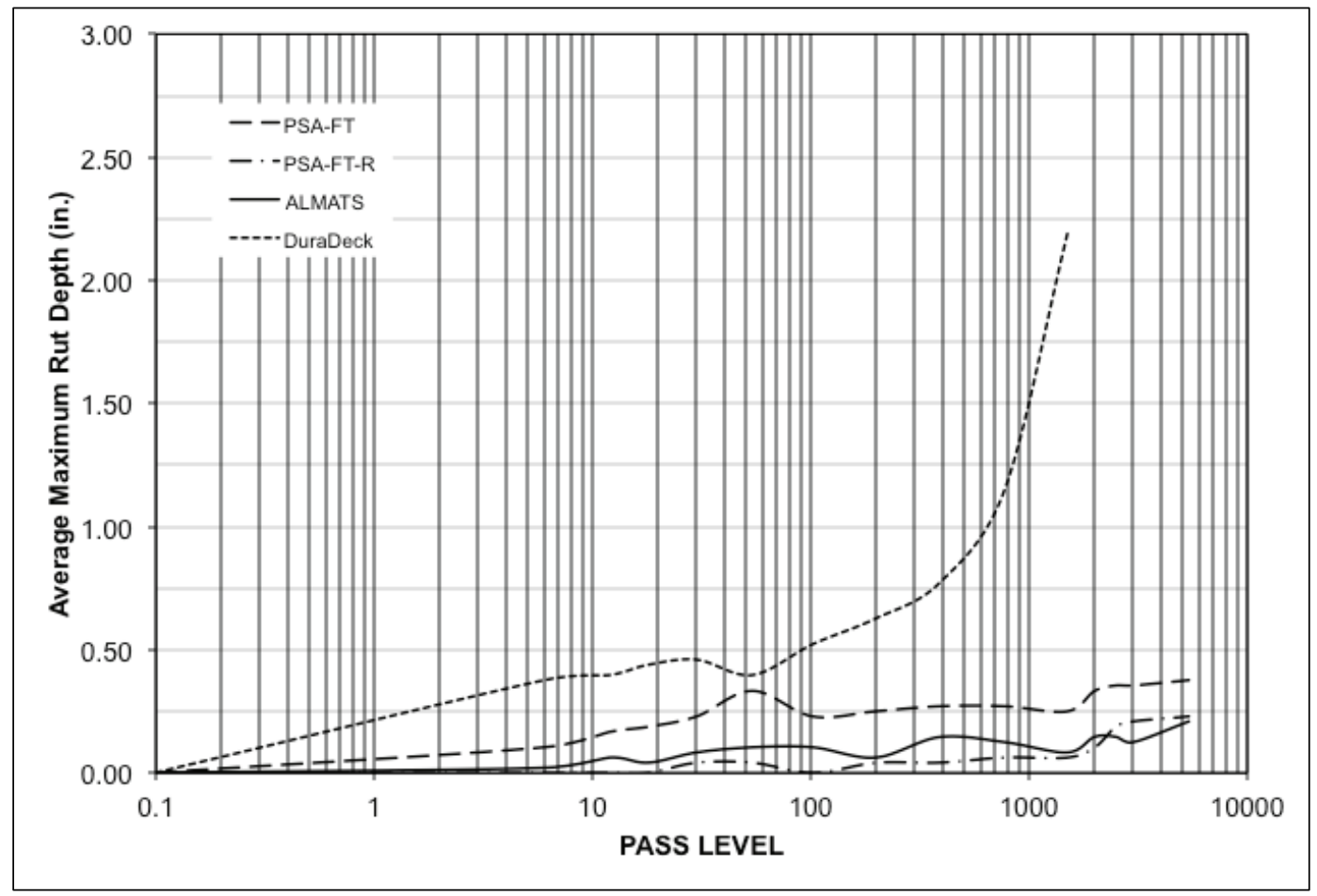




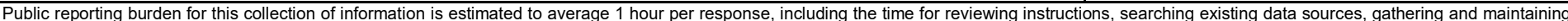

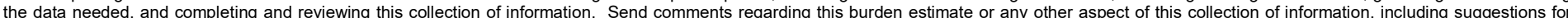

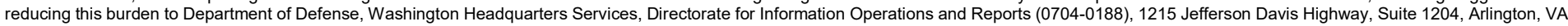

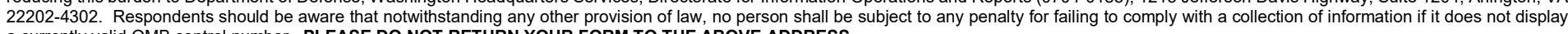
a currently valid OMB control number. PLEASE DO NOT RETURN YOUR FORM TO THE ABOVE ADDRESS.
1. REPORT DATE (DD-MM-YYYY) 2. REPORT TYPE
3. DATES COVERED (From - To)

December 2017 Final

\section{TITLE AND SUBTITLE}

5a. CONTRACT NUMBER

Evaluation of Expedient Surfaces for Remote Piloted Aircraft

5b. GRANT NUMBER

5c. PROGRAM ELEMENT NUMBER

\section{AUTHOR(S)}

Lyan Garcia, Timothy W. Rushing, and Craig A. Rutland

5d. PROJECT NUMBER

463347

5e. TASK NUMBER

5f. WORK UNIT NUMBER

\section{PERFORMING ORGANIZATION NAME(S) AND ADDRESS(ES)}

8. PERFORMING ORGANIZATION REPORT NUMBER

Geotechnical and Structures Laboratory

U.S. Army Engineer Research and Development Center

ERDC/GSL TR-17-27

3909 Halls Ferry Road

Vicksburg, MS 39180-6199

\section{SPONSORING / MONITORING AGENCY NAME(S) AND ADDRESS(ES)}

Headquarters, Air Force Civil Engineer Center

Tyndall Air Force Base, FL 32403-5319

10. SPONSOR/MONITOR'S ACRONYM(S)

AFCEC

11. SPONSOR/MONITOR'S REPORT NUMBER(S)

\section{DISTRIBUTION / AVAILABILITY STATEMENT}

Approved for public release; distribution is unlimited.

\section{SUPPLEMENTARY NOTES}

\section{ABSTRACT}

The U.S. military began using remote piloted aircraft (RPAs) for reconnaissance and offensive operations in the mid-1990s. Their effectiveness has led to the development of several new airframes with increasing capability and operational requirements. RPA ground movements are ideally separated from manned aircraft traffic areas with their own parking aprons and hangar facilities. For expedient construction of RPA facilities, a matting system is desired to rapidly create parking aprons and hangar flooring. This report describes the evaluation of four commercially available airfield matting systems that were investigated to determine their capabilities for supporting RPAs and support vehicle operations. Each mat system was tested on a full-scale test section consisting of a subgrade with a California bearing ratio (CBR) of 6 surfaced with the airfield mats. Simulated MQ-9A Reaper and P-19 fire truck traffic was applied to the mat surface. Mat breakage and deformation were monitored and compared to performance requirements for compliance. Recommendations were provided for each mat system based on suitability and risk to aid in future procurement decisions.

\section{SUBJECT TERMS}

Drone aircraft

Uninhabited combat aerial vehicles

16. SECURITY CLASSIFICATION OF:

\begin{tabular}{|l|r|}
\hline $\begin{array}{c}\text { a. REPORT } \\
\text { Unclassified }\end{array}$ & b. ABSTRACT \\
Unclassified
\end{tabular}
Lightweight mat
Landing Mat
Landing mats - Evaluation
Remote Piloted Aircraft
AM2
Air bases

\begin{tabular}{|l|c|l|} 
17. LIMITATION & $\begin{array}{l}\text { 18. NUMBER } \\
\text { OF ABSTRACT }\end{array}$ & $\begin{array}{l}\text { 19a. NAME OF RESPONSIBLE } \\
\text { OFERSON }\end{array}$ \\
\cline { 3 - 3 } & 107 & $\begin{array}{l}\text { 19b. TELEPHONE NUMBER (include } \\
\text { area code) }\end{array}$ \\
& &
\end{tabular}

